\title{
Untersuchungsresultate von 50 Schädeltrepanationen bei Epilepsie.
}

\author{
Von \\ Dr. med. Volland.
}

(Aus der Anstalt für Epileptische zu Bethel bei Bethel bei Bielefeld.)

(Eingegangen am 10. Oktober 1921.)

Die operative Behandlung der mit Konvulsionen verbundenen Nervenkrankheiten, dazu gehört in erster Linie die Epilepsie, durch die Schädeltrepanation ist ein Eingriff, der höchstwahrscheinlich schon in den ältesten Epochen der Menschheitsgeschichte vorgenommen wurde, in allen Kulturperioden zivilisierter Völker anzutreffen ist und auch noch heute selbst bei unzivilisierten Naturvölkern auf Grund naiver Uberlegungen ausgeführț wird. Mit Recht hält E. von Bergman $\mathbf{n}^{1}$ ) im Hinblick auf diese Tatsachen ein so hartnäckiges Verweilen dieses operativen Eingriffs im Heilschatze für kaum denkbar, wenn nicht immer wieder offensichtliche Erfolge danach zu beobachten gewesen wären. Von Bergmann selbst, der in Übereinstimmung mit Féré nur von derjenigen Behandlung einen Erfolg sich verspricht, die die Ursache der Epilepsie angreift, steht bekanntlich der operativen Behandlung der epileptischen Krankheitsformen skeptisch gegenüber. Mit um so größeren Nachdruck wird in neuerer Zeit von führenden chirurgischen Autoren auf diesem Gebiete (F. Krause, Tilmann, Friedrich, Kümmell, Großmann u. a.) auf Grund ihrer günstigen Resultate an einem großen Krankenmateriale auf die Notwendigkeit der hirnchirurgischen Behandlung der Epilepsie hingewiesen. Um die Statistik über die operativen Resultate der Epilepsie, die bis jetzt vorwiegend von chirurgischer Seite geführt worden ist, zu vervollständigen und zu ergänzen, um ein möglichst objektives Urteil über diese Frage zu erhalten, erschien es gerechtfertigt, die operierten Fälle einer großen Anstalt, in der die Kranken von allen Seiten zusammenströmen, einmal von bestimmten Gesichtspunkten aus zu durchmustern, sei es nun, daß die Kranken durch den Eingriff geheilt oder gebessert wurden oder ein Erfolg ihnen versagt blieb. Es ist ohne weiteres einleuchtend, daß bei solchen Feststellungen von Anstaltsinsassen sich eine verhältnismäßig große Zahl ungeheilter und scheinbar ungünstig beeinflußter Fälle ergeben wird. Trotzdem würde es verfehlt sein, deshalb eine von 
vornherein gegen die operative Behandlung der Epilepsie gerichtete Stellung einzunehmen. Es würde vielmehr auch im Hinblick auf die günstigen Erfahrungen der Chirurgen zu erörtern sein, welche Faktoren zu dem ungünstigen Ausgange jedes einzelnen Falles beitrugen, unter welchen Umständen die Prognose von vornherein ungünstig oder zweifelhaft zu stellen ist, was uns die operierten Fälle für unsere Auffassung über die Pathogenese des epileptischen Symptomkomplexes und ihre Behandlung zu lehren vermögen usw. Bei der Beurteilung des Wertes der operativen Behandlung der Epilepsie ist im Hinblick auf die große Reihe der in Frage kommenden Chirurgen auch in Betracht zu ziehen, welche Indikationen für sie maßgebend waren, worin der operative Eingriff bestand, welche Technik sie anwandten, wie der Heilverlauf sich gestaltete und welche Nachbehandlung sich anschloß. Um über alle diese Dinge sich möglichst Klarheit zu verschaffen, wurden die in den auswärtigen Krankenhäusern und hier erlangten Feststellungen in Tabellen zusammengefaßt, die folgende Einteilung enthielten: Name, Alter, erbliche Belastung, körperliche und geistige Entwicklung des Kranken, angebliche Ursachen für das Auftreten der Epilepsie, Alter des Kranken beim Auftreten des Leidens, Charakter der Anfälle und Krankheitsverlauf, Indikationen zur Operation, Alter des Kranken bei der Vornahme der Operation, Intervall zwischen Auftreten der Krämpfe und Vornahme der Operation, Befund bei der Operation und Art des operativen Eingriffs, Ausgang. Vom rein praktischen Gesichtspunkte aus wurden die Fälle - insgesamt sind es 50 - eingeteilt erstens in solche mit sicherer oder wahrscheinlicher traumatischer Entstehung bzw. Auslösung (26 Kranke) und zweitens solche, bei denen das traumatische Moment fehlt (24 Kranke). Mit der Besprechung der letzteren soll begonnen werden, wobei in jedem Falle eine kurze Zusammenfassung des Tabelleninhaltes vorausgeschickt sei, an die sich epikritische Bemerkungen anschließen sollen.

Gruppe I (nichttraumatische Fälle):

Fall 1. Guisbert B., epileptischer Anstaltspflegling. Der jetzt 17 jährige, erblich nicht belastete Patient erkrankte im zweiten Lebensjahre an einem drei Monate anhaltenden, rechtsseitigen Mittelohrkatarrh, an den sich allgemeine epileptische Krämpfe anschlossen. Schon nach ca. vierwöchigem Bestehen derselben wurde eine Dekompensativtrepanation rechterseits ausgeführt, wobei eine starke Meningitis serosa festzustellen war. Da im Laufe der Zeit der Zustand sich nicht besserte, vielmehr Zuckungen im 1 . Facialisgebiet sich hinzugesellten und die Trepanationsöffnung sich verkleinerte, nahm der gleiche Chirurg 3 Jahre später, also im 5. Lebensjahre des Kranken, die zweite Operation vor, bestehend in Vergrößerung der Trepanationsöffnung und Rindenexcision im Facialisgebiet. Zwei Jahre blieb Pat. nach der Krankenhausentlassung in häuslicher Pflege, wobei die Anfälle vorerst angeblich in der gleichen Zahl wiederkehrten. Dann erfolgte Anstaltsaufnahme, bei der u. a. ein ausgedehnter, pulsierender Knochendefekt über dem r. Os parietale und eine schwächere Entwicklung des l. Armes und Beines 
festzustellen war. Unter $4 \mathrm{~g}$ Bromkali pro die wurde der Kranke nach einjähriger Anstaitspflege anfallsfrei und ist es seit 6 Jahren geblieben. Seit $1^{1 / 1} / 2$ Jahren arbeitet er als Lehrling in der Schuhmacherei; ist zwar etwas langsam, aber geistig frisch und macht zufriedenstellende Fortschritte im Handwerk.

Epikrise: Der vorliegende Fall einer organisch bedingten Epilepsie ist in mancher Hinsicht bemerkenswert. Hingewiesen sei auf die frühzeitige, schon nach vierwöchigem Bestehen der Krampfanfälle vorgenommene Dekompensivtrepanation, die das Vorliegen einer starken Meningitis ergibt, ein Fingriff, der in solchen Fällen bei der Aussichtslosigkeit einer internen Therapie unbedingt so frühzeitig indiziert ist. Die Krampfanfälle bestehen zwar zunächst fort, Reizungserscheinungen in Gebiet des 1. Facialis kommen hinzu, dazu gesellt sich eine Verkleinerung der Trepanationsöffnung mit der. daraus sich vermindernden Entlastungswirkung. Diese Momente veranlassen den gleichen Chirurgen nach 3 Jahren zum zweiten, oben näher charakterisierten Eingriff. Aber auch die Rindenexcision und die erweiterte Ventilbildung ergeben vorerst nicht den gewünschten Erfolg, weil ein Faktor von anscheinend großer Bedeutung sich nicht hieran anschloß: Die Anstaltspflege mit ihrer geregelten Lebensweise, ihrer konsequenten medikamentösen Behandlung und der Fernhaltung schädigender Einflüsse. Trotzdem die Anstaltspflege erst nach 2 Jahren einsetzt, wird der Kranke innerhalb eines Jahres anfallsfrei, ist es seit 6 Jahren geblieben, hat geistig immer Fortschritte gemacht und verspricht ein nützlicher, erwerbsfähiger Mensch zu werden. Es könnte nach unserm Dafürhalten der erzielte Erfolg in Frage gestellt werden, wenn der $17 \mathrm{jährige} \mathrm{Kranke} \mathrm{jetzt} \mathrm{als} \mathrm{relativ} \mathrm{geheilt} \mathrm{in} \mathrm{ungewisse}$ Verhältnisse hinaus entlassen würde. Noch befindet er sich in den Pubertätsjahren, die im Hinblick auf die Epilepsie eine besondere gesundheitliche Überwachung erfordern.

Fall 2. Elisabeth D., Anstaltspflegling. Zur Zeit 33 jährige, erblich nicht belastete, links hemiparetische Patientin. Die im zweiten Lebensmonat aufgetretenen Krämpfe werden mit einer damals herrschenden Pockenepidemie in Verbindung gebracht. $\mathrm{Zu}$ den epileptischen Insulten gesellen sich im Laufe der Zeit Erregungszustände und zunehmende Verblödung. Nach 20 jähriger Krankheitsdauer im 20. Lebensjahr der Pat. operative Behandlung: Excision einer mit der Dura verwachsenen Hirnnarbe aus dem r. Fußzentrum, Dauerdrainage des r. Ventrikels infolge starker Liquoransammlung, Ventilbildung nach Kocher. Seit der Operation vor 13 Jahren frei von epileptischen Anfällen, geistig deutlich frischer geworden, nur etwas erregt während und nach der Regel.

Epikrise: Der Fall lehrt, daß bei Vornahme von Hirnoperationen zur Beeinflussung epileptischer Krankheitserscheinungen stets individualisierend vorgegangen werden muß, um solche günstige Erfolge selbst nach 20 jähriger Dauer des Leidens zu erzielen, wie dieser zweite Fall darstellt. Es ist fraglich, ob eine einfache Narbenexcision aus dem Gehirn genügt hätte. Bei starker Liquoransammlung ist es nötig, auch diesem Faktor Rechnung zu tragen. Der Umstand, daß sich auch jetzt noch während und nach der Regel Erregungszustände bei der Kranken einstellen, weist auf die Bedeutung innersekretorischer Vorgänge für die Genese epileptischer Symptome hin. Auf derartige Beziehungen soll später noch einmal kurz eingegangen werden. - In den drei nächsten Fällen haben sich encephalitische Prozesse an schwere Masernerkrankungen angeschlossen.

Fall 3. Reinhard M. Der jetzt 27 jährige Pat. mit indirekter erblicher Belastung von beiden Elternseiten (Bruder des Vaters nervös, durch Suicid $\dagger$, Großmutter mütterlicherseits geisteskrank) erkrankte im vierten Lebensjahr an Masern und eitrigem Mittelohrkatarrh; im Anschluß daran zweimal mehrere Stunden lang Krämpfe; dabei auf der r. Körperseite blaurote Flecken (fliegende Ery-

z. f. d. g. Neur. u. Psych. LXXIV. 
theme?). Nach 3 Jahren Gliederzuckungen, namentlich rechts; in der Folgezeit vereinzelte Anfälle, bestehend in Sprachstörungen, Zuckungen des Mundes, zuweilen auch Erbrechen und Schluckbewegungen, schließlich allgemeine Krämpfe, mehrere Male im Monat auftretend. Im 15. Jahre, 8 Jahre nach Bestehen der epileptischen Krampferscheinungen wird zu einer Entlastungstrepanation geschritten. Näheres über den damaligen autoptischen Befund steht nicht zur Verfügung. Nur 4 . Wochen bleiben die Krampfanfälle aus, dann Wiederkehr in der gleichen Form. 2 Jahre später halbjährige Anstaltsbehandlung, während der sich der Kranke zwar geistig frisch, doch häufig deprimiert bis zum Lebensüberdrusse zeigt. Vom körperlichen Befunde sei erwähnt: R. Arm und r. Rumpfseite etwas schwächer wie links. Trotzdem die Anfälle an Zahl und Schwere während der Anstaltspflege zurückgehen, verläßt er schon nach $1 / 2$ Jahr die Anstalt... Nach brieflicher Mitteilung des Vaters wechselt zur Zeit die Zahl und Schwere der Anfälle, nach 3-4 Wochen können bis zu 4 Anfälle sich einstellen; in der Zwischen. zeit zuweilen eigenartige „Stockungen im Denk- und Sprachvermögen“. Geistig ist der Kranke ziemlich frisch geblieben, zeitweise ist er sehr reizbar.

Epikrise: Der operative Eingriff ist 8 Jahre nach Auftreten der Krampfanfälle, also ziemlich spät, vorgenommen und bestand nur in einer Entlastungs. trepanation. Allerdings ist dieser Fall für eine eingreifendere Operation ungünstig, da die bei den Insulten zu beobachtenden Reizerscheinungen auf das motorische Sprachzentrum hindeuten und diese Region besonders geschont werden soll, ein Hinweis, auf den später noch einmal kurz eingegangen werden soll. Leider schlie Bt sich die Anstaltsbehandlung nicht sofort an die Operation an, sondern erfolgt erst 2 Jahre später und beschränkt sich nur auf ein halbes Jahr, obwohl der Kranke in dieser Zèit eine Besserung erfährt. Wenn hinsichtlich der Anfälle auch nur ein vorübergehender Erfolg erzielt wurde, so ist doch immerhin hervorzuheben, daß der indirekt erblich belastete Pat. nicht geistig zurückgegangen ist. Möglicherweise hat die Operation dazu beigetragen, einen psychischen Verfall aufzuhalten.

Fall 4. Karl S. Der jetzt 22 jührige, erblich nicht belastete, stark verblödete Anstaltspflegling erkrankte im 4. Lebensjahre an Masern mit linksseitiger Lähmung, war 14 Wochen blind und etwa 1 Jahr krank. Zu gleicher Zeit stellten sich linksseitig beginnende Krampfanfälle und seelische Veränderungen ein, bestehend in zunehmendem Schwachsinn, erregbarer Stimmung und bösartigem Verhalten gegen die Umgebung. Erst im 12. Jahre, 8 Jahre nach Bestehen der Krankheitserscheinungen, entschloß man sich zu einem operativen Eingriff, bestehend in einer rechtsseitigen Schädeltrepanation. Der Operationsbefund ließ sich infolge des Fehlens des Krankheitsblattes in dem betreffenden Krankenhaus nicht mehr feststellen. Die Operation blieb auf den Zustand des Kranken ohne EinfluB.

Epikrise: Die Masernerkrankung im 4. Lebensjahr hatte zu einer schweren rechtseitigen Meningoencephalitis geführt, die mit ihren Krankheitserscheinungen sich anscheinend bis zu 1 Jahr hinzog. Es ist darauf hinzuweisen, ob nicht in solchen Fällen analog dem Falle 1 schon viel früher operativ eingeschritten werden muß, da ein Erfolg von interner Behandlung doch nicht zu erwarten ist, und die Freilegung von entzündlichen Herden unseren allgemein anerkannten therapeutischen Grundsätzen entspricht. Daß nach 8jährigem Bestehen schwerer epileptischer Krankheitserscheinungen ein Operationserfolg ausblieb, ist begreiflich.

Fall 5. Cäcilie F. Die ietzt 29 jährige, erblich nicht belastete Anstaltspatientin erkrankte im Alter von 2 Jahren an Masern mit Krämpfen und linksseitiger Lähmung, an die sich zuerst petit mal, dann im l. Arm beginnende Krämpfe anschlossen. Erst im 2l. Jahre, nach 19 jährigem Bestehen der Krampfanfälle, wurde zur Schädeltrepanation geschritten, bei der eine Meningitis serosa im Bereich des FacialisArmzentrums nebst allgemeinen leptomeningitischen Veränderungen festgestellt 
wurde. Naeh elektrischer Bestimmung des Facialis-Armzentrums Exstirpation dieses Gebietes und Transplantation eines Fascienlappens auf die excidierte Stelle; Ventilbildung. Zustand nach der Operation: Kein Einfluß auf Zahl und Schwere der epileptischen Insulte, die nur zur Zeit der Regel auftreten, wohl aber Nachlaß der Kopfschmerzen; es ist auch kein geistiger Rückgang bemerkbar.

Epikrise: Auch dieser Masernfall mit den sich kombinierenden schweren cerebralen Prozessen drängt zu der Erwägung, ob nicht möglichst frühzeitig zur operativen Freilegung der erkrankten Hirnpartie geschritten werden muß in Anbetracht der geringen Gefahr des Eingriffs bei der heutigen operativen Téchnik einerseits und dem meist deletären Krankheitsverlauf andererseits. 'Das' Auftreten der epileptischen Insulte zur Zeit der Regel weist auf die Bedeutung innersekretorischer Vorgänge auch für die symptomatische Epilepsie hin.

Die beiden nächsten Fälle 6 und 7 sind meningoencephalitische Folgezustände, die sich im Anschluß an schwere pneumonische Prozesse entwickelt haben.

Fall 6. Ladislaus $Z$. Der erblich nicht belastete, im 20 . Lebensjahr verstorbene Kranke machte im 5. Jahre eine schwere Lungen-, Brustfell-, Herzbeutel- und Gehirnentzündung durch, an die sich im 6. Jahr Zuckungen im 1. Arm, später auf der ganzen Seite anschlossen. 3 Monate später bei einer Halsentzündung zwei heftige epileptische Krampfanfälle. Nach 3jähriger Pause Wiederauftreten derselben; nach 4jährigem, ununterbrochenem Bestehen und zunehmender Verschlimmerung des Zustandes im 13. Lebensjahre rechtsseitige Schädeltrepanation, bei der man sich infolge der Schwere des meningitischen Befundes auf die Ventilbildung beschränkt. Der Effekt besteht in einer nur Monate anhaltenden Besserung. Im 14. Jahre erhebliche Verschlimmerung, zunehmende rechtsseitige Parese, schließlich contracturiert, völlig unbeholfen, tief verblödet. Im 20. Jahre Exitus letalis infolge von Lungenentzündung. Sektion nicht gestattet.

Fall 7. Helene D. Die jetzt 16 jährige, unehelich geborene, hochgradig schwachsinnige Anstaltspatientin erkrankte im Alter von $31 / 2$ Jahren an Lungenund Gehirnentzündung, an die sich eine linksseitige Hemiparese, Auftreten von Krampfanfällen und Stillstand der geistigen Entwicklung anschlossen. Erst im 13. Lebensjahre nach 9 jährigem Bestehen der Krampfanfälle erfolgt die Schädeltrepanation mit folgendem Befund: Dura pulsiert nicht; nach Eröffnung des Subduralraums Abfließen einer mäßigen Menge Cerebrospinalflüssigkeit; in den weichen Hirnhäuten deutliche Narbenbildung, die bis in die Hirnrinde geht; Excision des ganzen Narbengewebes, dabei ziemliche Blutung unter die Arachnoidea. Ausgang: Zunahme der Krampfanfälle von 2 auf ca. 10 pro Monat, auch Verschlechterung des psychischen Zustands.

Epikrise beider Fälle: Beiden gemeinsam ist die Ätiologie, die späte Vornahme des operativen Eingriffs und der traurige Ausgang, der keinesfalls auf die Operation zurückzuführen ist. $\mathrm{Ob}$ die bei der Operation im 2. Fall aufgetretene Blutung: nachteilige Folgen gehabt hat, ist ja möglich; sicherlich hätte der traurige Ausgang frïher oder später auch ohne Gehirnoperation eintreten können. Im ersten Fall kommt es sogar nach dem Eingriff zu einer monatelangen Besserung. Möglicherweise hat zu der im 14. Jahre rapide einsetzenden Verschlimmerung auch die Pubertätszeit mit ihren innersekretorischen Umwälzungen beigetragen.

Beim nächsten Falle ist die Encephalitis als Komplikation nach Influenza aufgetreten.

Fall 8. Arthur $H$. Der jetzt 28 jährige, von einer jahrelang kränklichen Mutter abstammende Pat., dessen eine Schwester in frühester Kindheit nach 8 Tagen an Krämpfen verstarb, erkrankte im 17. Jahre im Anschluß an eine ,,übergtngene" 
Influenza plötzlich an Bewußtlosigkeit, Erbrechen und einer linksseitigen Lähmung, dazu kamen noch Augen- und Blasenstörungen. Nach 1/4 Jahr typische Jacksonanfälle mit Beginn im l. Fuß. Wiederkehr der Anfälle, namentlich beim Essen, bei Witterungswechsel und bei Biergenuß, leichtere stellten sich zuweilen täglich ein. $1 \mathrm{Jahr}$ später erfolgte die Schädeltrepanation mit folgendem Befund: Gehirnoberfläche rechts in der Gegend der Zentralwindungen eingesunken, Pia und Arachnoidea darüber verdickt. Arm- und Rumpfmuskulatur faradisch festzustellen, die des Beines nicht; Beschränkung auf Ventilbildung. Ausgang: ${ }_{1 / 4} \mathrm{Jahr}$ nach der Operation einzelne Anfälle im Monat, nach 6 anfallsfreien Monaten in gutem körperlichen und geistigen Zustande in die Heimat entlassen. Nach den eingezogenen Nachrichten befindet sich der Kranke weiterhin gut, ist erwerbsfähig und hat sich verheiratet.

Epikrise: Es ist möglich, daß es sich bei dem encephalitischen Prozeß, namentlich auch im Hinblick auf die Augen- und Blasenstörungen um eine Encephalitis lethargica gehandelt hat, die bekanntlich zur Zeit noch nicht ganz geklärte Beziehungen zur Influenza besitzt. Schon $1^{1} / 2$ Jahre nach Auftreten der Krampfanfälle wird zur Schädeltrepanation geschritten, bei der man sich auf die Ventilbildung beschränkt. Der autoptische Befund hatte encephalo-meningitische Veränderungen in der Gegend der Zentralwindungen ergeben. Trotzdem nur eine Ventilbildung vorgenommen wurde, ist der Ausgang ein günstiger.

In den folgenden Fällen 9, 10, 11 und 12 handelt es sich um Kranke, bei denen sich in frühester Jugend eklamptische Anfälle, höchstwahrscheinlich auf encephalitischer Basis, abspielten.

Fall 9. Karl K. Der jetzt 27 jährige, durch Trunksucht des mütterlichen Groß- und Urgroßvaters sowie durch uneheliche Geburt des Vaters belastete Anstaltspflegling war als kleines Kind auffallend unruhig gewesen und hatte gegen Ende des 1. Lebensjahres einige Male an Krampfanfällen gelitten. Angeblich im Anschluß an das UUberstehen von Furcht und Angst hatten sich im 9. Jahr zuerst petit mal-Zustände, dann $1 \mathrm{Jahr}$ später ausgebildete Anfälle eingestellt, die im 1. Arm, Bein und Facialisgebiet begannen und dann auf die r. Seite übergriffen. Im 3. Lebensjahre, 4 Jahre nach Bestehen der epileptischen Erscheinungen, als sich bereits eine Abnahme der Geisteskräfte bemerkbar gemacht hatte, wurde die rechtsseitige Schädeltrepanation vorgenommen, bei der sich makroskopisch ein negativer Hirnbefund ergab. Es gelang nicht mittels einpoliger Hirnrindenreizung das Armzentrum festzustellen; der Eingriff wurde auf die Ventilbildung beschränkt. Eine im Anschluß an die Operation aufgetretene Hemiparese ging bald wieder zurück. 3 Monate nach der Operation erfolgte die Überweisung in Anstaltspflege, in der sich der Kranke jetzt noch befindet. Der operative Eingriff hat den Zustand nicht gebessert: Der Kranke ist meist deprimiert, hat zeitweise sehwere Erregungszustände, auch Selbstmordideen und die Neigung fortzulaufen.

Epikrise: Möglicherweise haben zweierlei Momente zu dem ungünstigen Ausgang des Falles beigetragen: Erstens die erbliche Belastung, zweitens die während der 4 jährigen Krankheitsdauer bereits eingetretene epileptische Degeneration. Auf die auch in diesem Falle fehlende faradische Reaktion der Hirnrinde soll weiter unten noch einmal kurz eingegangen werden.

Fall 10. Hermann W. Der jetzt 22 jährige Anstaltspflegling stammt von einem Vater ab, dessen jüngerer Bruder in der Pubertätszeit jahrelang an Krämpfen litt. Der Vater selbst hat in den zwanziger Jahren einen Schanker durchgemacht. Im 5. Lebensmonat hatte Pat. eklamptische Anfälle und im 1. Lebensjahre wurde eine Schwäche der linken Körperseite festgestellt. Im 13. Lebensjahre zuerst Beugekrämpfe im 3. Arm und Bein bei erhaltenem Bewußtsein, später der gleiche 
Zustand im 1. Facialis und schließlich allgemeine Krämpfe mit vorwiegender Beiteiligung der l. Seite. Im Alter von $14^{1} / 2$ Jahren nach $1 \frac{1}{2}$ jährigem Bestehen der epileptischen Krampferscheinungen Trepanation in der $r$. Scheitelbeingegend mit folgendem Befund: Starke Leptomeningitis mit sulzigem Ödem und kleinen, ca. $1 / 4 \mathrm{~mm}$ im Durchmesser betragenden, weißen Knötchen in der Umgebung der Gefäße. Die Gefäße sind stark gefüllt; Gehirnpunktion mit negativem Ergebnis. Ausgang: 5 Monate anfallsfrei; im Anschluß an starkes Schütteln auf einer Sekundärbahn unangenehmes Gefühl im Kopfe, tags darauf Stechen in der l. Hand, am nächsten Tag Zucken in der 1. Hand mit Bewußtseinsverlust. Allmähliches Wiederauftreten vereinzelter Anfälle, erhebliche Zunahme nach Aussetzen des Luminals und Vornahme einer Tuberkulinkur, die nicht wegen Tuberkulose, sondern wegen der Epilepsie vorgenommen wurde. Im 20. Jahr Anstaltsaufnahme. Vom Aufnahmebefund: I. Körperseite schwächer entwickelt, Auraerscheinungen sensibler Natur in der l. Seite, psychisch etwas geschwächt. Wassermannsche Reaktion -. Während der seit 2 Jahren bestehenden Anstaltspflege treten die einen herdförmigen Charakter tragenden Insulte unregelmäßig auf, geistig ist der Kranke nicht zurückgegangen. Er verhält sich geordnet, ist von ruhiger Gemütsart; besitzt wenig Neigung sich zu betätigen.

Epikrise: Bei diesem Pat. mit den oben genannten belastenden Momenten hat im 5. Monat sich höchstwahrscheinlich eine rechtsseitige Meningoencephalitis abgespielt. Im 13. Jahr zeigen sich herdförmig die Anfänge der epileptischen Symptome, die entsprechend dem Jacksoncharakter zuerst bei erhaltenem Bewußtsein verlaufen, sich aber bald immer mehr zu vollkommenen Anfällen ansbilden. Der günstige Effekt der Ventilbildung zeigte sich in 5 anfallsfreien Monaten. Daß das Gehirn aber auch nach dieser Zeit eine große Empfindlichkeit besitzt und traumatische Schädigungen dringend zu vermeiden sind, zeigt die ungünstige Einwirkung des Schüttelns in der Sekundärbahn, das sofort unangenehme Sensationen im Kopf und den Gliedern und am darauffolgenden Tage einen epileptiformen Anfall zur Folge hat. Wenn nun in der Folgezeit auch die Krampfanfälle sich vereinzelt wieder einstellen, so kommt es doch erst zu einer erheblichen Verschlimmerung nach Aussetzen des Sedativums (Luminal) und Vornahme einer Tuberkulinkur. Hinsichtlich des operativen Eingriffs dürfte zu erwägen sein, ob es nicht in Anbetracht der Jacksonerscheinungen gerade in Fällen, wo es sich um die r. Hemisphäre wie hier handelt, geraten erscheint, das betreffende Rindenzentrum nach faradischer Reizung zu excidieren oder zu unterschneiden. Ferner lehrt dieser Fall die Notwendigkeit, auch nach dem operativen Eingriff längere Zeit, deren Dauer der spezialärztlichen Beurteilung überlassen werden muß, den Kranken unter der Einwirkung eines Sedativums (Luminal, Brom) zu halten. Daß die Wassermannsche Reaktion trotz der früheren spezifischen Erkrankung des Vaters negativ ausfällt, braucht nicht zu überraschen. Einmal besteht die Möglichkeit, daß sie früher einmal bei dem Pat. positiv gewesen ist, weiterhin ist es denkbar, daß die Hirnerkrankung nicht luetischen Charakters ist. Wiederholt wurde bei hiesigen Epileptikern mit negativer WaR. festgestellt, daß bei fehlender erblicher Belastung der Vater in der persönlichen Unterredung eine frühere Lues konzedierte, die in solchen Fällen höchstwahrscheinlich keimschädigend wirkt.

Fall 11. Martha M. Keine erbliche Belastung. Mit $1 \frac{3}{4}$ Jahren Gehirnentzündung mit anschließender rechtsseitiger Parese. Auftreten der Krampfanfälle im 9. Jahre mit Beginn in der r. Gesichtshälfte. 8 Jahre nach Bestehen der Krampfanfälle, im 17. Lebensjahre der Pat., wird die Schädeltrepanation in einer Universitätsklinik vorgenommen, von der aber auf die ergangenen Anfragen über' die Art des Eingriffs, Befund usw. keine Antwort eingegangen ist. Ausgang: $3 / 4$ Jahre völlig anfallsfrei, dann Wiederkehr in der gewöhnlichen Form, ungefähr 
wöchentlich einmal mehrere Anfälle hintereinander. Zur Zeit sind 9 Jahre nach der Operation verflossen. Geistig ist die Kranke in jeder Hinsicht als normal zu bezeichnen.

Epikrise: Bei der erblich nicht belasteten, jetzt 26jährigen Pat. handelt es sich um eine linksseitige, im Alter von $1^{1 / 2}$ Jahren überstandene Encephalitis, zu der sich im 9. Jahre epileptische Krampfanfälle von Jacksoncharakter hinzugesellen. Erst nach 8 jährigem Bestehen der Krampfanfälle Schädeltrepanation, über die keine näheren Daten zur Verfügung stehen. Auffallend ist im vorliegenden Falle die erfreuliche geistige Frische, die, wie auch in anderen Fällen, möglicherweise auf die Entlastungswirkung der Trepanation zurückzuführen ist.

Fall 12. Johanna P. Die jetzt 47 jährige, geistig etwas geschwächte Pat. ist indirekt erblich belastet (Schwester des Vaters war geisteskrank, eine Schwester der Mutter war epileptisch). Während der Zahnperiode wiederholt Krampfanfälle. Im 22. Jahre Auftreten von epileptischen Anfällen typischen Charakters. Nach 14 jährigem Bestehen derselben im 36. Jahre Entlastungstrepanation, die nur eine vorübergehende Besserung zur Folge hat. Pat. ist seit 24 Jahren verheiratet und hat zwei gesunde, jetzt erwachsene Kinder.

Epikrise: Die Entstehungstrepanation bei der erblich indirekt belasteten Kranken ist ziemlich spät vorgenommen, so daß die Prognose von vornherein zweifelhaft war. Ob der fehlende geistige Rückgang auf eine günstige Wirkung der Trepanation zurückzuführen ist, dafür besteht immerhin eine Möglichkeit.

Die 4 folgenden Fälle 13, 14, 15 und 16 wurden wegen Jacksonerscheinungen operativ behandelt, ohne daß vorausgegangene encephalitische Prozesse mit Sicherheit festzustellen waren.

Fall 13. Emma W.T Die jetzt 28 jährige, erblich nicht belastete Pat. erkrankte im 13. Jahre mit Krämpfen, die in der r. Hand begannen und ca. dreimal wöchentlich wiederkehrten. Im Alter von $17^{1 / 2}$ Jahren nach $4 \frac{1}{2}$ jährigem Bestehen der Krampfanfälle linksseitige Schädeltrepanation. Operationsbefund: Enorm harter Schädelknochen; faradische Bestimmung des Armzentrums, Excision eines Stückes von $2,5 \times 2 \mathrm{~cm}$ Breite und $1 \frac{1}{2} \mathrm{~cm}$ Tiefe; Ventilbildung. Keine Lähmungserscheinungen nach der Operation. Nach Heilung der Operationswunde Rückkehr in häusliche Pflege. Ausgang: Schon nach $1 \frac{1}{2}$ Wochen Wiederkehr der Anfälle, mit den Jahren Zunahme derselben an Zahl, fast täglich Schwindel, körperlich hilflos, geistig geschwächt.

Epikrise: Die erst nach $4 \frac{1}{2}$ jährigem Bestehen der Krampfanfälle vorgenommene Rindenexcision ist erfolglos geblieben. Das Ausbleiben von Lähmungserscheinungen im Anschluß an die Operation lassen es trotz der positiven faradischen Reaktion während des Eingriffs zweifelhaft erscheinen, ob das Handzentrum in notwendiger Ausdehnung getroffen wurde. Wahrscheinlich hat nach sofortiger Rücklehr in die häuslichen Verhältnisse auch keine konsequente Nachbehandlung stattgefunden.

Fall 14. Dora O. Die jetzt 28 Jahre alte, erblich nicht belastete Pat. erkrankte im 17. Jahre mit Jacksonkrämpfen, die mit Zuckungen in der 1. Hand begannen, ungefähr alle Monate und schließlich noch häufiger wiederkehrten. Im 18. Jahre, nach einjährigem Bestehen der Krankheitserscheinungen, Schädeltrepanation; dabei makroskopisch regelrechter Hirnbefund, Exstirpation des Handzentrums nach elektricher Bestimmung in einer Ausdehnung von $1 \frac{1}{2}-3 / 4 \mathrm{~cm}$ bis ins Mark hinein. Ausgang: In der ersten Woche nach der Operation 2 mal ein schwerer Anfall; die anfängliche Parese der r. Hand bildete sich nach ca. 2 Wochen zurück. Hierauf unter Bromkali ein anfallsfreies Jahr. 4 Wochen nach Weglassen des Bromkalis ein. Anfall. In den folgenden 9 Jahren nur vereinzelte Anfälle ohne 
Herderscheinungen, die nach der Operation nicht mehr auftraten. Im 26. Jahre Verheiratung. Zur Zeit Gravida im 6. Monat, während dieser Zeit 2 Anfälle. Geistig ist die Pat frisch.

Epikrise: Bei der jetzt 28 jährigen, erblich nicht belasteten, geistig frischen Frau ist die im 18. Jahr nach einjährigem Bestehen des Leidens vorgenommene Rindenexcision von Erfolg gewesen. Das einjährige Ausbleiben der Anfälle nach Brommedikation und das sofortige Wiederauftreten derselben nach Aussetzen des Medikaments beweist die große Wichtigkeit der sedativen Arzneibehandlung, auch nach Vornahme des Eingriffs. Von Interesse ist das Verschwinden des Jacksoncharakters der Anfälle nach der Operation. Die ungünstige Beeinflussung des Krampfleidens durch die Gravidität entspricht den innersekretorischen Veränderungen bei diesem Zustande, der ja auch bekanntlich durch die Erhöhung des antitryptischen Titers in dieser Zeit zum Ausdruck kommt.

Fall 15. Adalbert Sch. Der im Alter von $341 / 2$ Jahren aufgenommene Pat. ist durch Psychopathie des Vaters und dessen Bruders erblich belastet. In der Jugend übersteht er Masern, Diphtherie, Scharlach und einen Mittelohrkatarrh. Im 25. Jahr erkrankt er nach einer heftigen Gemütsbewegung mit epileptischen Krampferscheinungen herdförmigen Charakters mit Beginn im l. Arm und Facialisgebiet. Nach 9jährigem Bestehen der Krampferscheinungen Entlastungstrepanation rechts, nach der der herdförmige Charakter der Anfälle verschwindet. Im übrigen ist weder im Hinblick auf ihre Zahl, noch auf die erregbare Stimmung, die Impulsivität und Unstetheit des Kranken eine Beeinflussung eingetreten. Pat. verläßt schon nach 2 Monaten wieder die Anstalt. Die Nachforschungen nach seinem jetzigen Zustand sind erfolglos geblieben.

Epikrise: Möglicherweise sind die Herderscheinungen auf frühere encephalitische Prozesse zurückzuführen, die so häufig als Komplikationen von Infektionskrankheiten und otitischen Prozessen auftreten und nicht selten erst bei außergewöhnlichen cerebralen Schädigungen (Traumen, Erschöpfungszuständen usw,), zuweilen erst nach einer Reihe von Jahren, in Form epileptischer Krankheitserscheinungen sich wieder bemerkbar machen. Auch in diesem Falle sind sie erst im 25. Jahre nach einer heftigen Gemütsbewegung aufgetreten. Leider erfolgt erst nach 9 jährigem Bestehen der Krankheitserscheinungen, als bereits Etablierung der sog. epileptischen Veränderung angenommen werden muß, die rechtsseitige Entlastungstrepanation. Seit der Vornahme des Eingriffs $(3 / 4$ Jahre) war wieder, wie im vorigen Falle, der herdförmige Charakter der Insulte verschwunden, der psychische Zustand hatte sich jedoch nicht verändert.

Fall 16. Hans W. Der durch Hysterie der Schwester des Vaters indirekt erblich belastete, im 26. Jahre an Lungenentzündung verstorbene Pat. entwickelt sich bis zum 14, Jahr normal, erkrankt dann an leichten, allmählich stärker werdenden, meist linksseitigen Zuckungen. Im 23. Jahre, nach 9jährigem Bestehen der Krampfanfälle, einfache Entlastungstrepanation über der rechtsseitigen Scheitelbeingegend, dabei Feststellung einer Trübung der Hirnhäute. Nach der Operation Verminderung der Anfälle, es kommen anfallsfreie Monate vor, dann aber stellen sich auch wieder bis zu 4 Anfällen im Monat ein. Zeitweilig linksseitige Parese. Im 26. Jahre abermals linksseitig paretisch; Erkrankung an Lungenentzündung, Exitus letalis.

Epikrise: Bei dem indirekt erblich belasteten, im 14. Jahre an Jacksonkrämpfen erkrankten Pat. wịd erst spät, nach 9 jährigem Bestehen des Leidens, eine Entlastungstrepanation vorgenommen, wobei eine Trübung der Hirnhäute festgestellt wird. Wenn auch zu erwägen ist, ob in diesem Falle nicht zweckmäßiger die Excision des krampfenden Zentrums nach vorausgegangener faradischer Bestimmung hätte vorgenommen werden können, so hat doch die einfache Entlastung 
schon günstig gewirkt, und zwar durch Verminderung der Anfälle und Ausbleiben des geistigen Rückgangs. Allerdings stellt sich zeitweilig eine linksseitige Parese ein. Leider steht ein Sektionsbericht mit histologischem Hirnbefund bei dem in seiner Heimat verstorbenen Pat. nicht zur Verfügung, so daß nicht festgestellt werden kann, ob es sich bei der zeitweise aufgetretenen Hemiparese um circumscripte cerebrale Erschöpfungserscheinungen nach epileptischen Anfällen handelt, die sich vielleicht an der Stelle einer früheren Encephalitis entwickeln, oder ob entzündliche Prozesse wieder zum Aufflackern gekommen sind.

Bei den 5 folgenden Fällen $(17,18,19,20,21)$ handelt es sich $\mathrm{um}$ Kranke mit Krampfanfällen ohne Herderscheinungen, bei denen die einfache Entlastungstrepanation vorgenommen wurde.

Fall 17. Georg P. Vater hochgradiger Trinker, Pat., jetzt 30 jährig, ist jürg. stes Kind. Als Bäckerlehrling überanstrengt; mit 17 Jahren nervös, deprimiert, $1 / 2$ Jahr später Auftreten epileptischer Krampfanfälle in ausgebildeter Form. Fortgesetzt heftige Kopfschmerzen, namentlich vor den Anfällen, mit der Zeit zunehmend. Letztere bildeten die Indikation zur Entlastungstrepanation, die linksseitig im 22. Lèbensjahre des Pat. 5 Jahre nach Bestehen der epileptischen Krankheitserscheinungen vorgenommen wurde. Die Arteria meningea media wurde doppelt unterbunden, die Dura excidiert und ein Fascienfettlappen implantiert. Nach der Operation, die vor 8 Jahren stattfand; Seltenerwerden der Anfälle, die vorher ea. alle 4 Wochen auftraten, erhebliche Besserung der Kopfschmerzen, die selten und nur vorübergehend auftreten. Pat. arbeitet fleißig in der Bäckerei; abgesehen von selten auftretenden depressiven Gemütsstimmungen subjektives Wohlbefinden, kein geistiger Rückgang.

Epikrise: Bei dem erblich belasteten Kranken hat die im 22. Jahre nach 5jährigem Bestehen der epileptischen Krankheitserscheinungen vorgenommene Entlastungstrepanation entschieden günstig gewirkt, indem die quälenden, an Intensität zunehmenden Kopfschmerzen bis auf zeitweiliges, seltenes Auftreten in schwächerer Form geschwunden sind, die Anfälle sich vermindert haben und der jetzt 30 jährige, arbeitsfähige Kranke im Laufe der Jahre keine Einbuße seiner Geisteskräfte erlitten hat.

Fall 18. Helene G. Großvater (mater) der jetzt 32 jährigen Pat. litt 1 Jahr lang an epileptischen Anfällen, desgleichen ein Bruder der Mutter. Nach normaler Entwicklung Auftreten von epileptischen Anfällen im 16. Jahre, zuerst in leichter Form, nach einem Sturz sich verschlimmernd und schlieBlich alle 4 Wochen auftretend. Dabei zunehmende Reizbarkeit und Neigung zum Querulieren. Im 23. Jahr nach 1 jährige $m$ Bestehen Entlastungstrepanation mit Implantation eines Fascienfettlappens. Makroskopisch negativer Befund. Unmittelbar nach der Operation noch einige petit mal, dann 8 Monate anfallsfrei, allerdings dauernd reizbar und mißmutig. Nach der nun folgenden Entlastung bald wieder Anfälle, ungefähr alle 4 Wochen, 5-6 während und nach der Periode. In der Folgezeit wiederholt aufgenommen und entlassen; psychisch andauernd schwierig. Vom körperlichen Befund ist eine Vergrößerung der Schilddrüse hervorzuheben.

Epikrise: Bei der von beiden Seiten erblich belasteten, in der Pubertätszeit an epileptischen Anfällen erkrankten Pat. wird erst nach 7 jährigem Bestehen des Leidens im 23. Jahre die Entlastungstrepanation vorgenommen mit dem Erfolg, daß 8 Monate während des Anstaltsaufenthalts wohl die Anfälle, nicht aber die epileptische Seelenveränderung beseitigt werden. Nach dem Wegfall der geregelten Anstaltspflege stellen sich sofort wieder Anfälle ein. Es liegt also hier nur ein vorübergehender Erfolg vor; allerdings sind mehrere Faktoren vorhanden, die für die Prognose des Leidens ungünstig sind: erbliche Belastung von beiden 
Elternseiten, Vergrößerung der Schilddrüse, die auf Störungen der inneren Sekretion schließen läßt, langer Intervall zwischen Auftreten der epileptischen Anfälle und Vornahme der Operation, in der sich die sog. epileptische Veränderung entwickeln konnte; ungünstig war auch entschieden die frühe Rückkehr in die häuslichen Verhältnisse. Daß auch bei diesem Falle mit der Menstruation verbundene innersekretorische Störungen auslösend auf epileptische Anfälle wirken können, wird durch das Auftreten der Insulte während und nach der Periode wahrscheinlich gemacht.

Fall 19. Frieda $\mathrm{H}$. Erblich nicht belastete, jetzt 28 jährige Anstaltspatientin. Im 10. Jahre ausgebildete Anfälle, langsame Abnahme der Geisteskräfte. Mit 17 Jahren Entfernung der Eierstöcke und Eileiter. Nach röntgenologischer Feststellung von Knochenverdickungen im Schädel im 25 . Jahre nach 15 jährigem Bestehen der epileptischen Krankheitserscheinungen Resektion eines bis zu $12 \mathrm{~mm}$ dicken Knochens mit einem haselnußgroßen Krankheitsherd im l. Scheitelbein. Sonst kein weiterer Eingriff. Nach nunmehr 3 Jahren ist keinerlei Einfluß auf die Krankheitserscheinungen festzustellen.

Epikrise: Der vorliegende Fall gehört zu den bei Epileptikern nicht selten anzutreffenden, röntgenologisch feststellbaren Schädelanomalien, auf die zuerst von Redlich und Schüller ${ }^{2}$ ) hingewiesen ist. Die Entfernung des haselnußgroßen Knochenherdes ist völlig ohne Einfluß auf den Krankheitsverlauf geblieben, allerdings wurde auch in diesem Falle der Eingriff erst nach 15jährigem Bestehen der epileptischen Krankheitserscheinungen vorgenommen.

Fall 20. Bernhard L. Die Eltern des jetzt 37 jährigen Anstaltspatienten sind Vetter und Cousine. Pat. hatte immer einen auffallend großen Kopf. Zur Zeit beträgt sein Schädelumfang $61 \mathrm{~cm}$; nach Überanstrengung als Postgehilfe erkrankte er im 23. Jahre an epileptischen Anfällen, zu denen sich mit der Zeit Abnahme der Geisteskräfte und hypochondrische Stimmungsanomalien hinzugesellten. Im 28. Jahre nach 5 jährigem Bestehen der epileptischen Krampferscheinungen Ventilbildung über dem r. Scheitelbein; Duraexcision und Implantation eines Fascienfettlappens. Seit dem Eingriff sind nunmehr 9 Jahre vergangen, ohne daß ein Einfluß auf die Krankheitsäußerungen festzustellen wäre. Die Anfälle treten nach wie vor in unvollkommener und ausgebildeter Form auf; ziemlich häufig stellen sich Erregungs- und Tobsuchtszustände ein.

Epikrise: In hereditärer Hinsicht liegt höchstwahrscheinlich Schädigung durch Inzucht vor, die zu einer Megalencephalie mit epileptischen Anfällen und psychischen Störungen geführt hat. Wir dürfen wohl annehmen, daß bei diesem Falle neben der Hirnanomalie auch Anomalien in der Anlage des endokirinen Systems vorliegen, die die Prognose des Eingriffs von vornherein verschlechterten. Die nach 5jährigem Bestehen der Krampfanfälle vorgenommene Entlastungstrepanation ist ohne Einfluß auf den Krankheitsverlauf geblieben.

Fall 21. Konrad Sch., 35 Jahre alt. Anstaltspflegling. Als kleines Kind Masern. Im 5. Jahre Auftreten unvollkommener Anfälle, die sich allmählich zu ausgebildeten entwickelten. Nach 30 jährigem Bestehen im 35. Jahre Entlastungstrepanation über dem l. Scheitelbein. Ausgang: Geringe Zunahme der Anfälle nach der Operation, die vor der Operation in Zwischenräumen von einigen Wochen auftraten. Geistig ist Pat. frisch, ein Rückgang der Geisteskräfte ist nicht festzustellen. Vom körperlichen Befund ist hervorzuheben: Facialisinnervation links schwächer, das l. Auge kann isoliert nicht geschlossen werden.

Epikrise: Der vorliegende Fall zeigt von den bei Epileptikern so überaus häufig anzutreffenden Halbseitserscheinungen eine Schwäche des 1. Facialis. Erst nach 30jährigem Bestehen der epileptischen Krankheitserscheinungen wurde eine Entlastungstrepanation vorgenommen, die erfolglos gewesen ist. Hingewiesen 
sei auf die Tatsaehe, daß ein Rückgang der Geisteskräfte bisher ausgeblieben ist. Es ist allerdings $z \mathfrak{u}$ erwägen, ob nicht bei dem Bestehen von linksseitigen Halbseitserscheinungen wie in diesem Falle der obengenannte Eingriff nicht besser auf der rechten Seite vorzunehmen wäre.

Der nächste Anstaltspflegling (Fall 22) bietet wegen der Komplikationen einiges Interesse. Leider waren die Bemühungen, aus dem größeren städtischen Krankenhause, in dem die erste Operation stattfand, nähere Auskunft über die Patientin zu erhalten, erfolglos. Das, was hier anamnestisch zur Verfügung stand, ist folgendes:

Fall 22. Christine F. Die jetzt 35jährige Anstaltspatientin wurde im 21. Lebensjahre, $1 \mathrm{Jahr}$ nach der Excision des l. Armzentrums in hiesige Anstalt aufgenommen. Die Krampfanfälle sollen im 16. Lebensjahre aufgetreten sein. Nähere anamnestische Daten über Entwicklung der Krankheit, Indikationen und Art des operativen Eingriffs stehen nicht zur Verfügung. Bei der hiesigen Aufnahme täglich Zuckungen im paretischen r. Arm, die sich auf die ganze rechte und schlie Blich auch auf die linke Seite ausdehnten; motorische Aphasie. Psychisch etwas stumpf, allmählich teilnehmender. In den ersten Jahren vorïbergehende Albuminurie, Wiederkehr derselben nach größeren Anfallsgruppen. Im 22. Jahre Zunahme der Lähmungserscheinungen im r. Arm und Bein, zunehmende Schwere der Anfälle. Deshalb zweite Operation hier mit folgendem Befund: Der bei der ersten Operation gebildete Duralappen zusammengeschoben und mit der Hirnrinde verwachsen. Der Lappen wird abgetragen, die betreffende Stelle mit einem Fascienfettlappen überdeckt. Nach diesem Eingriff Besserung der Lähmungserscheinungen an den Extremitäten und der Sprache. Allmählich wieder Zunahme der Lähmungserscheinungen. Zur Zeit spastische Hemiparese rechts, motorische Aphasie, nur im Affekt einige Schimpfworte. Zuweilen Erregungszustände, pro Monat bis zu 15 schwere und ebenso viel leichte Anfälle.

Epikrise: Im Anschluß an die nach 4 jährigem Bestehen der Krampfanfälle erfolgte Excision des 1. Armzentrums sind schwere Ausfallserscheinungen hinsichtlich der Bewegung des 1 . Arms und der Sprache sowie des seelischen Verhaltens zurückgeblieben. Infolge weiterer Verschlimmerung des Zustandes, namentlich auch hinsichtlich der Insulte, wird nach 2 Jahren zur zweiten Operation geschritten, bei der sich in Gestalt des verschobenen und mit dem Gehirn verwachsenen Duralappens eine Erklärung für die Verschlimmerung des Krankheitsbildes findet. Nach nur $1 / 2$ jähriger Besserung tritt wieder eine Verschlimmerung ein, so daß die Kranke infolge der körperlichen Hilflosigkeit fast immer bettlägerig ist. Beim vorliegenden Fall besteht die große Wahrscheinlichkeit, daß durch den operativen Eingriff eine Verschlechterung des Zustandes eingetreten ist. Leider ist nichts Genaueres über den ersten operativen Eingriff festzustellen. Die schwere motorische Aphasie, die sich an die Excision des l. Armzentrums angeschlossen hat, weist jedoch auf die Gefahren hin, die mit den operativen Eingriffen in der Nähe der Sprachregion verbunden sind.

Die beiden vorliegenden Fälle 23 und 24 bilden den Abschluß der nicht traumatischen und nehmen hinsichtlich ihrer Eigenart innerhalb der mit epileptischen Krampfanfällen verlaufenden Krankheitsbilder eine Sonderstellung ein. Es handelt sich um das erst in den letzten Jahrzehnten festgestellte Krankheitsbild der tuberösen Sklerose.

Fall 23. Hans v. M. Vater luetisch, der älteste Bruder der Mutter imbezill. Zuerst normale Entwicklung. Im 3. Jahr petit mal, dann ausgebildete Anfälle; 
zuweilen einige Tage aussetzend, dann wieder 6-7 pro Tag. Seit Jahren auf der Gesichtshaut ziemlich symmetrisch knöchenförmige Bildungen;: am Kinn derbere herdförmige Knoten. Auf der r. Oberbauchseite derselbe Ausschlag wie auf dem Gesicht; auf der Rumpfhaut außerdem vereinzelte pigmentlose Stellen. Infolge Verschlechterung des Zustandes wird nach ca. 1 jährigem Bestehen der Krampfanfälle, als 9 Lumbalpunktionen und der Balkenstich erfolglos geblieben waren, die Entlastungstrepanation vorgenommen. Ihr Erfolg besteht in einer Vergrößerung der anfallsfreien Pausen. Schon $1 / 2$ Jahr später verstirbt Pat. $5^{1 / 2}$ Jahre alt an einem epileptischen Anfall. Bei der Autopsie finden sich die typischen Veränderungen an den Hirnwindungen, den Nieren und am Herzen.

Fall 24. Paul B. Völlig normale Entwicklung und körperliche und geistige Leistungsfähigkeit bis zum 29. Lebensjahre. In dieser Zeit viel Kopfschmerzen, zunehmende Verschlechterung des Sehens. Vereinzelte Krampfanfälle mit vorwiegender Beteiligung.des r. Arms. Infolge Zunahme der Hirndruckerscheinungen im 30. Jahre Trepanation über dem r. Scheitelbein. Keine Beeinflussung des Zustandes nach der Operation. Allmählich Erblindung. Stimmung während des Anstaltsaufenthalts wechselnd, vorwiegend deprimiert, geistig sonst ziemlich frisch, nur vereinzelte Krampfanfälle. Im Anschluß an zwei epileptische Anfälle Exitus letalis im Alter von 321/4 Jahren. Bei der Sektion die charakteristischen Verhärtungen der Hirnwindungen in unregelmäßiger Verbreitung über die ganze Hirnoberfläche. Von den beiderseitigen Ventrikeltumoren ist ein solcher von Walnußgröße im l. Ventrikel hervorzuheben, der durch die Druckwirkungen auf dem Ventrikelboden die Sehnerven im Chiasma zum Schwunde gebracht hat. Vom übrigen Organbefund sind die charakteristischen Tumoren in beiden Nieren hervorzuheben.

Epikrise: Es handelt sich in beiden Fällen um das eigenartige Krankheitsbild der tuberösen Sklerose mit den verhärteten, knollig veränderten Abschnitten der Hirnwindungen, die mikroskopisch die charakteristischen großen Zellen von ganglionärem und gliösem Typus enthalten. Zu dieser Anomalie gesellen sich noch Heterotopien in der weißen Substanz und eine Reihe charakteristischer Ventrikeltumoren, die bekanntlich nur die großen gliösen Elemente enthalten. Winer von ihnen bat beim 2 . Falle Walnußgröße erreicht und eine deletäre Wirkung auf die Sehnerven ausgeübt. Beiden Fällen gemeinsam sind ferner die typischen Nierentumoren mit ihrem gemischtzelligen Bau von fibroadenomatösem Charakter, die aber symptomlos verlaufen sind. Hinsichtlich ihres sonstigen Verhaltens zeigen beide Fälle gewisse Unterschiede. Der erste, hereditär durch Lues des Vaters belastet, durch das Auftreten von Hautanomalien, insbesondere der gleichfalls. charakteristischen Adenoma-sebacea-Bildungen im Gesicht ausgezeichnet, bietet den gewöhnlichen Verlauf des Krankheitsbildes: Frühzeitiges Auftreten von Krampfanfällen, Stillstand der geistigen Entwicklung, allmählich fortschreitende Verblödung, Tod in früher Jugend infolge epileptischen Anfalls. Der zweite Fall, der die Hautveränderungen vermissen läßt, ist durch eine seltene Verlaufsform ausgezeichnet: Normale körperliche und geistige Entwicklung bis zum 27. Jahre, Erst dann Auftreten von Krankheitserscheinungen in Form von Hirndruckerscheinungen. In erster Linie sind hierbei die heftigen Kopfschmerzen zu nennen, die durch Beeinflussung des Hirndruckes infolge des großen Ventrikeltumors bedingt sind. $\mathrm{Zu}$ ihnen gesellen sich dann der Druckschwund des Opticus und vereinzelte Krampfanfälle. Die Hirndruckerscheinungen sind es auch, die den behandelnden Chirurgen einen Hirntumor vermuten lassen und ihm die Entlastungs. trepanation indizieren. Im ersten Falle waren die druckentlastenden Operationen in Gestalt der Lumbalpunktion und des Balkenstichs völlig erfolglos, erst die Dekompensativtrepanation vermochte die anfallsfreien Pausen zu vergrößern, bis der Kranke nach wenigen Monaten im Alter von $5^{1 / 2}$ Jahren doch von seinem Schicksal 
ereilt wurde. Auch im zweiten Fall ist der Eingriff erfolglos gewesen: Es trat trotz der Entlastung völlige Erblindung ein, es zeigten sich auch weiterhin vereinzelte Anfälle. Allerdings blieb der Pat. bei krankhaftem Stimmungswechsel mit vorwiegend depressivem Charakter geistig verhältnismäßig frisch, bis gleichfalls epileptische Anfälle seinem Leben, allerdings in dem für tuberöse Sklerose weit fortgeschrittenen Lebensalter von $32^{3} /{ }_{4}$ Jahren ein Ziel setzten. Es ist hier nicht der Ort, auf das interessante Krankheitsbild der tuberösen Sklerose näher einzugehen, das bekanntlich auch noch durch das Auftreten von Tumorbildungen in anderen Organen, z. B. dem Herzen, der Schilddrüse usw., ausgezeichnet ist. Es sei nur Kraepelins ${ }^{3}$ ) Auffassung angeführt, wonach es sich bei der tuberösen Sklerose um einen eigenartigen Krankheitsvorgang handelt, der mannigfache Wucherungen erzeugt und damit die Ausbildung der wichtigsten Gewebsbestandteile und ihre Verbindungen schädigt. Daß nicht allein cerebrale Erscheinungen, sondern auch solche von anderen Organen Veranlassung zu chirurgischem Eingreifen geben können, wird durch einen in der hiesigen Anstalt noch lebenden, jetzt 20 jährigen Pflegling M. E. illustriert. Die charakteristischen Adənomasebacea-Bildungen in der Gesichtshaut, verbunden mit epileptischen Insulten, machten die Diagnose tuberöse Sklerose sehr wahrscheinlich. Letztere wurde bestätigt durch das Auftreten eines großen linksseitigen Nierentumors, der sich bei der Entfernung als die für tuberöse Sklerose typische Neubildung erwies. Zur weiteren Ergänzung über die verschiedenen Verlaufsformen der tuberösen Sklerose sei noch kurz auf die seinerzeit von Merkel (München) in Metz sezierten und von Weinert $t^{4}$ kurz beschriebenen Fälle von tuberöser Sklerose bei einem Soldaten hingewiesen. Die gesamte Großhirnrinde bei diesem Fall war von kleinsten und größeren tumorähnlichen Bildungen mit dem charakteristischen makroskopischen Bilde eingenommen, dagegen war die Wand der Ventrikel frei von gliomartigen Bildungen im Gegensatz zu der großen Zahl früher beschriebener Fälle. Gleichzeitig bestanden tumorähnliche Bildungen, Cysten, kleine Adenomknoten in den Nieren, ferner waren die Lungen von kleinen Geschwülsten (Fibromyomen) durchsetzt, ebenfalls zum Teil die thorakalen Drüsen. Auch die Lymphplatten des Dünndarms zeigten eine große Anzahl von gestielten kleinen Gebilden, die mikroskopisch der Bindegewebegruppe zugerechnet werden mußten. Im Gesicht fanden sich in schmetterlingsförmiger Anordnung zu beiden Seiten der Nieren die eigenartigen, als Adenoma sebacea bezeichneten Hautbildungen, die auch im Falle 23 bestanden und dort zur richtigen Diagnose hätten führen können. Im besonderen Maße ist bei dem Merkel - Weinertschen Falle bemerkenswert, daß der 29 jährige, an einem Rückenmarksschuß nach einigen Tagen verstorbene Soldat bis kurz vor seinem Tode den schweren Frontdienst mitgemacht und auch in früherem Leben, wie die in der Heimat und beim Regiment eingereichten Feststellungen ergaben, weder somatisch noch psychisch Krankheitserscheinungen dargeboten hatte. Dieser Fall zeigt noch deutlicher wie Fall 24, da B selbst b e i derartig schweren, auf Entwicklungsstörungen beruhenden Hirnanomalien regelrechte nervöse psychische Funktionen bestehen können, die eine erhöhte Irritabilität des Zentralnervensystems, wie sie $\mathbf{u}$. a. auch in epileptischen Krampferscheinungen zum Ausdruck kommt, vermissen lassen und die auch das Vorhandensein von krankhaften Abbauvorgängen unwahrscheinlich machen. Überraschend ist bei diesem Fall, daß auch keinerlei Zeichen für das Bestehen inkretorischer Störungen festzustellen sind, obwohl an einer Reihe lebenswichtiger innerer Organe sich schon makroskopisch ausgesprochene Ano. malien erkennen ließen. Bei der Wichtigkeit derartiger Fälle für die Frage der epileptischen Prädisposition, die bekanntlich $u$. a. auch durch cerebrale Entwicklungsanomalien bedingt sein soll, und die Frage der epileptischen Reaktionsfähig. keit soll später noch einmal kurz auf sie eingegangen werden. 
Mit diesen 24 Fällen ist die Zahl derjenigen trepanierten Anstaltspfleglinge erschöpft, bei denen traumatische Schädigungen anamnestisch nicht in Frage kommen. Es mögen jetzt 26 Fälle folgen, wo tra u ma. tische Schädigungen in irgendeiner Form wahrscheinlich oder sicher vorhanden gewesen sind. Von diesen 26 Fällen sollen zuerst 15 Fälle besprochen werden, bei denen es ohne weiteres ersichtlich ist, daß die traumatischen Schädigungen nicht allein ätiologisch in Frage kommen, da sich komplizierende Faktoren: Konvulsionen $u$. ä. in frühester Kindheit, infektiöse Erkrankungen in späterer Zeit, verlangsamte Entwicklung und Alkoholintoxikation mit dem Trauma kombinieren In diese 15 Fälle sind auch 5 Fälle mit traumatischen Geburtsschädigungen eingereiht.

Es mögen zuerst 4 Fälle mit konvulsivischen Zuständen in früher Jugend folgen, zu denen sich später die traumatische Gehirnschädigung hinzugesellte.

Fall 1. Oswald F. Bruder der Mutter geistig abnorm, Trinker, Irrenanstaltspflegling. Pat. ist Zwillingskind. Beide Zwillingskinder hatten Schreikrämpfe, ,blieban weg“". Zwillingsbruder als Kind nervös. Mit 13 Jahren erhielt Pat. mit einem Bücherpaket Schläge auf den Kopf. 1 Stunde nachher der erste Krampfanfall. Im weiteren Verlauf Beginn der Krämpfe im r. Arm.

Aura: Gefühl, „als ob etwas vom Herzen käme". Vom Organbefund bei des Anstaltsaufnahme im 21. Jahre: Uvula nach links. Henkelohren, unregelmäßige Stellung der Schneidezähne; viel Kopfschmerzen, psychisch leichter Schwachsinn. Auf Grund der Herderscheinungen und der Kopfschmerzen im gleichen Jahre Ventilbildung über dem 1. Scheitelbein nach 8jährigem Bestehen der Krämpfe; makroskopisch negativer Gehirnbefund. Im ersten halben Jahre nach der Operation kein Einfluß auf die Anfälle, dann über $1 / 2 \mathrm{Jahr}$ anfallsfrei und Freisein von Kopfschmerzen. Die weiteren jetzt nach 8Jahren vorgenommenen Nachforschungen sind leider erfolglos geblieben.

Epikrise: Der vorliegende Fall eines Zwillingskindes hat ein besonderes Interesse deshalb, weil in der frühen Jugend das sog. „Wegbleiben der Kinder" bestanden hat. Beide Zwillingskinder waren mit diesem Phänomen behaftet, das Bratz zu den affektepileptischen Anfällen in Beziehung bringt. Ibrahim ${ }^{6}$ ), der sich besonders mit dieser Frage befaßte, bezeichnet sie als respiratorische Affektkrämpfe und sieht ganz allgemein in hereditärer Neuropathie die Grundlage dieser Krampferscheinungen. Zur Epilepsie haben sie nach dem genannten Autor keine weiteren als andere auf dem Boden der hereditären Neuropathie sich entwickelnde, periodische Zustände, wobei allerdings die Möglichkeit besteht, daß bei dem einen oder dem anderen der in Frage kommenden Kinder sich doch späterhin wirkliche epileptische Anfälle entwickeln. Von den hier in Frage kommenden Zwillingskindern ist der eine nach Ausheilung der nervösen Erseheinungen im Kindesalter später völlig gesund geworden, bei dem anderen kam es direkt im Anschluß an Schläge auf den Kopf zu epileptischen Anfällen mit Herderseheinungen. Leider wurde auch erst wieder nach 8jährigem Bestehen der Krampferscheinungen zur Trepanation geschritten, bei der man sich bei dem Fehlen makroskopischer Veränderungen auf die Entlastung beschränkte. Wenn auch im ersten halben Jahre nach der Trepanation kein Erfolg zu verzeichnen war, so blieb der Kranke doch im zweiten halben Jahre anfallsfrei, wozu als große, subjektive Erleichterung noch das Fortbleiben der Kopfschmerzen kam. Ob sich ein Dauererfolg aus diesem 
Fall entwickelt hat, war infolge der vergeblichen Nachforschungen nicht festzustellen.

Fall 2. Otto B. Eine Schwester der Mutter hat dreimal an puerperaler Psychose gelitten. Als Kind 2-3 mal leichte Zahnkrämpfe. Mit 20 Jahren Sturz vom Reck, Gehirnerschütterungen; seit dieser Zeit Kopfschmerzen, allmählich Schwindelzustände und epileptische Anfälle mit vorwiegender Beteiligung des r. Armes und Beines. Nach 1 jährigem Bestehen der Krankheit im 2l. Jahr Schädeltrepanation links mit folgendem Operationsbefund: Auffallend geringe Pulsation der prall gespannten Dura; weiche Hirnhäute leicht getrübt, auffallend reichlich Flüssigkeit in ihren Maschen, gelbliçhe Knötchen in der Nähe der Gefäße; Freilegung und faradische Bestimmung des Facialis-Arm- und -Schulterzentrums; Excision dieses Bezirks. Erfolg: Mehrere Wochen Aussetzen der Anfälle, dann wieder Zunahme. Nach $1 \mathrm{Jahr}$ und in der Folgezeit verwirrt, mißgestimmt, seelische Störungen mit religiöser Färbung, einmal auch manisch erregt, ein anderes Mal katatonisch, negativistisch, dabei Erscheinungen von Flexibilitas cerea. Unter zunehmender Verschlimmerung der Anfälle und Verblödung Exitus letalis nach einer Anfallsserie im 22. Jahre.

Epikrise: Es liegt bei diesem Patienten mit Zahnkrämpfen in der Jugend und einem im 20. Jahre erlittenen Kopftrauma ein operativer Mißerfolg vor. Der autoptische Operationsbefund: Pralle Spannung der Dura, Trübung der weichen Hirnhäute, gelbliche Knötchen in der Nähe der Gefäße stellen den chronisch entzündlichen Folgezustand akuter, traumatisch entstandener hämorrhagischer Veränderungen der weichen Hirnhäute dar, auf deren folgenschwere Bedeutung und deshalb möglichst frühzeitige Behandlung Tilman $\left.n^{7}\right)^{8}$ ) nachdruicklich hinweist. Im vorliegenden Falle wurde sie nach 1 Jahre erst vorgenommen. Es besteht die große Wahrscheinlichkeit, daß die chronischen leptomeningitischen Veränderungen zu schweren destruktiven Veränderungen der Hirnsubstanz geführt hatten, die später bei diesem Fall klinisch ein katatonisches Gepräge darboten und auch durch den operativen Eingriff nicht mehr beseitigt werden konnten.

Fall 3. Johannes W. Zur Zeit 46 Jahre alt. Mutter litt an manisch-depressiven Gemütszuständen, der Vater der Mutter an periodischer Manie. Bald nach der Geburt konvulsivische Zuckungen. Mit 3 Jahren erst Laufen gelernt, schlechter Schüler. Mit 10 Jahren Steinwurf in die r. Schläfengegend. Auftreten der Anfälle im 11. Jahr. Beginn im r. Arm mit einem Gefühl, ,,als ob eine Schlange im rechten Arm nach oben kriecht". In den ersten Jahren vereinzelt Anfälle, dann Zunahme derselben, besonders im 16. Jahre. Dabei hochgradige Erregungszustände mit Halluzinationen (sah Schlangen usw.). Im 20. Jahre nach 9jährigem Bestehen der Krankheitserscheinungen Trepanation in der r. Stirnschläfengegend, der Stelle des Steinwurfs. Operationsbefund: Deutliche Knochenverdickungen, am Gehirn makroskopisch nichts Abnormes; Ventilbildung. Erfolg: Nach der Operation nur noch vereinzelte Anfälle in den nächsten 2 Jahren, hierauf 6 Jahre anfallsfrei. Dann Wiederbeginn mit petit mal, allmählich auch ausgebildete Anfälle. Zeitweise Depressionen, einmal ein Suicidversuch. In den letzten Jahren nur vereinzelte Anfälle beim Weglassen des Bromkalis, geistig dauernd ziemlich frisch, kein geistiger Rückgang, etwas schwieriger Charakter. Vom körperlichen Befund sei hervorzuheben: Linke Stirnschläfengegend flacher als rechts, geringes Abweichen der Zunge nach rechts. In der r. Stirnschläfengegend 5-markstïickgroße nicht pulsierende Knochenimpression.

Epikrise: Wenn auch bei dem Kranken noch vereinzelte epileptische Anfälle beim Weglassen des Bromkalis sich einstellen und im Hinblick auf den etwas schwierigen Charakter fortgesetzte Anstaltspflege geraten erscheint, so kann doch im Hinblick auf den fehlenden Rückgang der Geisteskräfte und die bestehende, 
wenn auch beschränkte Arbeitsfähigkeit von einem gewissen Erfolg des operativen Eingriffs gesprochen werden, der trotz der erblichen Belastung, trotz der eklamptischen Anfälle in frühester Jugend und trotz des langjährigen Bestehens der epileptischen Krankheitserscheinungen bis zur Vornahme der Operation eingetreten ist. Der Chirurg hat der allgemeingültigen Indikation entsprechend die Trepanation an derjenigen Schädelstelle vorgenommen, wo das Trauma in Form des Steinwurfs eingewirkt und feststellbare Knochenveränderungen hervorgerufen hatte. Im Hinblick auf das Abweichen der Zunge nach rechts und die im r. Arm lokalisierte Aura ist allerdings zu erwägen, ob bei dem negativen Hirnbefund an der Stelle des Traumas und bei wiedereinsetzenden Krankheitserscheinungen in Anbetracht der rechtsseitigen Halbseitensymptome nicht noch einmal auf der entsprechenden kontralateralen Schädelhälfte einzugehen gewesen wäre. Bei dem jetzigen Zustand des Kranken kommt ein operativer Fingriff nach unserem Dafürhalten nicht mehr in Frage.

Fall 4. Bruno B., 19 Jahre alt, Anstaltspflegling. Großvater (mater) potator. Ein Onkel des Vaters hatte Krämpfe, war auch Trinker. Ein anderer : Onkel geistig abnorm, eine Tante der Mutter geisteskrank. Im 13. Monat 1 Stunde lang in Krämpfen, dabei wahrscheinlich Fieber und Magenverstimmung. Mit 31/2 Jahren Schlag durch eine Schaukel, darnach Bewußtlosigkeit, 6 Monate darauf Sturz von einer $4 \mathrm{~m}$ hohen Mauer ins Wasser. 3 Monate später Krampfanfälle, nach denselben linksseitige Extremitätenlähmung. Im 6. Lebensjahre nach 2 jährigem Bestehen der linksseitig beginnenden Krampfanfälle Entlastungstrepanation über dem r. Scheitelbein. Operationsbefund: Leistenartige Wölbungen auf der Innenseite des Schädels; Dura getrübt. Erfolg: Kein Einfluß auf die Anfälle; letztere zahlreich. Nach denselben tage- und wochenlang schwach und bettlägerig, zeitweise erregt, hochgradiger Schwachsinn, Sammeltrieb.

Epikrise: Der indirekt erblich belastete Kranke hat höchstwahrscheinlich schon im 13. Monat eine Encephalitis durchgemacht. Das in seiner Widerstandskraft schon geschwächte Gehirn wird im 3. zum 4. Lebensjahre noch durch zwei erhebliche Kopftraumen betroffen, so daß abermals encephalitische Erscheinungen mit nachfolgenden, linksseitig beginnenden Krampfanfällen und linksseitige: Hemiparese hervorgerufen werden. Wieder ist sehr spät, nämlich nach 2 jährigem Bestehen und erheblicher Verschlimmerung der Krankheitsbeschwerden zur Trepanation geschritten, die autoptisch chronisch-ostitische und pachymeningitische Befunde umschriebener Natur ergaben. Diese Veränderungen sind mit größter Wahrscheinlichkeit auf die wiederholten traumatischen Schädigungen zurückzuführen. Die so entstandenen entzündlichen Prozesse haben sich von den Hüllen auf das Gehirn selbst fortgepflanzt, das schon auf Grund der Encephalitis in frühester Jugend eine verminderte Widerstandsfähigkeit besaß oder die früheren entzündlichen Prozesse wieder aufflackern ließ.

In den beiden folgenden Fällen 5 und 6 ist das Gehirn nicht allein durch Traumen, sondern auch noch durch Scharlachinfektionen geschädigt.

Fall 5. Friedrich D., 20 Jahre alt. Mutter an Diabetes gestorben, Vater litt vorübergehend an alimentärer Glykosurie. Im 4. Jahre infolge von Sturz Schädelzertrïmmerung. Im 13. Jahre schwere Scharlacherkrankung mit Gehirnerscheinungen. Seit dieser Zeit eigenartige Verdrehung des Kopfes. Im 14. Jahre nach schwerer Erkältung ausgesprochene epileptische Anfälle. Nach ca. 1/2 jährigem Bestehen der epileptischen Krankheitserscheinungen im 14. Lebensjahre die erste Schädeltrepanation, über deren Verlauf nichts Näheres mehr festzustellen ist. Da keine Besserung eintritt, erfolgt $1 / 2$ Jahr später die zweite Trepanation 
mit folgendem autoptischen Befund: Verwachsungen der Hirnsubstanz mit den Schädeldecken, mehrere kirschgroße cystöse Bildungen; Implantation eines Fascienfettlappens. Vom Zustand 6 Jahre nach der Operation: Hemiparese des r. Beines, eine gewisse Schwäche auch im r. Arm, auf der Höhe des Scheitels links eine $9 \mathrm{~cm}$ lange, $5 \mathrm{~cm}$ breite bis $2 \mathrm{~cm}$ tiefe Impression mit fühlbarer Pulsation Die Anfälle sind nach der Operation etwas häufiger, aber nicht mehr so schwer aufgetreten; stundenlang vorher empfindet der Kranke eine eigenartige Spannung im Kopfe, das Bewußtsein bleibt ziemlich lange erhalten, kurz vor dem Ausbruch der Krämpfe besteht Urindrang. Die Schädelimpression gleicht sich während des Anfalls teilweise aus, auch nach dem Anfall erreicht sie erst nach einiger Zeit wieder die gewöhnliche Tiefe.

Epikrise: Bei dem vorliegenden Fall, der einen jetzt 20 jährigen, geistig noch ziemlich frischen Anstaltsinsassen betrifft, haben eine Reihe schwerer Hirnschädigungen stattgefunden, bis es zum Ausbruch der epileptischen Krankheitserscheinungen kam: Schädelzertrümmerung im 4. Jahr, Scharlacherkrankung mit cerebralen Erscheinungen im 13. Jahr, eine infektiöse Erkrankung im 14. Jahr. . Es ist bekannt, $\mathrm{da} ß$ von den Infektionskrankheiten besonders Scharlach verhältnismäßig häufig cerebrale Komplikationen mit sich bringt, die nicht selten die Grundlage zu früher oder später auftretenden epileptischen Krankheitserscheinungen bilden. Später soll auf diese Frage noch einmal kurz eingegangen werden. Auch im vorliegenden Falle schlossen sich an die Scharlacherkrankungen im 13. Jahre epileptiforme Symptome an, die sich nach einer weiteren, anscheinend wieder infektiösen Erkrankung zu ausgesprochenen epileptischen Anfällen entwickelten. Der mildere Verlauf der Anfälle nach der zweiten Operation, auch wenn sie etwas häufiger auftreten, sowie das Fehlen eines geistigen Rückgangs sind möglicherweise als ein günstiger Effekt der Operation anzusehen. Von Interesse ist die oben beschriebene Verlaufsart des Anfalls: Das stundenlang vor dem Anfall einsetzende Gefühl der Spannungszunahme im Schädel, das höchstwahrscheinlich einer intrakraniellen Druckzunahme entspricht; das ziemlich lange erhaltene Bewußtsein, der Urindrang als cerebrale Reizerscheinung, dem der Kranke noch möglichst schnell nachzukommen sucht, schließlich die objektiv beobachtete Ausgleichung der Schädelimpression während des Anfalls, die erst stundenlang nach dem Anfall wieder ihre gewöhnliche Tiefe erreicht.

Fall 6. Hans B., 27 Jahre alt, Anstaltspflegling; keine erbliche Belastung; in 7. Jahre Scharlach, seit dieser Zeit Hemiparese links. Im 13. Jahre mit einem Schlitten gegen einen Baum gefahren, darnach bewußtlos, 2 Tage später epileptische Anfälle. Nach 6 jährigem Bestehen im 19. Lebensjahre Vornahme der rechtsseitigen Schädeltrepanation. Indikation des betreffenden Krankenhauses: Jacksonanfälle mit Konzentrierung auf den 1 . Arm und die 1 . Seite, täglich und nächtlich 4-5 Anfälle; Patellarsehnenreflex links gesteigert, Fußklonus links. Operationsbefund: Über der rechten Zentralwindung umschriebenes Ödem von Zehnpfennigstückgröße; die Dura mater wird etwa $4 \mathrm{~cm}$ lang gespalten, nachher wieder durch die Naht geschlossen; wegen starker Blutung aus den Gefäßen der weichen Hirnhaut wird zunächst tamponiert. Zustand nach der Operation: Anfälle eher etwas vermehrt, zur Zeit ungefähr zehn schwere Anfälle und mehrere Schwindel im Monat. Psychisch kein Rückgang der Geisteskräfte. Immer sehr erregbar.

Epikrise: Zu den encephalitischen Folgeerscheinungen nach der Scharlacherkrankung im 7. Jahr mußte erst noch die traumatische Schädigung im 13. Jahr sich hinzugesellen, um den epileptischen Symptomkomplex auszulösen. Die nach 6 jährigem Bestehen der epileptischen Krankheitserscheinungen vorgenommene Trepanation wurde nur auf die Entlastung beschränkt. Es ist zu erwägen, ob in solchen Fällen ein eingreifenderes chirurgisches Vorgehen ratsamer erscheint. 
Möglicherweise hat auch die starke Blutung während der Operation den Operationseffekt beeinträchtigt.

\section{Der nächste Fall (7) stellt eine Kombination von Lues und Trauma dar.}

Fall 7. Heinrich R. Eine Schwester angeblich epileptisch. Mit $1 \frac{1}{2}$ Jahren Sturz auf die r. Kopfseite, darnach Schädeldeformierung. Auftreten der epileptischen Anfälle im 6. Jahr ohne Gelegenheitsursache. Infolge Zunahme der. Anfälle bis zur täglichen Wiederkehr wird nach 2 jährigem Bestehen eine Beseitigung der drückenden Knochenteile vorgenommen. Nach der Operation zuerst 1/2 Jahr lang deutliche Besserung, dann Wiederkehr der Anfälle alle 6 Wochen. Bei der Anstaltsaufnahme im 9. Jahre starke narbige Deformierung der Kopfoberfläche, Hemiparese links, Hervortreten der Augäpfel, Sprache undeutlich, geistig hochgradig geschwächt; Wassermannsche Reaktion +++ .

Im 15. Jahre meningitische Symptome, die auf Spinalpunktion zurückgingen. Schließlich dauernd bettlägerig und blöde, im 19. Jahr an gehäuften Anfällen verstorben. Sektion wurde infolge äußerer Gründe nicht ausgeführt.

Epikrise: Der stark positive Ausfall der Wassermannschen Reaktion macht es sehr wahrscheinlich, daß außer der traumatischen Schädigung im Alter von $1^{1 / 2}$ Jahren die hereditär-luetische Affektion für das Zustandekommen des vorliegenden Krankheitsbildes anzuschuldigen ist. Höchstwahrscheinlich liegt der epileptischen Erkrankung der Schwester gleichfalls eine luetische Basis zugrunde. Die Prognose dieses Falles wäre vielleicht günstiger gewesen, wenn man von vornherein die WaR. vorgenommen und im Anschluß an den positiven Ausfall eine antiluetische Kur eingeleitet hätte. Von Interesse ist die halbjährige günstige Beeinflussung des Krankheitsbildes durch die Operation. Der Fall lehrt jedoch, daß vor einem operativen Eingriff möglichst alle diagnostischen Hilfsmittel zur Klarstellung des Krankheitsbildes anzuwenden sind.

Der nächste Fall ist eine Kombination von Kopftrauma mit Alkoholmißbrauch.

Fall 8. Louis Schw., 35 Jahre alt, keine erbliche Belastung, normale Entwicklung. Im 18. Jahr schwerer Sturz auf die rechte Kopfseite. Im Anschluß daran linksseitig beginnende Krampfanfälle, die pach 1 jährigem Bestehen zum erstenmal mit Schädeltrepanation behandelt werden. Operationsbericht: An Stelle einer umschriebenen Delle findet sich keine Impression des Knochens; keine Gehirnpulsation nach Eröffnung des Schädeldachs. Abfließen von Ödem nach Einschnitt in die Dura, worauf sich leichte Pulsation einstellt. Im Anschluß an die Operation soll sich eine Parese des 1. Armes eingestellt haben. Infolge Wiederkehr der Anfälle 5 Jahre später die zweite Trepanation, über die ein Operationsbericht nicht zu erlangen war und die eine Parese des l. Beines hinterläßt. Da auch die zweite Operation erfolglos bleibt und psychische Störungen dazukommen, erfolgt im 25. Jahre Anstaltsaufnahme. Im 1. Jahr ein wochenlang dauernder schwerer Verwirrtheitszustand, später monatelang anfallsfrei, oft erregt, Neigung zum Stehlen. In den letzten 6 Jahren Zunahme der linksseitigen Parese, Anfälle selten, in Pausen bis zu $1 / 2$ Jahr.

Epikrise: Bei dem erblich nicht belasteten Kranken ist der zweimalige operative Eingriff erfolglos geblieben. Möglicherweise hat der Alkoholmißbrauch dazu beigetragen. Die Zunahme der linksseitigen Lähmung deutet auf eine Zunahme des destruktiven Prozesses im Zentralnervensystem hin. Bemerkenswert ist bei dem autoptischen ersten Befund die erhöhte Duraspannung und das Fehlen der Hirnpulsation, die erst nach Einschnitt in die Dura wieder in Erscheinung tritt.

z. f. d. g. Neur. u. Psych. LXXIV. 
Fall 9. Georg R., 15 Jahre. Mutter debil. Mit 21/2 Jahren lernte Pat. erst laufen. Im 11. Jahre Schädelbruch, im Anschluß daran Anfälle. Nach mehreren Monaten Trepanation. Operationsbefund und Art des Eingriffs nicht festzustellen. Zustand nach der Operation: Keine Änderung, wenig Absencen; psychisch: schwachsinnig, albern, doch sonst kein Rückgang der Geisteskräfte.

Epikrise: Bei dem durch Debilität der Mutter erblich belasteten Kranken, dessen Minderwertigkeit auch in Gestalt der späteren Entwicklung in Erscheinung tritt, werden durch einen Schädelbruch im 11. Jahre epileptische Krankheitserscheinungen ausgelöst. Die Erfolglosigkeit der verhältnismäßig bald vorgenommenen Trepanation ist höchstwahrscheinlich durch die erbliche Belastung von seiten der Mutter und die angeborene Minderwertigkeit des Kranken selbst bedingt.

Fall 10. Florenz W., Schwester der Mutter vorübergehend geisteskrank. Im Alter von 6 Monaten Fall aus dem Kinderwagen, 2 Tage darauf Erbrechen und leichte Anfälle. Im Alter von 1 Jahr rechtsseitige Lähmung, die wieder vorüberging. Im Alter von $3 \frac{1}{4}$ Jahren nach $3^{1} / 4$ jährigem Bestehen der Krampfanfälle, die unregelmäßig auftraten und besonders Zuckungen im rechten Facialisgebiet aufwiesen, linksseitige Schädeltrepanation. Befund: Pia etwas serös durchtränkt. Windungen nicht abgeflacht, Gehirn pulsierend, von einer Vernähung der Dura wird abgesehen. 3 Monate nach der Operation Seltenerwerden der Anfälle, Besserung des geistigen Zustandes, dann wieder fast täglich Anfälle, meist petit mal, schließlich völlig idiotisch, fortgesetzt Zwangswürgen. Im 7. Jahre Tod an Marasmus.

Epikrise: Bei einem indirekt erblich belasteten Kinde stellen sich 2 Tage nach einem Fall auf den Kopf cerebrale Reizerscheinungen in Form von Erbrechen und leichte Krampfanfälle ein, zu denen sich im Alter von 1 Jahr ausgesprochene encephalitische Symptome hinzugesellen. Erst nach 21/4 jährigem Bestehen der herdförmigen Krampferscheinungen wird die Trepanation vorgenommen. Im Hinblick auf die nur auf die Entlastung beschränkte Trepanation ist zu erwägen, ob die einfache Druckentlastung allein bei derartigen Kranken mit Herderscheinungen ausreichend ist.

Die nächsten 5 Fälle $(11,12,13,14,15)$ sind mit Geburtstraumen kompliziert.

Fall 11. Peter v. W., 30 Jahre alt. Eltern blutsverwandt, Vater psychopathisch; der älteste Bruder der Mutter geisteskank. In der Familie eine Reihe abnormer Charaktere. Pat. wurde durch Zange geboren, es bestand starke Kopfdeformation und Facialisparese. Im Alter von $3 / 4$ Jahren gelegentlich einer Er. kältung Zustand von Bewußtlosigkeit, mit 7 Jahren bei einer fieberhaften Erkrankung einen Krampfanfall. Nach geistiger Überanstrengung im 19. Jahre Auftreten von epileptischen Anfällen, vorwiegend linksseitig. Im 22. Jahre Depressionszustände. Nach 5jährigem Bestehen der epileptischen Krankheitserscheinungen erste Schädeltrepanation. Knöcherner Verschluß, darnach sehr heftige Kopfschmerzen, auch gehäufte Anfälle. Deshalb nach 1/4 Jahr zweite Operation: Nach der zweiten Operation Besserung des Zustandes. Seit der Anstaltsaufnahme im 29. Jahre nur 1 Anfall. Pat. ist völlig geordnet, geistig noch ziemlich frisch und läßt keine Abnahme der Geisteskräfte erkennen.

Epikrise: Zur Auslösung des epileptischen Krankheitsbildes, das außer Krampfanfällen herdförmigen Charakters auch noch psychische Störungen aufweist, haben eine Reihe von verschiedenartigen Faktoren beigetragen, die erbliche Belastung, das erhebliche Geburtstrauma, die zweimaligen infektiösen Erkrankungen, wozu noch die geistige Überanstrengung während des Abiturienten- 
examens hinzukommt. Die resultierenden krankhaften Störungen, bestehend in vorwiegend linksseitigen Krämpfen und seelischen Depressionen, werden erst nach 5jährigem Bestehen operativ mit Schädeltrepanation behandelt. Der vorliegende Fall reiht sich mit seinen schweren Symptomen, die sich nach dem $\mathrm{k} n o ̈ c h e r n e n$ Schädelverschluß einstellen, anderen Beobachtungen in der Literatur, sowie auch dem Fall 26 dieser Kasuistik an, so daß es auch nach unserem Dafürhalten bedenklich erscheint, an die Trepanation den knöchernen Verschluß anzuschließen. Auch auf diese Frage soll zum Schluß noch einmal kurz eingegangen werden. Wenn im vorliegenden Fall auch nicht von Heilung im Sinne einer Restitutio ad integrum gesprochen werden kann, so ist doch entschieden von einer Bəsserung zu sprechen, die im Anschluß an den zweiten Eingriff eingetreten ist.

Fall 12. Theodor H., 36 Jahre alt. Ein Bruder litt vom 12. bis 17. Jahre an Krampfanfällen. Pat. wurde wegen Wehenschwäche durch Zange geboren. Im Alter von 4 Wochen zweimal 1/2 Stunde lang Krämpfe. Im Alter von 7 Jahren unvollkommene Anfälle (ging auf den Zehen, streckte die Hände aus). Bei Examensvorbereitungen Auftreten ausgebildeter Anfälle, die zuerst vorwiegend rechtsseitig auftraten. Nach 16 jährigem Bestehen der epileptischen Symptome im 23. Lebensjahr des Pat. Entlastungstrepanation links. Ausgang: Kein Erfolg hinsichtlich des Auftretens der Krampfanfälle; letztere haben sich mit den Jahren vermehrt, treten jetzt täglich, allerdings in leichter Form, auf. Geistig ist Pat. noch ziemlich frisch, körperlich leidend und verfallen.

Epikrise: Auf Grund der vorübergehenden Erkrankung des Bruders an epileptischen Krampfanfällen kann im vorliegenden Falle eine familiäre Prädisposition angenommen werden. $\mathrm{Zu}$ dieser gesellt sich die Schädigung durch die langdauernde Geburt und die Zange. Die 4 Wochen nach der Geburt einsetzenden eklamptischen Zustände sind höchstwahrscheinlich durch hämorrhagisch-meningitische Veränderungen hervorgerufen, die erfahrungsgemä $\beta$ nicht selten durch traumatische Geburtsschädigungen entstehen. Auf diesem Boden entwickelten sich. zuerst die unvollkommenen, dann die Jackson- und schließlich die ausgebildeten typischen, epileptischen Anfälle. Die erst nach 16jährigem Bestehen der epileptischen Symptome vorgenommene erfolglos gebliebene Entlastungstrepanation war von vornherein prognostisch ungünstig, da die epileptischen Krankheitserscheinungen bereits einen allgemeinen Charakter angenommen hatten. Auffallend ist die noch jetzt bestehende verhältnismäßig geistige Frische bei der zugenommenen Verschlimmerung des körperlichen Befindens.

Fall 13. Valentin N. Großvater mütterlicherseits hatte jahrelang Krämpfe, Großvater väterlicherseits war Trinker; ein Bruder des Großvaters hatte Krämpfe, ein Vetter des Vaters gleichfalls. Langdauernde, schwere Geburt des Pat. Im 3. Jahre nach Fall auf den Hinterkopf einmalig Krämpfe. Im 7. Jahre Auftreten und Bestehenbleiben epileptischer Krampfanfälle. Im 11. Jahre wochenlang Polyurie, Erbrechen, starker Durst. Im 13. Jahre gehäufte Anfälle, im I. Facialis beginnend, auf die l. Seite übergehend. Selten Anfallspausen von Tagen und Wochen. Linker Facialis sehwächer innerviert. Im Alter von $13^{3} / 4$ Jahren nach $6^{3 / 4}$ jährigem Bestehen Sehädeltrepanation. Makroskopisch negativer Himbefund; Excision des r. Facialiszentrums. Ausgang: 1 Monat lang Lähmung im I. Facialisgebiet. Keine Beeinflussung hinsichtlich der Anfälle und des psychischen Verhaltens. Zunehmende Verblödung. Im 20. Jahre an Marasmus verstorben.

Epikrise: Im vorliegenden Fall besteht gleichfalls eine Häufung prognostisch ungünstiger Faktoren: Erbliche Belastung von beiden Seiten, langdauernde schwere Geburt, Fall auf den Hinterkopf mit cerebralen Reizerscheinungen. Von Beginn der zweiten Dentitionszeit an bestehen epileptische Krankheitserscheinungen. $\mathrm{Zu}$ ihnen treten im 11. Tahre noch wochenlang anhaltende Diabetes 
insipidus-Symptome hinzu, denen bekanntlich Störungen wichtiger cerebraler Stoffwechsel-Regulationszentren zugrunde liegen. Erst nach $6^{1} / \mathbf{4}$ jähriger Dauer der epileptischen Krankheitserscheinungen wird auf Grund von Herdsymptomen zur Excision des r. Facialiszentrums geschritten. Der operative Eingriff ist ohne Erfolg geblieben.

Fall 14. Walter F., 20 Jahre alt, Anstaltspflegling. Keine erbliche Belastung, lange Geburt, Nabelschnurumschlingung um den Hals. Mit $1 \frac{1}{2}$ Jahr Konvulsionen; Reizerscheinungen, namentlich in der r. Hand. Nach 10 jährigem Bestehen Entlastungstrepanation über dem 1. Scheitelbein. Operationsbefund: Freigelegte Dura, stark hyperämisch, mit zahlreichen, feinsten Blutgefäßen durchsetzt, nicht gespannt, nach innen einsinkend, kein Ödem der Arachnoidea. In der Nähe der Gefäße mehrere kleine, mehr als hirsekorngroße, weiße Punkte, die sich nach unten zu in eine diffuse, milchige Trübung der Spinnwebenhaut fortsetzen; Eindruck einer Gehirnschrumpfung oder eines Zurückbleibens des Gehirns in seiner ganzen Anlage. Ausgang: Kein Einfluß auf die Anfälle. Psychisch: Unstetheit, wechselnde Stimmung, kein merklicher Rückgang der Geisteskräfte.

Epikrise: Es besteht die Wahrscheinlichkeit, daß bei der langen Geburt mit ihrer Komplikation intrakranielle Veränderungen entstanden, die zu der manifesten Meningoencephalitis im Alter von 11/2 Jahren führten bzw. prädisponierten. Erst nach 10 jährigem Bestehen der Jacksonerscheinungen erfolgt eine Fntlastungstrepanation mit der Feststellung von meningitischen Zuständen an der Dura sowohl wie an den weichen Hirnhäuten, an letzteren mehr von umschriebenem Charakter. Der Hirnbefund ist als Folgezustand der Hirnhautveränderungen anzusehen. Von Interesse ist das Fehlen der Duraspannung, die sonst häufig bei Epilepsie anzutreffen ist. Höchstwahrscheinlich tritt sie beim vorliegenden Fall nur vorübergehend auf. Daraus erklärt sich vielleicht die noch bestehende yerhältnismäßige geistige Frische des Kranken.

Fall 15. Kurt Pf, 10 Jahre alt, keine erbliche Belastung, langdauernder schwieriger Geburtsverlauf. Mit 2 Jahren 5 Monaten Gehirnhautentzündung, 4 Tage später der erste Anfall, fortgesetzte Verschlimmerung, schließlich fast täglich Anfälle. Mit 4 Jahren Verlernen des Sprechens. Nach 21/4 jährigem Bestehen der Krämpfe im Alter von $4^{3} / 4$ Jahren Schädeltrepanation, die im Mai 1914 in Kurland vorgenommen wurde. Näheres ist darüber nicht mehr festzustellen. Nach der Operation angeblich Hemiparese rechts, die auch jetzt noch besteht. Zur Zeit ist Pat. ein tief stehender Idiot mit fast täglich wiederkehrenden ausgebildeten und unvollkommenen Anfällen.

Epikrise: Wenn die Anfälle $2^{1 / 4}$ Jahre lang in größter Heftigkeit bestanden hatten, und ein so schwerer, geistiger Rückgang, wie das Aufhören des Sprechvermögens, eingetreten war, so mußte die Prognose des operativen Eingriffs von vornherein als ungünstig erscheinen.

Die nächsten Fälle stellen die Folgezustände traumatischer Schädlichkeiten dar. Ihre Besonderheiten werden in der Epikrise angeführt.

Fall 16. Wilhelm L., 31 Jahre. Normale Entwicklung, strebsamer, guter Schüler. Im 21. Jahre Fall auf den Hinterkopf. Im Anschluß daran typische, epileptische Anfälle. Allmähliche Veränderung des Seelenzustandes, bestehend in Abnahme der Verstandeskräfte und zunehmender Erregbarkeit. Nach 3 jährigem Bestehen der Krankheitserscheinungen im 24. Jahre Trepanation in der Occipitalgegend. Befund: Unter dem Knochen ein losgelöster Knochensplitter; nach Eröffnung der Dura zeigt sich die Arachnoidea serös durchtränkt und in einer Ausdehnung von Fünfmarkstückgröße mit der Dura verwachsen. Lösung der Verwachsungen, Vernähen der Dura und des Hauptperiostknochenlappens. Ausgang: 
In der ersten Zeit Ausbleiben der Anfälle, später Wiederauftreten in Zwischenräumen von 14-18 Tagen. Fortgesetzter Rückgang der Geisteskräfte. Im 29. Jahre Anstaltsaufnahme. Vom jetzigen Befund: Vertiefte, feste Schädelnarbe; nie ganz klar bei Bewußtsein, meist mürrisch und unzufrieden, zuweilen heiter erregt, ausgesprochener Schwachsinn.

Epikrise: Der vorliegende Fall mit seinem traurigen Ausgang illustriert auf das deutlichste die Notwendigkeit der möglichst frühzeitigen operativen Behandlung bei traumatisch entstandenen Krampfzuständen. Es besteht die große Wahrscheinlichkeit, daß bei sofortigem Eingreifen dieser erblich nicht belastete, normal entwickelte, gut veranlagte Kranke völlig geheilt worden wäre. So wurde erst nach 3jährigem Bestehen schwerer Krankheitserseheinungen und eingetretenen psychischen Verfalls die Schädeltrepanation vorgenommen. Bei dem vorliegenden Fall ist fernerhin zu erwägen, ob im Hinblick auf die lange Dauer eine einfache Lösung der Verwachsungen genügt, ob es sich nicht empfiehlt, die darunterliegende Gehirnsubstanz genau zu explorieren (evtl. auch mittels der Hirnpunktion) und alle erkrankten Gewebsteile als reizauslösende Zentren zu excidieren. Im vorliegenden Falle ist es denkbar, daß die später eingetretene Verschlimmerung auf die Bildung neuer Verwachsungen und das Wiederaufflackern und Fortschreiten chronisch-entzündlicher Prozesse zurückzuführen ist, während völlig aseptische, im Bereich des Gesunden gesetzte Hirnwunden erfahrungsgemäß keinerlei Reizerscheinungen hervorrufen.

Fall 17. Geoffrey F., 11 Jahre. Mit 3 Jahren Sturz aus der ersten Etage auf den Kopf. Knochenfraktur hinter dem l. Ohr. Keine Lähmungen, sofortige Operation. Im 6. Jahre Auftreten von epileptischen Schwindeln und Anfällen ohne Herderscheinungen. Nach $3^{1} / 2$ jährigem Bestehen unter zunehmender Verschlimmerung der Krankheitserscheinungen Schädeltrepanation. Art des Eingriffs: Excision des Narbengewebes am Gehirn und an seinen Häuten, Fettimplantation. Ausgang: Zuerst mehrere Wochen anfallsfrei, dann erneutes Auftreten der Krampfanfälle, eher etwas stärker wie früher. Seit 11/2 Jahren Anstaltspflege. Vom Befund: Strabismus und leichter Exophthalmus; unmittelbar nach den schweren Anfällen Babinski beiderseits positiv. Psychisch: Sehr lebhaft, unruhig, Verstandestätigkeit wechselnd. Weiterer Verlauf in den ersten 9 Monaten der Anstaltsbehandlung: Fast jede Woche Absencen und große Anfälle, meist in Gruppen, danach Steigerung der Unruhe. Seit 7 Monaten anfallsfrei, gutes körperliches und geistiges Befinden.

Epikrise: Die erst nach $3^{1} / 2$ jährigem Bestehen von epileptischen, sich fortgesetzt verschlimmernden Krankheitserscheinungen vorgenommene Hirnoperation scheint sich trotz anfänglich fehlender günstiger Beeinflussung doch noch zu einem Erfolg zu gestalten. Es ist mit größter Wahrscheinlichkeit anzunehmen, daß der bisherige Erfolg nur unter der geregelten Anstaltspflege erreicht werden konnte, die sich zweckmäßigerweise sogleich an den operativen Eingriff anschließen muß.

Fall 18. Edgar N., 31 Jahre alt. Im 9. Jahre Hinterkopfverletzung durch einen vorstehenden Nagel. 11/2 Jahr schwer krank, rechtsseitig gelähmt, Sprachbehinderungen, Lach- und Weinkrämpfe, Unfähigkeit, den Urin zu halten. Im 17. Lebensjahre epileptische Anfälle. Unmittelbare Vorboten: Augenflimmern, dann Gefühl eines elektrischen Schlages, Verziehen des Kopfes, dann Bewußtlosigkeit. Nach 1jährigem Bestehen Schädeltrepanation; Excision einer Narbe in der Dura; infolge weiterer Anfälle nach 1 Monat Revision der Wunde; weiteres ist über die Art des Eingriffs nicht festzustellen. Ausgang: Beseitigung der rechtsseitigen Lähmung, Besserung der Sprache, Fähigkeit, den Urin zu halten. Zur Zeit noch Steigerung der rechtsseitigen Sehnenreflexe. Leichte Störungen der feinen Koordination rechts, Berührungsempfindung rechts herabgesetzt. Anfälle 
an Zahl zurückgegangen. Zur Zeit vorwiegend Absencen. Geistig besteht leichter, epileptischer Schwachsinn. Ein Rückgang der Geisteskräfte ist nicht feststellbar.

Epikrise: Der erblich nicht belastete, bis zum Eintritt des Anfalls völlig normal entwickelte Kranke läßt die schwere Schädigung erkennen, die entzündliche Vorgänge an den Hüllen auf das Gehirn selbst auszuüben vermögen. Bekanntlich führen solche Prozesse, die sich nicht selten an Traumen anschließen, besonders häufig zur traumatischen Epilepsie. Auf Grund solcher Erfahrungen ist ein möglichst frühzeitiges operatives Eingreifen dringend indiziert, das im vorliegenden Falle erst nach 1 jährigem Bestehen schwerer Gehirnerscheinungen, also verhältnismäßig spät, erfolgt ist. Was die Operation selbst anbelangt, so wird beim ersten Eingriff nur von einer Narbenexcision aus der Dura gesprochen. Da die erhoffte Besserung ausbleibt, wird nach einem Monat eine nochmalige Revision der Wunde rorgenommen, ohne daß Näheres über die Art des Eingriffs zu erfahren ist. Jedenfalls empfiehlt es sich in solchen Fällen, nicht allein die narbigen Hüllen des Gehirns, sondern die abnormen Gehirnpartien selbst möglïchst ausgiebig bis in das gesunde Gewebe hinein zu excidieren, um epileptische Reizquellen zu beseitigen. Immerhin ist im vorliegenden Falle insofern von einer Besserung und somit von einem Erfolg zu sprechen, als durch die Operation schwere Lähmungserscheinungen beseitigt worden sind, ein Rückgang der Geisteskräfte auszubleiben scheint und eine gewisse Arbeitsfähigkeit erhalten wurde.

Fall 19. Wilhelm L., 33 Jahre. Im 15. Jahre Revolverschuß in die Stirn. Nach 3 Tagen linksseitige Lähmung. Mehrere Monate später Auftreten von tagebis wochenlangen seelischen Störungen, die sich in der Folgezeit periodenweise wiederholten. Sie bestanden in Depressionen. Dann setzten wieder Wutanfälle mit tätlichen Angriffen gegen die Umgebung ein. Nach 3 jährigem Bestehen der Krankheitserscheinungen Entfernung des Geschosses aus der Occipitalgegend. Nach $2^{1} / 2$ jähriger Anstaltspflege sind die psychischen Störungen seit über Jahresfrist ausgeblieben. Pat. ist geistig ziemlich frisch, ruhig und geordnet, wird zu Botengängen verwendet.

Epikrise: Der vorliegende Fall läßt zwar ausgesprochene epileptische Anfälle vermissen, dafür treten jedoch periodenweise die oben beschriebenen seelischen Störungen auf, die man als epileptische Äquivalente bezeichnen kann. Man könnte annehmen, da $ß$ bei dem erblich nicht belasteten Pat. keine Disposition für den eigenartigen epileptischen Krampfmechanismus besteht, an dessen Stelle die oben beschriebenen Aquivalente treten; auf der anderen Seite ist aber zu beachten, daß das Geschoß beim Eindringen in das Gehirn nur sog. stumme Rindenbezirke verletzt hat, da die Hemiparese höchstwahrscheinlich auf Zerstörungen in der Marksubstanz zurückzuführen ist. Bekanntlich führen ja in erster Linie Rindenalterationen zu Krampfanfällen. Trotz des 3jährigen Verweilens des Geschosses im Gehirn mit seinen Folgeerscheinungen ist doch schließlich unter der Anstaltspflege ein Erfolg eingetreten.

Fall 20. Lauritz H. Vater war Trinker, dessen Mutter litt an Krämpfen. In der Schule ein schwacher Schüler. Im 19. Jahre fiel ihm ein Stein auf den Kopf. Nach dem Unfall allmählich stiller und gedächtnisschwächer. Epileptische Insulte zuerst im 29. Jahre. Angeblich zuerst voll entwickelte, typische Anfälle. Anstaltsaufnahme im 36. Jahre. Während der Anstaltspflege 4 Anfallsformen: 1. Vorwiegend tonischer Krampfzustand rechts mehr als links. 2. Leichter ähnlicher Anfall mit anschließender motorischer Unruhe. 3. Rötung des Gesichts mit angstvollem Hin- und Herlaufen. 4. Zuckungen im r. Arm und Bein bei erhaltenem Bewußtsein. Nach 3 jährigem Bestehen epileptischer Krampfanfälle und 19 jährigem Bestehen von psychischen Veränderungen im 32. Jahre Trepanation in der 1 . Scheitelgegend mit angeblich negativem Befund. Da eine Besse- 
rung ausbleibt, folgt 4 Jahre später die zweite Trepanation, bei der eine Vorwölbung des Gehirns, sonst nichts Abnormes, auch keine Verwachsungen vorgefunden werden. Ausgang: 4 Jahre lang Anfälle leichter, an Zahl geringer, der Kranke selbst geistig frischer. Im 5. Jahre nach Anfällen erregt und verwirrt. Nach einer Anfallsserie Lungenentzündung und Exitus letalis im 29. Jahre. Sektion konnte nicht ausgeführt werden.

Epikrise: Bei dem erblich belasteten Kranken treten im Anschluß an das Kopftrauma im 19. Jahre wohl sofort seelische Veränderungen, aber erst nach 10 Jahren epileptische Insulte in verschiedenen Modifikationen, aber auch mit Herdcharakter auf. Nach der Erfolglosigkeit des ersten im 32. Jahre vorgenommenen Eingriffs wird 4 Jahre später der zweite vorgenommen, der eine deutliche vierjährige Besserung aller Krankheitserscheinungen zur Folge hat. Von Interesse ist, daB der erste operative Eingriff keinerlei Folgeerscheinungen in Gestalt von Verwachsungen usw. hinterlassen hat, wodurch die Gefahrlosigkeit eines aseptisch verlaufenen Eingriffs bewiesen wird.

Fall 21. Adolf K. Eine Schwester des Vaters blödsinnig. Im 10. Jahre Fall von einer Schaukel, einige Zeit besinnungslos. Im 14. Jahre Auftreten von epileptischen Anfällen von gewöhnlichem Typus. Im 16. Jahre Entlastungstrepanation bei negativem Hirnbefund. Ausgang: 4 Wochen lang Aufhören der vorher alle 8-10 Tage eintretenden Anfälle, dann Wiederkehr wie vorher. Im 19. Jahre mehrere Tage manisch erregt, im 20. und 21. Jahre wieder manische Zustände, im 22. Jahre religiöse Ekstase, desgleichen auch im 23. Jahre, dabei auch tobsüchtig 14 Tage lang, Stimmung sonst vorwiegend depressiv und mürrisch. Im 29. Jahre im Anschluß an einen Erregungszustand verstorben.

Epikrise: Ob im vorliegenden Fall die krankhafte familiäre Veranlagung oder mittelbar das Trauma oder beide Faktoren zusammen für die Entstehung des epileptischen Krankheitsbildes in Frage kommen, ist schwer zu sagen. Die im Hinblick auf das stattgefundene Trauma nach 2 jährigem Bestehen der epileptischen Krankheitserscheinungen vorgenommene Entlastungstrepanation hat nur einen ganz kurzen Erfolg gehabt.

Fall 22. Hans B. 19 Jahre. Mutter leidet an Hysterie. Sturz von einem Heuboden aus 3-4 m Höhe im 2. Lebensjahre. Schädelbruch. Mit 15 Jahren Sturz von einem Reck. Im gleichen Jahre häufig starrer Blick. Im 16. Jahre epileptische Anfälle. Im 18. Jahre linksseitige Schädeltrepanation mit Entfernung einer Cyste. Ausgang: Nach der Operation Anfälle etwas häufiger (etwa alle 8 Tage), aber leichter. Vom sonstigen Befund: Reizbar, eigensinnig, umständlich, Verstandestätigkeit eingeengt.

Epikrise: Bei dem erblich belasteten Pat. hat ein schweres Schädeltrauma im 2. und 15. Jahre eingewirkt. Trotzdem schon kurz nach dem zweiten Trauma epileptoide Zustände auftraten, die schon im nächsten Jahre zu ausgesprochenen epileptischen Anfällen sich entwickelten, wird erst nach 3 jährigem Bestehen der Krankheitserscheinungen die Trepanation vorgenommen, die in Gestalt einer Hirncyste die schädlichen Folgezustände des Traumas ergibt. Bis jetzt ist ein Erfolg der Operation ausgeblieben und auch die Prognose für die Zukunft ist im Hinblick auf die epileptische Seelenveränderung zweifelhaft, was durch die erbliche, neuropathische Belastung, durch die zweimalige Gehirnschädigung und durch die verhältnismäßig spät vorgenommene Trepanation, also eine Häufung ungünstiger Faktoren, bedingt sein kann.

Fall 23. Gustav K., Bäckermeister, 51 Jahre. Im 28. Jahre Schlag mit einem Billardqueue auf den Kopf. Am gleichen Tage ein typischer epileptischer Anfall, dem in den beiden folgenden Wochen noch mehrere folgten. Deshalb 14 Tage 
nach der Verletzung Trepanation über dem 1. Scheitelbein. Befund: Einzelne kleine, subarachnoideale Hämorrhagien; knöcherner Verschluß durch Zurückklappen des Hautperiostknochenlappens. Ausgang: Ca. 3 Jahre lang ungefähr alle 4 Wochen ein epileptischer Anfall, dann größere Pausen, seit 10 Jahren anfallsfrei. Seit 20 Jahren verheiratet. Pat. hat zwei gesunde, gut begabte Söhne.

Epikrise: Der Fall lehrt, daß der Eingriff zuweilen nicht sofort die epileptischen Krankheitsäußerungen zum Verschwinden zu bringen braucht, um doch schließlich in Heilung überzugehen. Hinsichtlich der Erblichkeit bietet der Fall insofern Interesse, als Pat. zwei normale, sogar gut begabte Kinder hat, die mit ihrem derzeitigen Lebensalter schon über die für die Erkrankung an Epilepsie am meisten kritische Zeit hinaus sind.

Fall 24. Emil P. Vater starker Trinker, ein Bruder $21 / 2$ Jahre alt an Krämpfen gestorben. Nach normaler Entwicklung im 23. Jahr Sturz mit einer schweren Last. 1 Monat später eigentümliche, asthmatische Beschwerden, die nach einem weiteren Monat in epileptische Anfälle übergingen. Im Alter von 30 Jahren Anstaltsaufnahme. 21/2 Jahre lang hysteriforme und epileptische Anfälle mit nachfolgenden Tobsuchts- und Erregungszuständen. Hierauf ca. 1/2 Jahr lang eigenartige Respirationskrämpfe mit nachfolgender Bewußtlosigkeit wie bei Epilepsie, ihr Beginn und Verlauf ähnlich den laryngealen Krisen der Tabiker. Unter Codein, Heroin und Bromkali allmähliches Nachlassen dieser Krampferscheinungen. Im 33. Jahre vor den epileptischen Anfällen Druckschmerzen im r. Schädel und Zucken des 1. Armes und Beines nach den Anfällen. Deshalb Entlastungstrepanation über dem r. Scheitelbein; dabei negativer Hirnbefund. Ausgang: Dauernde Herabsetzụng der Anfälle auf weniger als ein Drittel pro Monat gegen früher. Keine Herderscheinungen mehr, von Gemütsart ruhiger, keine Abnahme der Geisteskräfte. Im 35. Jahr unter dem Bilde einer Gallensteinkolik in Abwesenheit des Verf. verstorben.

Epikrise: Der mit Trunksucht des Vaters erblich belastete Kranke stellt ein ziemlich viel gestaltetes, epileptisches Krankheitsbild dar: Die Kombination von asthmatischen Beschwerden mit epileptischen Krampfanfällen, von denen die ersteren höchstwahrscheinlich auf rein nervöser Basis beruhen, nach der starken Erschütterung des Körpers aufgetreten waren und dann in die letzteren übergingen; hierauf sich anschließend die Kombination hysteriformer und epileptischer Anfälle, im weiteren Verlauf das Zurücktreten dieser Symptome und Auftreten der krisenartigen Respirationsstörungen und schließlich die Herderscheinungen, die zur Entlastungstrepanation führten, mit der sichtlichen Besserung im Befinden des Kranken.

Fall 25. Otto K. Im 4. Jahre linksseitiger Schädelbruch durch Hufschlag (Zertrümmerung des 1 . Stirnbeins). Im 5. Jahre abermaliger Hufschlag, und zwar an die Backe. Im 10. Jahr nach einer großen Angst Auftreten von epileptischen Krämpfen. Vom 31. Jahre an Anstaltspflege; neben unvollkommenen und ausgebildeten Anfällen wiederholt Depressionen, halluzinatorische und Verwirrtheitszustände. Im 38. Jahre nach 28 jährigem Bestehen epileptischer Krankheitserscheinungen Trepanation: Entfernung einer ca. hühnereigroßen Cyste, die von der Rinde des Stirnhirns sich bis zum vorderen Teil des Corpus striatum erstreckt. Im Anschluß an die Operation anhaltendes, remittierendes Fieber bei dauerndem Liquorfluß und fehlenden meningitischen Erscheinungen. Am 19. Jahre Aufhören des Liquorflusses, Exitus letalis bei $41^{\circ}$ Temperatur. Bei der Sektion völliges Fehlen entzündlicher Erscheinungen. Das Fieber ist demnach als cerebrales aufzufassen, hervorgerufen durch eine Irritation des Nucleus caudatus.

Epikrise: Der Fall zeigt, mit welchen Komplikationen zu rechnen ist, wenn ein chirurgisch anzugreifender Herd in eine zu große Tiefe geht. Es ist deshalb 
während eines solchen Eingriffs zu erwägen, ob der Zustand des Kranken ein lebensgefährdendes Vorgehen rechtfertigt. Im vorliegenden Fall war dies zu bejahen. Der Kranke mit seinen fortgesetzten epileptischen Anfällen und seinen immer wiederkehrenden seelischen Störungen wäre ohne Eingriff dem körperlichen und seelischen Verfall entgegengegangen.

Fall 26. Martin K. 31 Jahre. Ingenieur. Im 25. Jahre Streifschuß mit Verletzung des Stirnhirns links. Trepanation: Nach 31/2 Monaten Knocheneiterung an der Verwundungsstelle, Sequesterentfernung. Ca. 6 Wochen nach Abheilung dieser Komplikation (also 5 Monate nach der Verletzung) Knochenimplantation zum Verschluß des Defekts. 6 Wochen später der erste Anfall von typischem Charakter. Wiederkehr der Insulte alle 8 Tage. Deshalb 1 Jahr nach Auftreten der epileptischen Anfälle abermalige Trepanation: Entfernung einer Cyste an der Verletzungsstelle des Gehirns. Nach 3 Monaten Wiederkehr der Anfälle, deshalb nach 1 Jahre abermalige Trepanation, dabei Befund negativ; es wird nunmehr ein ausgiebiges Ventil gebildet. Ausgang: Nach 6 Monaten Wiederauftreten eines Anfalls, bisher stets längere Pausen bis zu 10 Monaten. Die Anfälle kehren in der Regel nach Überanstrengungen und Aufregungen wieder. Pat. ist aber imstande, als Ingenieur einen größeren Betrieb mit Erfolg zu leiten.

Epikrise: Der vorliegende Fall ist in mancher Hinsicht lehrreich. Die im Anschluß an erhebliche Knochenverletzungen auftretenden Knocheneiterungen, wie wir sie bei diesem Pat. vor uns haben, disponieren bekanntlich in besonderem Maße zur traumatischen Epilepsie. Wir haben nach Tilmann als Ursache hierfür die Entstehung von entzündlichen Veränderungen in der Arachnoidea anzusehen, deren Intaktheit von größter Bedeutung für die normale Zirkulation und den regelrechten Ablauf der Vorgänge in der Hirnsubstanz selbst ist. Als daher bei unserem Kranken 6 Wochen nach dem Aufhören der Eiterungen eine Abheilung des entzündlichen Prozesses angenommen und überdies noch eine Deckung des Knochendefekts vorgenommen wird, erfolgt 6 Wochen später der erste Anfall mit Wiederkehr der Insulte in 8 tägigen Zwischenräumen. Erst nach 1 Jahre wird ein abermaliger Eingriff vorgenommen, bei dem eine Hirncyste entfernt wird. Wohl bessert sich danach der Zustand, indem die Anfälle in größeren Pausen auftreten. Es wird aber zur Erzielung der Heilung ein weiterer Eingriff vorgenommen, bei dem sich entsprechend unseren Erfahrungen bei aseptisch verlaufenen Hirnoperationen ein negativer Hirnbefund ergibt. Erst jetzt wird zur Bildung eines ausgiebigen Ventils geschritten, was eine nachhaltige Besserung zur Folge hat und eine günstige Prognose für die Zukunft erwarten läßt. Wenn auch bei der durch den letzten Eingriff erzielten Besserung die Erwerbs- und Leistungsfähigkeit des Pat. erreicht und die Prognose für die Zukunft günstig ist, so wäre es doch entschieden noch günstiger, wenn ein derartiger Pat. in einer Umgebung wäre, die ihm wohl die nötige Pflege und Beschäftigung gibt, alle schädigenden Einflüsse wie Erregung und Überanstrengung von ihm fernhält. Auch dieser Fall lehrt wieder, daß vor der knöchernen Deckung des Schädeldefekts bei Epilepsie zu warnen ist.

Wenn wir jetzt zu einer Besprechung der angeführten Krankheitsschilderungen übergehen, so würden sich folgende Feststellungen, Erwägungen und daraus resultierende Richtlinien für das operative Vor. gehen bei epileptischen Krankheitsbildern ergeben.

Von den 24 trepanierten Fällen der ersten Gruppe hatte natur. gemäß bei dem größeren Teil, nämlich bei 16 Patienten, der Jackson ty pus der Kram pfanfälle die Indikation zum operativen Eingreifen 
gegeben. Von ihnen bieten 3 , nämlich 13,14 und 16, weder anamnestisch noch bei der körperlichen Befundsaufnahme irgendwelche Anhaltspunkte für vorausgegangene encephalitische, bzw. meningoencephalitische Prozesse dar. Auch die Autopsie in vivo während der Operation war in dieser Hinsicht ergebnislos - wenigstens makroskopisch -, was übrigens im Hinblick auf die zuweilen bei Status hemiepilepticus u. a. vorkommenden negativen Hirnbefunde nicht zu überraschen braucht. In 13 Fällen hatten schon in den ersten Lebensjahren encephalitische Prozesse verschiedener Herkunft abgespielt, während nur bei einem Fall (8) erst im 17. Lebensjahre im Anschluß an eine Influenza die cerebrale Erkrankung eingesetzt hatte. Von Initeresse ist bei allen Kranken mit sicher vorausgegangenen encephalitischen Krankheitsprozessen die linksseitige Lokalisation der Paresen, ein Befund, der auch in der Literatur als der häufig anzutreffende bezeichnet wird. Im Zusammenhang hiermit sei noch erwähnt, daß bekanntlich von Redlich ${ }^{9}$ ) das Zustandekommen der Linkshändigkeit in einem großen Teil der Fälle auf eine überstandene linksseitige Encephalitis zurückgeführt wird. Im Hinblick auf operative Eingriffe in die Gehirnsubstanz selbst zur therapeutischen Beeinflussung der epileptischen Krankheitserscheinungen ist in Anbetracht der funktionellen Überwertigkeit der linken Hemisphäre diese linksseitige Lokalisation natürlich ungünstig. Was die Entstehung der encephalitischen, bzw. meningoencephalitischen Prozesse in den vorliegenden Fällen betrifft, so decken sich die ätiologischen Faktoren mit den in der Literatur niedergelegten Beobachtungen: Es sind kurz zusammengefaßt vorwiegend Allgemeininfektionen verschiedenster Art, bei denen bekanntlich häufig cerebrale Reizerscheinungen, auch in Form von Krämpfen, vorkommen. Für das Zustandekommen der Krampfzustände spielen nach den Feststellungen der inneren Medizin verschiedenartige Momente eine Rolle: einmal rein toxische Vorgänge, ferner meningitische Prozesse, sowie solche embolischer Art. Die oben erwähnten Allgemeininfektionen führen aber auch nicht selten zu otitischen Komplikationen, von denen sich dann lymphangitische und thrombophlebitische Prozesse intrakraniell fortpflanzen können; schließlich sind noch Formen echter Encephalitis zu erwähnen, die durch pyämische Metastasen hervorgerufen werden. Einen lehrreichen Fall der letzteren Kategorie mit erfolgreicher chirurgischer Behandlung hat Bungart ${ }^{11}$ ) veröffentlicht. Es handelte sich um einen 31 jährigen Mann, bei dem sich am 27. Tage nach einer Scharlachinfektion zunehmende cerebrale Störungen entwickelten; am 42. Tage traten Kopfschmerzen hinter dem linken Ohr und aphasische Störungen ein, am 44. Tage Verschlimmerung und beginnender Hirndruck, am 47. Tage Status epilepticus. Bei der nun vorgenommenen Trepanation wurde ein linksseitiger Herd von dem Charakter einer echt entzündlichen Encephalomalacie 
festgestellt, für welche bereits die langsame Entwicklung des Krankheitsbildes gesprochen hatte. Der Fall wurde durch die operativen Eingriffe völlig geheilt und damit vor dauerndem körperlichem und geistigem Siechtum bewahrt. Nach Romberg und anderen Autoren spielen sich die allerdings nicht häufig auftretenden, reinen Encephalititiden nach Scharlach mit Vorliebe in den Rindengebieten ab und hinterlassen dann gewöhnlich schwere Ausfalls- und Reizerscheinungen: geistige Minderwertigkeit, Athetose, Epilepsie u. a.

Wenn auch in der vorliegenden Kasuistik der Scharlach für die spätere epileptische Erkrankung nur zweimal, in dem einen Falle vorbereitend $\left(\mathrm{II}_{5}\right)$ in dem anderen auslösend $\left(\mathrm{II}_{6}\right)$, ätiologisch in Frage kommt, so spielt doch nach der allgemeinen Erfahrung gerade die genannte Infektion bei ihrer Neigung zu pyämisch-septischen und otitischen Komplikationen für die Entstehung der Epilepsie eine ganz besondere Rolle. Konnte doch von Wildermuth ${ }^{11}$ ) bei 187 Epileptikern in 12 Fällen die zugrunde liegende Gehirnerkrankung auf die Scharlachinfektion zurückgeführt werden. Daß auch die allgemein als harmlos geltenden Masern, ferner pneumonische Prozesse $u$. a. in ähnlicher Weise wirken können, geht auch aus der Durchsicht der vorliegenden Kasuistik hervor. Bei einer Anzahl derartiger Infektionen kommt es bekanntlich zur Ausbildung meningitischer Affektionen. Auf die seröse Meningitis als Komplikation von Infektionskrankheiten und von eitrigen Erkrankungen der Schädelknochen, bei denen es sich auch um kollaterales Ödem handeln kann, sowie auf die Meningitis nach Schädeltraumen mit ihren schwerwiegenden Folgeerscheinungen weist $\mathbf{u}$. a. We ndel ${ }^{\mathbf{1 2}}$ ) hin, wobei er erwähnt, daß auch eine Meningitis serosa rheumatica und toxica beschrieben ist. Neben umschriebenen gibt es diffuse Formen, bei denen durch Lumbalpunktion wiederholt Heilung erzielt worden ist. Versagt diese, dann ist nach Wendel die Trepanation indiziert, die bei circumscripter Meningitis von vornherein in Frage kommt. Es ist dringend zu erwägen, ob diese Grundsätze nicht auch im Hinblick auf die Prophylaxe späterer Epilepsie bei meningitischen Erscheinungen in der Kindheit, insbesondere bei cerebralen Komplikationen akuter Infektionskrankheiten in Zukunft allgemeine Geltung haben sollen. Stunden- und tagelang anhaltende Bewußtlosigkeit mit Fieber und Krämpfen, die man nicht selten bei späteren Epileptikern anamnestisch feststellen kann, dürften als berechtigte Indikationen für chirurgisches Handeln anz usehen sein. Wird der meningitische Prozeß sich selbst überlassen, so besteht jedenfalls die Gefahr, daß der vermehrte und entzündlich veränderte Liquor bei der Erschwerung des peripheren Ausweichens in das Hirnparenchym hineindiffundiert. So kommt es dann besonders auf diesem Wege zu einer Encephalitis mit nachfolgender Lähmung, 
der sog. cerebralen Kinderlähmung, bei der sich bekanntlich in $2 / 3$ aller Fälle früher oder später unheilbare Geistesschwäche und Epilepsie einstellen. Was die bisherige Behandlung der zur Kinderlähmung führenden Encephalitis, die natürlich auch auf andere Weise entstehen kann, betrifft, so hatte meist das expektative Verhalten Geltung, für das auch Oppenheim ${ }^{13}$ ) im allgemeinen eintritt. Der genannte Autor selbst hat zwar im akuten Stadium eines seiner schweren Fälle einen günstigen Umschwung im Befinden unmittelbar im Anschluß an die Punktion des Herdes beobachtet; trotzdem möchte er daraus aber keineswegs die Indikation für die operative Eehandlung der Encephalitis ableiten, sondern nur allenfalls die Punktion für die schweren Fälle, in denen eine Indicatio vitalis vorliegt, reserviert $\mathrm{zu}$ wissen, Von Wichtigkeit ist allerdings, daß auch F. Kra use ${ }^{14}$ ) mit seiner Autorität auf dem Gebiete der Hirnchirurgie von der Operation im akuten Stadium der cerebralen Kinderlähmung abrät und erst abzuwarten empfiehlt, ob bei den Kindern nach Ablauf des akuten Stadiums und nach der Erholung Epilepsie eintritt; dann aber soll man, wenn die eine gewisse, aber nicht allzulange Zeit, fortgesetzte interne Therapie erfolglos geblieben ist, zur Operation schreiten. Einen aktiveren Standpunkt gegenüber der operativen Behandlung der Encephalitis nimmt Tilma $\mathbf{n}^{15}$ ) ein. Von der Erwägung ausgehend, daß die entzündlichen Encephalititiden denselben Verlauf wie die traumatischen nehmen (Erweichung, Cystenbildung, Verkalkung) plädiert er für ein frühzeitiges, möglichst nach dem ersten Anfall vorzunehmendes Eingreifen. Auch Grossmann und Auerba $\mathrm{ch}^{16}$ ) treten für eine frühzeitige operative Behandlung geeigneter encephalitischer Prozesse ein, auf Grund der Erfahrung, daß diese eine ausgesprochene Neigung zur Ausbreitung über große Teile der Hemiphäre besitzen und für das Zustandekommen der Epilepsie im Kindesalter von großer Bedeutung sind.

Wenn somit zur Frage des operativen Eingreifens bei Encephalitis nur von einzelnen Autoren ausdrücklich Stellung genommen ist und für das zukünftige allgemeine chirurgische Verhalten erst noch weitere Erfahrungen maßgebend sein werden, so dürfte doch wenigstens zur Zeit die Indikation zu Recht bestehen, daß bei epileptischen Krankheitserscheinungen nach entzündlichen Hirnerkrankungen möglichst früh operativ vorgegangen werden muß, und zwar, sobald sich nach einer gewissen, nicht allzulange fortgesetzten Zeit die Nutzlosigkeit der internen Therapie ergibt. Wie verhält es sich damit in unseren Fällen? Eine Übersicht über unsere Kasuistik zeigt, daß die Zeitspanne vom ersten Auftreten der epileptischen Krankheitserscheinungen bis zur Vornahme der Operation bis zu 20 Jahre beträgt. Hierbei ergibt sich die bemerkenswerte Feststellung, daß der vereinzelt dastehende, schon nach einem Monat im Alter von 2 bzw. 5 Jahren operierte Kranke (I 1) 
seit 11 Jahren anfallsfrei geblieben ist und sich normal entwickelt hat. Der Fall mit 20 jährigem Zwischenraum (I 9) stellt allerdings gleichfalls insofern einen günstigen Ausgang dar, als die Kranke wohl infolge ihres schwachsinnigen Geisteszustandes am zweckmäßigsten der Anstaltspflege bedarf, jedoch seit 3 Jahren anfallsfrei geblieben und geistig frischer geworden ist. Auch der nach $\mathrm{l}^{1} / 2$ jährigem Bestehen der epileptischen Krankheitserscheinungen trepanierte, geistig noch frische Kranke konnte seiner Zeit als relativ geheilt entlassen werden und ist als erfolgreich operiert zu betrachten. Bei den übrigen erfolglos operierten Kranken waren unter fortgesetzter Verschlimmerung der epileptischen Krankheitserscheinungen 4-19 Jahre bis zur Vornahme der Operation verflossen; immerhin kann noch bei 3 Kranken das Ausbleiben des geistigen Rückgangs - einer von ihnen ist außerdem von den lästigen Kopfschmerzen befreit - als günstige Beeinflussung des Krankheitsverlaufes durch die Operation angesehen werden. Kurz sei noch auf die drei Kranken mit Jacksonerscheinungen ohne meningitische Antecedentien (I 13, 14, 16) hingewiesen; auch hier ist eine unzweifelhafte Besserung bei derjenigen Kranken eingetreten, die sich schon nach einem Jahre dem operativen Eingriff unterzog (I 14). Was das Lebensalter der Kranken bei Vornahme der Trepanation betrifft, so schwankt sie von 2-36 Jahren, hält sich somit unter dem Alter von 40 Jahren, das im allgemeinen als äußerste Grenze für die Vornahme der Operation gilt. $\mathrm{Zu}$ berücksichtigen ist auch noch die erbliche Belastung, die bei 22 Fällen 10 mal festzustellen ist und als ungünstiges Moment hinsichtlich der Prognose des operativen Eingriffes gilt. A uf Grund unserer Erfahrungen darf sie jedoch nicht als Kontraindikation für die Operation betrachtet werden. Ferner geht auch aus unserer Kasuistik hervor, daß eine Verschlimmerung des epileptischen Zustandes durch einen operativen Beeinflussungsversuch bei keiner Epilepsieform zu befürchten ist. Für die vorliegenden wie überhaupt alle Epilepsieformen gilt unzweifelhaft der Satz, daB je länger und je stärker alle Faktoren bestanden haben, die zur Auslösung des epileptischen Krampfmechanismus führten, und je mehr sich die charakteristischen, körperlichen und seelischen Ver. änderungen im Organismus entwickeln konnten, um so geringer die Chancen für jede therapeutische Beeinflussung, auch der operativen, sind.

Ein wichtiger Faktor ist noch zu berücksichten, der sowohl bei der cerebralen Kinderlähmung, den anschließend noch zu besprechenden traumatischen Fällen, wie überhaupt bei allen epileptischen Krankheitsbildern eine bedeutungsvolle Rolle spielt, auch wenn uns sein Wesen vorläufig noch dunkel ist, das ist die e pileptische Prädis position, die wir bei den mit Epilepsie Behafteten unbedingt postulieren müssen 
und deren Grad auch für einen günstigen Ausgang der Krankheit von großer Bedeutung ist. Auch F. Krause vertritt diesen Standpunkt auf Grund seiner autoptischen Feststellungen, daß bei manchen an cerebraler Kinderlähmung Erkrankten grob anatomische Veränderungen in der Zentralregion, z. B. Cysten, zu allerschwersten Krampfanfällen, ja auch zu allgemeiner Epilepsie geführt hatten, während bei anderen Kranken mit gleichen Veränderungen an derselben Stelle niemals ein epileptischer Antall beobachtet war. Dasselbe gilt auch für traumatische Schädigungen des Zentralnervensystems. Diese epileptische Prädisposition bildet nach Redlich ${ }^{17}$ ) die Grundlage zur Auslösung eines im Gehirn vorgebildeten Mechanismus, der unter den verschiedensten Einflüssen in Form epileptischer Insulte zum Ablauf gebracht werden kann. Diese eigenartige Reaktionstähigkeit des menschlichen Gehirns und des der höheren Säugetiere bezeichnet Redlich als epileptische Reaktionsfähigkeit. Mit Recht betont Redlich in seinem eingehenden Referate die Wichtigkeit der Aufgabe, die für die epileptische Reaktionsfähigkeit des Menschen in Betracht kommenden Verhältnisse möglichst in allen Details festzustellen, wobei er auf Grund seiner reichen Erfahrungen wertvolle Erläuterungen und Anregungen gibt. In diesem Sinne haben sich nun auch eine Reihe von Autoren mit dem genannten Problem befaßt. So unterscheidet J. Bauer ${ }^{18}$ ) bei der epileptischen Reaktionsfähigkeit 2 Kategorien, die eine ist als konstitutionell, die andere als konditionell bedingte im Sinne Tandlers anzusehen. Von weiteren Autoren ist $\mathrm{Marburg}^{19}$ ) zu nennen, der die genannten Begriffe weiter ausführt. Die konstitutionelle epileptische Reaktionsfähigkeit, die in ihrer Bedeutung gegenüber der konditionell bedingten zurücktritt, ist nach Ma r burg aus den genetischen Elementen der Eltern in das Keimplasma übergegangen. Er nimmt das an, wenn in der Ascendenz erstens degenerative Erkrankungen wie Epilepsie, Psychosen, Migräne, Lues, vielleicht auch schwere Intoxikationen vorgekommen sind; zweitens bei homologen Erkrankungen mehrerer Geschwister, drittens bei spezifischen Degenerationszeichen, die nur bei Epileptikern vorkommen: Familiäre Linkshändigkeit (Steiner), Sprachstörungen (Heilig und Steiner), familiär vorkommende Facialisasymmetrien und einzelne Sensibilitätsstörungen (Richter und Muskens). Eine konditionell bedingte, epileptische Reaktionsfähigkeit kann nach Marburg eintreten erstens nach traumatischen Schädigungen in der Kindheit, wobei zuweilen die Scheidung schwierig sein kann, ob die Epilepsie konstitutionell oder konditionell bedingt ist; zweitens nach infektiösen cerebralen Erkrankungen, die Redlichs Halbseitenerscheinungen hinterlassen. schließlich nach innersekretorischen Störungen, wobei er den weiblichen Genitaldrüsen etwas mehr Bedeutung zumißt. Marb urg selbst bemerkt dazu, daß sich die konstitutionelle und konditionelle Reaktionsfähigkeit 
hinsichtlich der angeführten Ursachen zuweilen nicht scharf voneinander trennen lassen. Eingehend hat sich mit dem wichtigen Problem der epileptischen Reaktionsfähigkeit auch Felix Frisch ${ }^{20}$ ) befaßt. Er bezeichnet als Grundlage des epileptischen Geschehens die konvulsivische Reaktionsfähigkeit, die als eine biologische Funktion des Zentralnervensystems anzusehen ist. Diese konvulsivische Reaktionsfähigkeit ist bei den einzelnen Individuen je nach ihrer Toleranz verschieden. Abhängig ist sie von der chemischen Konstitution der Ganglienzelle und dem Massenverhältnis der Zellstoffe (Kationenverhältnis Löbs, Basengleichgewicht Luithlens). Die betreffenden Faktoren, die zu einer Änderung der konvulsiven Toleranz führen, bezeichnet er als die dispositionellen Steu€rungsfaktoren der konvulsiven Toleranz. Sie werden beeinflußt durch an sich unspezifische, konditionelle Reize; zu ihnen gehören auch die strukturellen Veränderungen im Bereich des Gehirns und seiner Häute mit ihren Folgezuständen. Eine außerordentlich bedeutungsvolle Rolle kommt aber nach Frisch auch den intermediären Stoffwechselvorgängen zu, welche die intracellulären Prozesse und damit auch das Kationenverhältnis der Zelle beeinflussen und unter dem Einfluß des endokrinen Systems stehen. Nun wissen wir auf Grund der bedeutungsvollen Arbeiten von Aller $\mathrm{s}^{21}$ ) u. a., daß der Stoffwechsel gerade beim Epileptiker eine außerordentliche Labilität zeigt. Es sei ereinnert an die Unfähigkeit des Epileptikers, sich während der intervallären Periode ins Stickstoffgleichgewicht zu setzen, an die Störung des exogenen Purinstoffwechsels und die Vermehrung des Cholesterins und Lecithins im Blute während der gleichen Zeit, an das Ansteigen des Restkohlenstoffes im Blute vor dem Anfall, an die Schwankungen des antiproteolytischen Titers (Rosental), auf die verschiedenen Blutanomalien und anderes mehr. Das Zustandekommen aller dieser Faktoren, die begreiflicherweise die physiologischen Erregbarkeitsverhältnisse des Zentralnervensystems beeinflussen, sind zu erklären durch Störungen des endokrinen Systems, die ihrerseits wieder vielfach auf eine degenerative Konstitution zurückzuführen sind. Auf diese Weise ist es nach Frisch zu verstehen, warum die gleichen konditionellen Einwirkungen bei dem einen Falle nur einfache Ausfalls- oder überhaupt keine Symptome, bei dem anderen schwere epileptische Krankheitserscheinungen auslösen.

Bei den Erklärungsversuchen für das Wesen der epileptischen Prädisposition und der epileptischen Reaktionsfähigkeit verdienen auch die Ausführungen Hauptmanns ${ }^{22}$ ) das weitgehendste Interesse. Hauptmann weist auf die Möglichkeit hin, daß der epileptischen Reaktionsfähigkeit ein abnorm angelegtes Gehirn zugrunde liegt. das auf bestimmte Reize mit krankhaften Erscheinungen reagiert und gewissermaßen mit einem überempfindlichen Instrument verglichen 
werden kann. Auch Polla k ${ }^{23}$ ) tritt für die Bedeutung der cerebralen Entwicklungsstörungen und Hemmungsbildungen für das Zustandekommen der Epilepsie ein. Mit Recht weist jedoch demgegenüber F. H. Lew y darauf hin, daß bei einer großen Zahl Nichtepileptischer nicht ganz so selten einzelne dieser Bedingungen zu finden sind, und da $\beta$ es doch sehr fraglich ist, ob die betreffenden Personen alle Epilepsieanwärter gewesen sind, während sich auf der anderen Seite auf toxischer Basis experimentelle Epilepsien fast regelmäßig hervorrufen lassen. Neben der abnormen Anlage des Gehirns befaßt sich Ha uptmann bei der Frage nach der Pathogenese der Epilepsie auch mit den Reizstoffen, die eine entsprechende Wirkung auf ein derartig angelegtes Zentralnervensystem ausüben können. Er stellt hierbei das a b n or $m$ angelegte Gehirn einmal den exogenen, weiterhin den endogenen-Reizstoffen gegenüber. Bei den endogen entstandenen Reizstoffen unterscheidet er einmal solche, die normale, und ferner solche, die pathologische Stoffwechselprodukte darstellen. Bei den pathologischen Stoffwechselprodukten besteht nach $\mathrm{Hauptmann}$ die Möglichkeit, daß sie entweder primär aufgetreten oder sekundär, vom Gehirn abhängig, entstanden sind. Weiterhin führt er noch als Entstehungsmöglichkeiten für die Epilepsie an: Normal angelegte Gehirnstoffwechselstörung; als letzte: primär fortschreitenden Gehirnprozeß. Sämtliche Möglichkeiten müßten durch entsprechende Untersuchungen klargestellt werden, wozu gerade jetzt in Gestalt der Kriegsepileptiker ein reichliches und günstiges Material zur Verfügung stände, ein Appell Hauptmanns, der entschieden die größte Beachtung verdient. Aus der eigenen Erfahrung seien für die Frage der epileptischen Reaktionsfähigkeit einige ganz kurze Beiträge angeführt.

Im Hinblick auf die Beziehung Entwicklungsanomalie und epileptische Krankheitserscheinungen sei auf Fall 24 der I. Gruppe (tuberöse Sklerose) hingewiesen. Es ist von Interesse, daß diese Anomalie hier bis zum 29. Lebensjahre völlig symptomlos verlief. Die ersten Krankheitserscheinungen, deren Verschlimmerung schließlich zur Trepanation führte, waren nicht epileptische, sondern Hirndruckerscheinungen infolge des großen linksseitigen Ventrikeltumors. Vor allem aber ist hierbei auch der Fall Merkel-Weinert anzuführen, der bis zu seinem infolge einer Kriegsverwundung erfolgten Tode somatisch und psychisch einen völlig normalen Befund dargeboten hatte (abgesehen von der Hautanomalie im Gesicht), so daß die tuberöse Sklerose einen zufälligen Obduktionsbefund darbot. Also bei einer derartig ausgesprochenen cerebralen Entwicklungsanomalie wie die tuberöse Sklerose genügen die normalen Stoffwechselprodukte nicht, es müssen noch andere Momente hinzukommen, um epileptische Krankheitserscheinungen auszulösen; zu denken wäre da in erster Linie an pathologische Stoff wechsel- 
produkte. Uberraschend ist nun im Falle Merkel-Weinert, daß trotz ausgebreiteter Organveränderungen die inkretorischen Vorgänge ohne sichtliche Störungen verliefen. Zur weiteren Klärung in diesen Fragen dürfte es angezeigt sein, schon intra vitam mit Hilfe der modernen Methoden alle Fälle mit den charakteristischen Adenoma-sebaceum. Bildungen im Gesicht zu untersuchen im Hinblick darauf, daß bei der Autopsie eine tuberöse Sklerose zu erwarten ist. Bei entsprechenden Fällen könnten sich auf Grund der vorausgegangenen Untersuchungen und des späteren Sektionsbefundes wichtige Resultate für die Frage ergeben, unter welchen Bedingungen eine epileptische Reaktionsfähigkeit zustande kommt.

Es seien nunmehr kurz zwei Beispiele für die Tatsache angeführt, daß die epileptische, bzw. konvulsivische Reaktionsfähigkeit nach Ablauf einer gewissen Zeit, nämlich der Wachstums- und Entwicklungsperiode, die bekanntlich in besonderem Maße unter dem Einfluß der inkretorischen Drüsen steht, wieder völlig verschwinden kann, selbst wenn später so erhebliche, cerebrale Irritationen wieTrau ma und meningitische Prozesse a uf das Gehirn einwirken. Es handelt sich um folgende zwei hier beobachtete Fälle:

Fall 1. Der am 1. X. 1888 geborene Albert W. erlitt im 14. Jahre einen Sturz von einer Treppe. 8 Tage später der erste Anfall. 11 Monate lang viel Anfälle und petit mal, dann Anstaltsaufnahme mit folgendem Befund: Zäpfchen nach links, der linke Gaumenbogen steht tiefer, die linke obere Extremität und der linke Pectoralis major dünner als rechts. Nach einem anfallsfreien Jahr relativ geheilt entlassen. Im 30. Jahre heftige Kopfschmerzen, fortgesetztes Erbrechen, leichte Genickstarre, mittelweite reaktionslose Pupillen, geringes Fieber, so daß die Diagnose Meningitis zu stellen war. Bei der Spinalpunktion Entleerung von reichlichem Liquor unter starkem Druck, worauf die Krankheitserscheinungen zurückgingen. Wir haben in diesem Fall anzunehmen, daß durch das Trauma im 14. Jahr eine Meningoencephalitis mit nachfolgenden epileptischen Erscheinungen hervorgerufen wurde, die unter Anstaltspflege wieder schwanden. Es ist nun von Interesse, daß eine im 30. Jahre wieder aufgetretene Meningitis nicht imstande war, konvulsivische Symptome auszulösen.

Fall 2. Johannes K., geb. 17. X. 1881. Im 10. Jahr eine heftige Ohrfeige. Klagte nachher viel über Kopfschmerzen. In der Folgezeit badete Pat. viel und blieb lange in kaltem Wasser. Im Alter von $15^{3} / 4$ Jahren der erste epileptisehe Anfall, dem in den nächsten 4 Monaten weitere folgten. Deshalb Anstaltspflege, aus der Pat. nach 1 jähriger, anfallsfreier Behandlung als relativ geheilt entlassen wurde. Im 22. Jahre mittels eines Spatens eine $10 \mathrm{~cm}$ lange, klaffende Wunde auf der Stirn, wobei der Knochen zertrümmert wurde und Gehirnmasse heraustrat. Nach 2 Tagen Überführung in eine große städtische Krankenanstalt. 8 Tage nach der Verletzung bei Fieber und reaktionslosem Verlauf bei fortgesetzter Behandlung der Wunde mit Wasserstoffsuperoxyd Wundrevision, wobei mehrere Knochensplitter sowie zertrümmerte Gehirnsubstanz ohne nennenswerte Blutung entfernt wurden. Reaktionsloser Verlauf. Pat. hat später theologische Studien aufgenommen und ist jetzt Geistlicher in einer deutschen Gemeinde Brasiliens. Wir haben in diesem Fall anzunehmen, daß durch die Ohrfeige im 10. Jahre eine 
Meningitis sich eingestellt hatte. Erst in der kritischen Pubertätszeit traten die epileptischen Anfälle auf, die unter der Anstaltsbehandlung verschwanden. 12 Jahre später zeigt sich die epileptische Reaktionsfähigkeit erloschen, trotzdem ein so erhebliches Kopftrauma einwirkt, das bei manchem vorher intakten Gehirn genügt hätte, um epileptische Krampferscheinungen auszulösen.

Beide Fälle stellen eigentlich traumatische Epilepsieformen dar. Sie zeigen aber die innigen Beziehungen der idiopathischen zur traumatischen Epilepsie, auf die besonders Ha uptmann und Tilmann hinweisen, und seien an dieser Stelle bei der Besprechung der konvulsivischen Reaktionsfähigkeit angeführt.

Wenden wir uns nun zur zweiten Hauptgruppe.

Von den 26 traumatischen Fällen weisen die 4 ersten außer erblicher Belastung noch Konvulsionen in früher Kindheit auf. Zu diesen schwerwiegenden Faktoren tritt das heftige Kopftrauma im 3. -20. Jahre des Patienten, das nach 1-8jährigem Bestehen von epileptischen Krampferscheinungen die Indikation zur Trepanation bildet. In den nächsten 4 Fällen ist gleichfalls eine doppelte Hirnschädigung festzustellen, nämlich Scharlachinfektion und Trauma (Fall 5 und 6), Trauma und Lues (Fall 7) sowie Trauma und Alkoholismus (Fall 8). Unter den traumatischen Fällen sind auch die 5 Kranken mit Geburtsschädigungen aufgeführt, die nach F. Krause $\mathrm{e}^{27}$ ) ein Mittelglied zwischen traumatischen und infektiösen Formen bilden. Die Beziehungen von Geburtsstörungen und Epilepsie an der Hand des hiesigen Anstaltsmaterials wurden vom Verfasser in einer früheren Arbeit erörtert. Daß Geburtsstörungen in ihren Folgewirkungen nicht zu unterschätzen sind, geht aus den neuerlichen Feststellungen von $\mathrm{Ph}$. Schwartz ${ }^{28}$ ) hervor. Er fand bei Sektionen von Neugeborenen, die während oder kurz nach der Geburt zugrunde gingen oder auch bis zu mehreren Wochen am Leben blieben, spezifische Geburtsschädigungen des Kopfes und insbesondere des Gehirns in Form von Blutungen in den Hirnhäuten und vor allem auch solche in großer Zahl in der Gehirnsubstanz selbst. Diese miliaren Gehirnblutungen waren in allen Teilen des Gehirns, besonders stark aber im Bereich der Kopfgeschwulst anzutreffen und sind auf die Druckdifferenz zwischen Uterusinhalt und Atmosphäre zurückzuführen. Besonders fanden sich die Blutungen bei Frühgeburten ausgeprägt, was deshalb von Wichtigkeit ist, weil unter den Epileptikern nicht selten frühgeborene Kinder anzutreffen sind. Mit Recht weist Schwartz darauf hin, daß die Erforschung der Folgen dieser Ansaugungsblutungen, die durch die Überfüllung und schließlich das Reißen der Gefäße infolge der Stauung entstehen, nicht nur für krankhafte Zustände der Neugeborenen, sondern auch für viele Erkrankungen des späteren Lebens (Idiotie, angeborene Taubstummheit und Blindheit, Lähmung und Krämpfe) von Bedeutung sein können. Allerdings ist im Hinblick auf aie Entstehung epileptischer 
Krankheitsformen immer wieder zu bemerken, daß zur Geburtsschädigung noch andere Faktoren hinzukommen müssen.

Um in der Betrachtung der traumatischen Fälle fortzufahren, so ergeben sich noch folgende Feststellungen: Direkte oder indirekte er blich e Belastung ist in der Hälfte der Fälle anzutreffen; die trau matische Gehirnschädigung fand im Alter von $3 \frac{1}{2}-25$ Jahren statt. In der Hälfte der Fälle haben sofort oder noch im gleichen Jahre die epileptischen Krankheitserscheinungen eingesetzt. In den übrigen Fällen sind ent. sprechend den Beobachtungen in der Literatur eine ganze Reihe von Jahren bis zum Ausbruch der epileptischen Krämpfe verflossen. Nach Redlich ${ }^{26}$ ) kommen für den Intervall, der zwischen der Verletzung und dem Auftreten der Anfälle liegt, zwei Möglichkeiten in Frage: Entweder sind die anfallsauslösenden Schädlichkeiten erst später in Wirksamkeit getreten (z. B. in der Pubertät), oder an die primäre Schädigung haben sich sonstige krankhafte Prozesse angeschlossen. - Untersuchungen des Blutdrucks, der bei den in der Anstalt noch weilenden Patienten im Hinblick auf die Möglichkeit einer klinischen Unterscheidung von den nicht traumatischen Fällen vorgenommen wurde, ergaben normale Befunde. Was die zeitliche Vornahme des operativen Eingriffs betrifft, so wurde er in den vorliegenden Fällen im 6.-38. Lebensjahre des Patienten ausgeführt, nachdem die Krampfanfälle wenige Wochen bis zu 28 Jahren bestanden hatten. In ungefähr der Hälfte der Fälle beschränkte man sich im Hinblick auf das Fehlen gröberer Veränderungen auf die bloße Entlastungstrepanation. Den günstigsten Ausgang, so da $\beta$ von Heilung gesprochen werden kann, repräsentiert Fall 23, bei dem im 28. Jahre schon 14 Tage nach dem Kopftrauma der operative Eingriff vorgenommen wurde und das Bestehen von subarachnoidealen Hämorrhagien ergab. Die Krampferscheinungen bei diesem erblich nicht belasteten Fall wären allerdings nach Tilman n noch nicht als epileptische, sondern als epileptiforme Reizerscheinungen von seiten des Gehirns anzusehen. Auch dieser Patient illustriert die Notwendig keit möglichst frühzeitiger operativer Behandlung derartiger Krankheitsfälle. Eine entschiedene Besserung der epileptischen Krankheitserscheinungen nach der Operation ist in den Fällen 1, 3, 10, 19 und 24 und namentlich 26 festzustellen, trotzdem bei der Mehrzahl erbliche Belastung vorliegt und bei den drei ersten Fällen auch noch Konvulsionen in früher Jugend sich abspielten. Eine günstige Prognose bietet entschieden auch der Fall 17. Näher auf diese Kranken an dieser Stelle einzugehen, erübrigt sich im Hinblick auf die betreffenden epikritischen Ausführungen. Auch Fall 5 (Kombination von Trauma mit einer Scharlach- und dann noch einer weiteren Infektion) kann als günstig beeinflußt bezeichnet werden, da die Anfälle seit der zweiten Operation milder verlaufen und der Kranke geistig eher etwas frischer geworden ist. In 6 Fällen ist der 
Zustand nach der Operation derselbe geblieben, während die übrigen mit der Zeit psychisch und auch im Hinblick auf die Anfälle eine deutliche Verschlimmerung erfahren haben, ohne daß jedoch die Verschlimmerung auf den operativen Eingriff zurückzuführen wäre.

Was die seelischen Störungen bei den traumatischen Epileptikern betrifft, so sei zuerst Fall 2 angeführt, bei dem indirekte erbliche Belastung, Zahnkonvulsionen und das im 20. Jahr erlittene Kopftrauma zusammenkommen. Der im 21. Jahr mit Rindenexcision behandelte und im 22. Jahr verstorbene Patient litt nach der Operation über ein Jahr lang bis zu seinem Tode an vielgestaltigen seelischen Störungen: katatonischen Erscheinungen, depressiven und manischen Zuständen. Fünf weitere Fälle zeigen das Vorwiegen einer Depression, mürrische Gemütsstimmung mit zeitweisem Übergang in große Erregt- und Verwirrtheit, Krankheitszustände, die an die akute Kommotionspsychose (Kraepelin) erinnern und der traumatischen Epilepsie eigentümlich zu sein scheinen. Kopfschußverletzte aus dem Kriege mit nachfolgender Epilepsie finden sich nicht in vorliegender Kasuistik, obwohl eine ganze Reihe von solchen Kranken in der Anstalt - meist allerdings nur vorübergehend - Aufnahme gefunden haben. Über ihr psychisches Verhalten seien einige Bemerkungen hier eingeschaltet. Kurz zusammengefaßt stellen sie mit ihrer vorwiegend mürrischen, depressiven Stimmung, mit ihrer Ablehnung jeder ablenkenden Beschädigungstherapie, mit ihrer Neigung zum Verhetzen der Mitkranken und ihrer großen Erregbarkeit schwierige Elemente dar. Spätepilepsie nach Kopfschußverletzungen im Kriege ist nach den bisherigen Beobachtungen ziemlich häufig. Erfahrungsgemäß disponieren besonders Verletzungen der Scheitel- und Schläfenregion zur traumatischen Epilepsie, während Epilepsie nach Stirn-, Hinterhaupts- und Basisverletzungen im Vergleich dazu seltener beobachtet wird [Braun $\left.{ }^{27}\right]$. Da nach der allgemeinen Annahme aseptische Hirnnarben keinerlei Reizerscheinungen hervorrufen, so würde bei späterer histologischer Untersuchung der betreffenden Gehirne unter anderem sich auch feststellen lassen, ob an alte Hirnverletzungen oder Hirnentzündungen sich auch noch später mit oder ohne erkennbare Veranlassung schleichende Krankheitsprozesse anschließen können. Für das Bestehen dieser Möglichkeit ist M. Bielschowsk ${ }^{28}$ ) anzuführen, nach dem es auf dem Boden alter encephalitischer Narben $z u$ einer fortschreitenden degenerativen Erkrankung gewisser Rindenschichten kommen kann, welche viele Jahre nach der primären Erkrankung noch nicht abgeschlossen ist.

Wenden wir uns jetzt zu denjenigen krankhaften Veränderungen des Gehirns und seiner Umhüllungen, die im Hinblick a uf operative Therapie der epileptischen Krankheitserscheinungen von Interesse sind. Wir haben hier neben den Sek- 
tionsbefunden vor allem auch diejenigen zu berücksichtigen, die sich während der Operation ergeben und deren Kenntnis wir den Chirurgen, vor allem F. Krause und Tilmann, verdanken. In aller Kürze seien die ausgebreiteten histologischen Befunde des Epileptikergehims erwähnt. Wir haben dabei außer den häufig anzutreffenden, als Entwicklungsanomalien anzusehenden architektonischen Störungen, die bereits oben erwähnt sind, solche anzuführen, die in Beziehung zu dem epileptischen Krankheitsprozeß, namentlich den Insulten, stehen; es sind da die sog. Abbauvorgänge (Alzheimer) zu nennen, die sich durch degenerative Veränderungen an den Ganglienzellen, massenhaftes Auftreten von Abbauprodutken und Wucherungsvorgänge an den gliösen Elementen manifestieren. Was makroskopisch bei einer ganzen Reihe von Epilepsiefällen verschiedenster Ätiologie bei der operativen Freilegung des Gehirns so überaus häufig zuerst entgegentritt, das ist eine hochgradige Duraspannung, bei der die Gehirnpulsationen völlig verschwunden sein können. Die intrakraniellen Druckanomalien haben sowohl pathogenetisch wie therapeutisch das größte Interesse, so daß auf sie etwas näher eingegangen werden muß.

Von großer Bedeutung für unsere Anschauungen zwischen intrakraniellem Druck und epileptischem Insult und für das sich hieraus ergebende chirurgische Handeln war bekanntlich die Theorie Kochers ${ }^{29}$ ), daß die Ursache oder das Wesentliche der Epilepsie eine lokal oder allgemein erhöhte intrakranielle Spannung sei. Plötzliche Drucksteigerung der in großer Menge vorhandenen und bereits unter hohem Druck stehenden Cerebrospinalflüssigkeit ruft nach dem genannten Autor sofort Aufhebung des Bewußtseins und allgemeine Krämpfe hervor; bei einer entsprechenden Veranlagung eines Kranken, deren Bestehen allerdings angenommen werden müsse, genügten bereits geringe Zirkulationsstörungen und Druckschwankungen zur Erzeugung eines epileptischen Anfalls. Demgegenüber ergaben die wichtigen, mit der Stauungsbinde ausgeführten Versuche Bier $\mathrm{s}^{30}$ ), daß hochgradige venöse Gehirnhyperämie, starke Druckerhöhung in der Schädelkapsel, sowie plötzliche intrakranielle, selbst hochgradige Druckschwankungen weder einen Anfall hervorriefen noch eine Vermehrung und Verstärkung der Anfälle bewirkten, während durch seelische Erregungen bei 2 Epileptikern sofort Anfälle ausgelöst wurden. Die große Mehrzahl der Autoren, von ihnen seien nur Tilmann und Bungart genannt, sehen daher die Drucksteigerung im Schädelinnern nicht als Ursache der epileptogenen Zustände, sondern als deren Folge an, sie sei auf Störungen in der Produktion oder im Abtransport des Liquor oder schließlich auf eine Kombination beider Prozesse zurückzuführen.

Im Hinblick auf den in der Schädelrückenmarkshöhle herrschenden Druck haben wir übrigens nach Tilman $\mathrm{n}^{31}$ ) auch zu berücksichtigen, 
daß die sowohl bei der Lumbal- wie bei der Ventrikelpunktion sich ergebenden Werte je nach der Körperhaltung variieren, welche Mensch und Tier im Moment der Punktion einnehmen. Bedeutungsvoll sind im Hinblick auf ein operatives Eingreifen auch die von Redlich und Pötzl ${ }^{32}$ ) bei Epileptikern ausgeführten Druckmessungen, wobei sich erstens Fälle mit dauernd hohem Liquordruck ergaben, zweitens solche mit einer vor und nach den Anfällen bestehenden Erhöhung der Liquorspannung und drittens subnormale Druckverhältnisse bei Kranken mit postepileptischen Psychosen. Mit Recht machen die genannten Autoren darauf aufmerksam, daß durch die Lumbalpunktion nicht immer der im Schädelraum herrschende Druck festgestellt werden kann, falls z. B. die Schädel- und Rückenmarkshöhle nicht miteinander kommunizieren. Weiterhin könnten bei ungleichmäßigem Verhalten des Liquordruckes individuelle Schwankungen desselben eine Rolle spielen, bedingt durch eine ungleichmäßige sekretorische Tätigkeit dès Plexus chorioideus. Schließlich wären auch die Resorptionsverhältnisse des Liquors zu berücksichtigen. Jedenfalls liegen den Druckanomalien des Liquors bei Epilepsie komplizierte ineinandergreifende Verhältnisse zugrunde, auf die nicht näher eingegangen werden kann.

Was das druckentlastende Vorgehen bei der Epilepsiebehandlung betrifft, so erzielte bekanntlich Kocher damit eine ganze Reihe von Erfolgen, namentlich bei den traumatischen Epilepsieformen, von denen er bei seinen theoretischen Erwägungen ausgegangen war, und die auch seinem Schüler Ito bei seinen interessanten, experimentellen Untersuchungen zugrunde lagen. Die gleichen günstigen Erfahrungen sind bekanntlich von anderen Autoren gemacht worden, die sich seinem chirurgischen Vorgehen anschlossen, während sie die theoretische Begründung, wie oben erwähnt, für unhaltbar hielten. So nimmt Friedrich $^{11}$ ) an, daß es bei makroskopisch fehlenden Gehirnveränderungen unter Umständen gelingen kann, ,,durch irgendwelche mechanische Beeinflussung der den ersten Reiz zum epileptischen Insult abgebenden Stelle das ganze epileptische Krankheitsbild zu beeinflussen". Nach Joll y wird durch eine Lüftung des Gehirns entweder die Blutzirkulation der erkrankten Partien durch die Operation beeinflußt oder die Reizbarkeit des Gehirns vorübergehend herabgesetzt. Nach Bier ist der wirksame Faktor bei der Freilegung des Schädelinhaltes die längere Zeit anhaltende Hyperämie. Jedenfalls erscheint es begreiflich, daß durch einen derartigen Eingriff, wie ihn die Freilegung der Hirnrinde und das Anlegen eines Ventils darstellt, eine tiefgehende Beeinflussung der gesamten regulativen Vorgänge erreicht werden kann im Hinblick darauf, daß in der Hirnrinde auch wichtige Sympathicuszentren lokalisiert sind. Allerdings ist hierbei nicht zu vergessen, daß zuweilen jeder größere operative Eingriff selbst an entfernteren Körperteilen das epi- 
leptische Krankheitsbild, wenn auch meist nur vorübergehend, günstig beeinflussen kann.

Um in der Besprechung der bei der Autopsie in vivo festgestellten Veränderungen fortzufahren, so ist von größtem Interesse für die $\mathrm{Pa}$ thogenese des epileptischen Anfalls die Beobachtung F. Krauses ${ }^{24}$ ). bei einigen Epileptikern, bei denen während der Operation sich Anfälle einstellten: ,Wie eine auf das äußerste gespannte, blaurote Blase preßte sich das Gehirn aus der Trepanationsöffnung hervor; es bestand keine Pulsation, kein Liquorfluß, das Gehirn erschien trocken." Dieser hochinteressante Befund entspricht ohne Zweifel der von Reichard $\mathbf{t}^{34}$ ) bei epileptischen und katatonischen Zuständen festgestellten Gehirnschwellung. Auch wir haben diesen eigenartigen Befund bei den Sektionen der Epileptiker immer wieder beobachtet, wenn der Exitus plötzlich mit oder ohne erkennbaren Zusammenhang mit epileptischen Anfällen oder einer seelischen Störung sich einstellte und das epileptische Geschehen nicht mit andern pathologischen Vorgängen wie Suffokation usw. kompliziert war. Das Gehirn erscheint hierbei voluminös, die Hirnhäute können völlig zart sein; die Windungen sind verstrichen, die Gehirnsubstanz hat eine eigenartige zähe, trockene Beschaffenheit. Scharf zu trennen ist von diesem Befunde, worauf Reichardt nachdrücklich hinweist, die Volumvergrößerung des Gehirns durch Hirnöde $\mathrm{m}$, wobei wir es mit einer Vermehrung freier Flụissigkeit in der Hirnsubstanz zu tun haben, während bei der Hirnvolumvermehrung durch Hirnschwellung eine vermehrte, freie Flüssigkeit nicht nachweisbar ist. Bei der Hirnschwellung ist in einer Reihe von Fällen ein anatomisches Substrat in Gestalt von eigenartigen Gliazellwucherungen festgestellt, in anderen Fällen vermochte die histologische Untersuchung die Volumvergrößerung nicht zu erklären. Es liegt daher nahe, an eine Steigerung kolloidchemischer Vorgänge hinsichtlich der Wasserverbindung, an eine erhöhte Quellbarkeit der Zellkolloide zu denken, die unter den verschiedensten Einflüssen und nach Reichardt bei den verschiedensten krankhaften Zuständen zustande kommen kann. Es ist ohne weiteres einleuchtend, daß die therapeutischen Bestrebungen bei der Epilepsie sich auch in dieser Richtung bewegen müssen.

Bei einer weiteren Besprechung der anatomischen Hirnbefunde während der chirurgischen Freilegung des Gehirns sei auf die Tilmannsche, auf ein großes Beobachtungsmaterial gestützte Erfahrung hingewiesen, daß das Aussehen der Hirnoberfläche beim lebenden und toten Menschen außerordentlich verschieden sein kann; z. B. war post mortem das in vivo festgestellte Ödem des Subarachnoidealraums nicht mehr vorhanden; ferner sah man beim Lebenden weißliche Streifen und Knötchen, die an der Leiche völlig verschwunden waren. Nach Tilmann sind die autoptischen Befunde bei der traumatischen und sog. genuinen 
Epilepsie im Wesen identisch; der Unterschied besteht nur darin, daß man bei den traumatischen Epilepsien oft einen lokal umschriebenen Herd findet, während bei der sog. genuinen oft die ganze Hirnoberfläche an dem Proze $B$ sich beteiligt. Das Hauptgewicht legt der genannte Autor auf chronisch-entzündliche Vorgänge in den feineren Maschen des Subarachnoidealraums, die nach Traumen mit nachfolgender Entzündung sowie durch entzündliche Prozesse bei Allgemeininfektionen oder auch in der Nachbarschaft (u. a. auch im Schädelknkochen) entstehen und Zirkulationsstörungen und damit eine behinderte Ernährung der Hirnrinde bedingen. Hierdurch würden dann die epileptischen Anfälle ausgelöst. „Solange der chronische Entzündungsprozeß noch besteht, was man an dem Eiweißgehalt der Cerebrospinalflüssigkeit sehen kann, sind Chancen zur Beseitigung da. Ist der Prozeß endgültig durch Narbenbildung beendigt, dann kommt man mit dem Eingriff meistens zu spät." Im Hinblick auf diese Ausführungen sei bemerkt, daß ihnen in erster Linie ein chirurgischer Standpunkt zugrunde liegen dürfte. Was die eigene Stellungnahme zu den bei Epilepsie so häufig auch postmortal anzutreffenden Trübungen der weichen Hirnhäute, namentlich längs der Gefäße, betrifft, so möchten wir sie nach unseren hiesigen Erfahrungen eher als sekundäre Befunde ansehen, die in erster Linie infolge der mit den epileptischen Insulten verbundenen, intrakraniellen Stauungserscheinungen entstanden sein können; andererseits haben wir derartige leptomeningitische Trübungen auch bei alten chronischen Psychosen nicht spezifischer Natur festgestellt, die niemals an epileptischen Insulten gelitten hatten, so da $\$$ wir sie, ganz allgemein gesprochen, als die Folge abnormer cerebraler Zirkulations- und Stoffwechselvorgänge betrachten möchten. Tilmanns Annahme von dem Entstehungsmodus der epileptischen Insulte durch Liquorstaung infolge chronisch-arachnoitischer Prozesse und dadurch bedingten Hineindiffundierens von Liquor in die Hirnsubstanz deckt sich übrigens mit der Auffassung von Gennerich ${ }^{35}$ ) über die Auslösung von Krampfzuständen bei der Paralyse durch die rückläufige Bewegung des Liquors bei diesem cerebralen Krankheitsprozeß. Von großer Bedeutung für die Pathologie und chirurgische Therapie der Epilepsie sind die reichen Erfahrungen F. Krauses, denen wir auch so überaus wichtige physiologische Ergebnisse verdanken. Auf die anatomischen Befunde am Lebenden und auf deren möglichste Erweiterung legt auch er das größte Gewicht. Beim Vorhandensein von Ödem der Arachnoidea von bindegewebig. narbigen Verdickungen der Hirnhäute, von cystösen Bildungen, atrophischen und sklerotischen Veränderungen kommt natürlich diesen Befunden nach Kra use eine ursächliche Bedeutung für die Krampfanfälle zu. Zu ihrer Auslösung muß jedoch, wie oben erwähnt, noch ein anderes unbekanntes Moment, die Disposition, hinzukommen. Mit Recht weist 
er darauf hin, daß die Epilepsie keine einheitliche Erkrankung sei, daß sie vielmehr eine Gruppe von Krankheitsformen darstelle, und daß es das weitere Bestreben sein müsse, aus diesem großen Gebiet die einzelnen Formen weit schärfer herauszulösen, als es bisher der Fall ist.

Für unser chirurgisches Handeln gegenüber den epileptischen Krankheitserscheinungen sind von größter Wichtigkeit die Indikationen zum operativen Eingreifen, die in den folgenden Zeilen erörtert werden sollen. Den Ausführungen liegen die bisherigen Erfahrungen von chirurgischer und neurologischer Seite $[$ F. Kra use, Tilmann, Friedrich,Großmann, Küm mell ${ }^{36}$ ), Sahli ${ }^{37}$ ), A uerbach ${ }^{38}$ ), Weil ${ }^{39}$ ), Eliasberg ${ }^{40}$ ) u. a., auf deren Arbeiten bereits mehrfach hingewiesen ist], sowie die eigenen, aus den vorliegenden Fällen genommenen Beobachtungsresultate zugrunde.

Von großer Wichtigkeit ist die sorgfältige Erhebung der A na m nese. Die Feststellung schwerer erblicher Belastung, in deren Gefolge nicht allein Anomalien, funktionelle Schwäche und Minderwertigkeit des Zentralnervensystems, sondern auch eine solche der Drüsen mit innerer Sekretion auftreten, wird naturgemäß die Prognose des operativen Eingriffs trüben. Allerdings sollte sie keine Kontraindikation abgeben, da auch bei den vorliegenden Fällen trotz erblicher Belastung noch eine günstige Beeinflussung der Krankheitserscheinungen durch die Operation zu beobachten war. Von großem, praktischem Interesse ist die Feststellung des Geburtsverla ufs und etwaiger Schädeltrau men in früher Jugend sowie in späterer Zeit. Von großer Wichtigkeit ist fernerhin die Feststellung eklamptischer Zustände in den ersten Kindheitsjahren, die einerseits - wahrscheinlich in der Mehrzahl der Fälle - auf encephalomeningitische Prozesse zurückzuführen sind und deshalb auch besonderes chirurgisches Interesse beanspruchen. In gleicher Weise sind die Krampfzustände bei den akuten Infektionskrankheiten zu bewerten. Beginn der Krämpfe mit Fieber oder im Anschluß an eine fieberhafte Erkrankung oder Beginn der Krämpfe im frühesten Kindesalter aus voller Gesundheit heraus deutet auf eine organische Erkrankung entzündlichen Charakters, besonders, wenn eine stärkere erbliche Belastung nicht nachweisbar ist. Mit Nachdruck weist H. Vog ${ }^{41}$ ) darauf hin, daß immer wieder die Möglichkeit einer organischen Epilepsie auch im Hinblick auf ein chirurgisches Eingreifen zu prüfen ist, ehe man diese Diagnose endgültig fallen läßt und eine sog. genuine Epilepsie annimmt. Der Verlauf der Krampfanfälle, wie er in Form von motorischen und sensiblen Herderscheinungen zum Ausdruck kommt, bietet allerdings nicht immer ein solches Unterscheidungsmerkmal für eine organische oder sog. genuine Grundlage des Leidens; eher kann hierfür, wenn auch nicht in allen Fällen, nach Bonhöffer eine vorhandene oder fehlende Trübung des Bewußtseins herangezogen 
werden. Epileptische Herdsymptome und natürlich auch Allgemeinerscheinungen können keine chirurgische Bedeutung haben und bilden eine Kontraindikation für die Trepanation, wenn sie durch Intoxikationen (Blei, Alkohol, Urämie) oder durch Hysterie bedingt sind $\mathrm{Da}$ auch die auf luetischer Grundlage beruhenden, herdförmigen oder allgemein epileptischen Krankheitssymptome für operatives Eingreifen nicht in Frage kommen, empfiehlt sich dringend die Vornahme der Wassermannschen Reaktion und die Prüfung auf sonstige luetische Folgeerscheinungen, ehe man an die operative Behandlung herantritt. Auszuscheiden haben bei der letzteren auch diejenigen Epilepsieformen, die auf fötalen Entwicklungsstörungen und Encephalitiden (tuberöse Sklerose, die zuweilen schon intra vitam durch die eigentümlichen Hautanomalien diagnostizierbar ist, Megalencephalie, Mikrocephalie usw.) beruhen. Auszuschließen sind fernerhin, wie schon früher erwähnt, arteriosklerotische Formen und Fälle, die im höheren Lebensalter stehen, wobei im allgemeinen das 40 . Lebensjahr als äußerste Grenze gilt. Bei den genannten Schädigungen handelt es sich eben in der Regel um eine diffuse Ausbreitung der krankhaften Veränderungen, die nicht durch operative Eingriffe zu beeinflussen sind. Sehr geringe Aussichten für einen operativen Erfolg versprechen naturgemäß auch diejenigen epileptischen Krankheitsformen, bei denen infolge jahrelangen Bestehens der Krampfanfälle und bereits eingetretener mehr oder weniger hochgradiger Verblödung anatomisch das Vorhandensein schwerer anatomischer Veränderungen in Gestalt von Rindenverödung und Gliawucherung, klinisch ein irreparables „Ausschleifen“ der entsprechenden Bahnen anzunehmen ist. Wohl aber ist trotz eines vorhandenen Schwachsinnes immer noch eine Indikation zum operativen Eingreifen gegeben, wenn man annehmen kann, daß die seelische Veränderung durch umschriebene Prozesse, z. B. eine Cyste unterhalten wird, nach deren Beseitigung schon wiederholt Besserung des ganzen Zustandes bis zum völligen Schwinden der seelischen Störung beobachtet worden ist. Selbst. verständlich bilden eine Kontraindikation zur Operation auch diejenigen epileptischen Krankheitsfälle einschließlich derer mit Herderscheinungen, bei denen der Zustand durch interne Medikation (Brom, Luminal) und hygienisch-diätetische Behandlung eine günstige Beeinflussung erfährt.

Um jeden Fall vor der Operation weiterhin möglichst zu klären, empfehlen sich noch zweierlei Maßnahmen, einmal die früher schon erwähnte Spinalpunktion, vor allem aber die Röntgenaufnahme des Schädels, die nicht allein über das Bestehen traumatischer Schädlichkeiten, sondern auch über andere, chirurgisch wichtige Veränderungen wertvolle Aufschlüsse geben kann, z. B. über hydrocephalische Zustände, die nicht mit Vergrößerung des Schädels einhergehen. Die Wichtigkeit der Röntgenuntersuchungen bei Epileptikern wird namentlich von Red. 
lich betont, auch mit dem Hinweis auf Schüllers ${ }^{42}$ ) Publikation, der in $30 \%$ der Fälle von Epilepsie einen positiven Röntgenbefund hatte. Während man sich bisher mit einer röntgenographischen Darstellung des Schädels begnügen mußte, ist mit Hilfe der durch Lufteinblasung in die Hirnrückenmarkshöhle bewirkten Encephalographie Bingels ${ }^{43}$ ) eine solche des Gehirns selbst ermöglicht, die auch im Hinblick für die chirurgische Therapie epileptischer Krankheitserscheinungen von größter Bedeutung sein kann.

Ein sehr wichtiger Faktor bei der operativen Epilepsiebehandlung ist die Feststellung, ob der Kranke an allge meinen Krä m pfen oder solchen von Jacksoncharakter leidet. Eine dringende Indikation zum operativen Eingreifen bei allge meinen Konvulsionen ist gegeben, wenn ein Tra u ma ätiologisch in Frage kommt, selbst bei dem geringsten Anhaltspunkt für das Einwirken einer solchen Schädlichkeit. Ferner ist nach unsern Erfahrungen ein entlastender Eingriff sehr zu empfehlen, wenn der Kranke unter tagelang anhaltenden Kopfsch merzen leidet, sei es, daß eine direkte Beziehung zu den epileptischen Anfällen nachweisbar ist oder nicht; selbstverständlich sind vorher die anderen Entstehungsmöglichkeiten auszuschließen (Allgemeinerkrankungen, behinderte Nasenatmung, Erkrankungen der Nebenhöhlen der Nase usw.). Nach der Operation fühlten sich vier derartige hiesige Fälle nicht allein subjektiv hinsichtlich der Kopfschmerzen auf das günstigste beeinflußt, sondern erfuhren auch eine erhebliche Verminderung ihrer epileptischen Insulte und eine Besserung in ihrem psychischen Zustand. Bei drei Kranken ergab die Autopsie in vivo bei der Entlastungstrepanation einen negativen Hirnbefund, bei dem dritten, zuletzt operierten, wurde nur der Suboccipitalstich ausgeführt, auf den weiter unten noch einmal kurz eingegangen werden soll. Was die Art des Eingriffs anbelangt, so repräsentieren die drei Entlastungstrepanationen Dauerresultate; seit dem Suboccipitalstich sind erst 7 Monate verflossen. Da nach unseren Erfahrungen die Entlastungstrepanation kaum wesentlich gefährlicher als der Suboccipitalstich anzusehen ist und überdies noch einen autoptischen Aufschluß über die Hirnrinde und ihre Umhüllungen gibt, so dürfte bei der Epilepsie nach unserem Ermessen in erster Linie die Entlastungstrepanation in Frage kommen. Der günstige Effekt, der bei den eben erwähnten Fällen durch keinerlei interne Medikation erzielt werden konnte, erklärt sich ohne weiteres durch die mit der Trepanation erzielte Beeinflussung der intrakraniellen Blut- und Lymphzirkulation. Man wird sich um so eher zur operativen Freilegung des Gehirns ent schließen können, wenn man auf Grund der Anamnese die Krankheitserscheinungen auf Folgezustände entzündlicher Vorgänge (Liquorstauung, cystöse, ödematöse Bildungen usw.) zurückführen kann. Beim Bestehen von Krampfanfällen allgemeinen Charakters ist die Indikation 
zur Freilegung des Gehirns weiterhin gegeben, wenn die Krampfanfälle vorübergehend herdförmigen Charakter getragen haben und schließlich in allgemeine übergegangen sind. Nicht nur in derartigen Fällen, sondern auch in anderen, die infolge des Fehlens irgendeines Anhaltspunktes für exogene Entstehung klinisch den Eindruck der sog. genuinen Epilepsie erweckten, wurden wiederholt bei der Autopsie ausgesprochene Veränderungen umschriebenen Charakters (Cysten, Angiome, Echinokokkusblasen usw.) beobachtet, nach deren Beseitigung die Krankheitserscheinungen schwanden oder eine erhebliche Besserung erfuhren. Man wird namentlich beim Vorhandensein einer konstanten, lokalisatorisch verwertbaren Aura und bei inter- oder postparoxystischen Halbseitenerscheinungen zum genannten Eingriff veranlaßt werden. Man darf sich nach Erfolglosigkeit der internen Behandlung um so eher zur Entlastungstrepanation entschließen, als sie bei der heutigen Technik als relativ ungefährlich anzusehen und eine Verschlimmerung des Krankheitszustandes weder auf Grund der Erfahrungen anderer Autoren noch der eigenen zu befürchten ist. Es wäre ja wohl denkbar, daß die operative Freilegung des Gehirns mikroskopische Schädigung der Hirnrinde hinterlassen könnte. Es wurde daher beim Falle 24 I der entsprechende Rindenbezirk histologisch untersucht: Es fanden sich keine auffallenden Ganglienzellveränderungen; die Punktionskanäle erwiesen sich von einem lockeren, maschigen Gliagewebe umgeben, das einzelne Körnchenzellen enthielt; sonstige infiltrative und irritative Veränderungen waren jedoch nicht festzustellen.

Eine Hirnrindenschädigung wäre ja wohl denkbar, wenn die nach der Operation herausdrängende Hirnrinde, die sonst von der schützenden, an der Innenfläche mit Endothel bekleideten Dura umschlossen ist, dem periostalen Gewebe in mehr oder weniger großer Ausdehnung anliegt, um so mehr, wenn der Vorschlag noch befolgt wird, auch noch ein Stück aus der Dura zu excidieren. Andererseits würde die entlastende Wirkung illusorisch werden, wenn man die Wundränder der Dura wieder nachträglich durch die Naht miteinander vereinigen wollte. Um ein ausgedehntes Freilegen der vordrängenden Hirnsubstanz zu vermeiden, ist von F. Kra use die Brüning sche Lappenbildung empfohlen worden, wobei der Duralappen nach oben, der Hautperiostlappen nach unten geschlagen wird. Groß mann verfährt so, daß er die untere Hälfte oder die untern $2 / 3$ des Knochenlappens quer herüber reseziert unter sorgfältiger Exstirpation des Periosts von der Innenseite des Hautlappens; dadurch wird der Vorteil erreicht, daß die Knochenlücke von dem intakten Temporalmuskel überdacht wird. Das wiederholt seit Jahren hier verwandte Verfahren besteht darin, daß ein entsprechend großer Fascienfettlappen nach Le x er-Reh $\mathrm{n}$ aus dem Oberschenkel entnommen, unter die klaffenden Duraränder geschoben und durch feine Nähte 
fixiert wird. Dieses Vorgehen hat sich bisher stets bewährt, was deshalb erwähnt sei, weil die Deckung der Hirnrinde, namentlich bei einem durch Excision entstandenen Defekt, wiederholt auf dem Chirurgenkongreß zuletzt 1920, erörtert wurde.

Wenden wir uns jetztzu den Epilepsieformen mit de m Jacksontypus der Krampferscheinungen. In erster Linie können sie durch umschriebene Rindenreizungen tra u matischer Horkunft bedingt sein. Der traumatische Insult kann bekanntlich auf mannigfache Art und Weise zur Auslösung epileptischer Krankheitserscheinungen Veranlassung geben. Es können sich einmal entzündliche Prozesse in den Schädelknochen anschließen, die manchmal zu Hyperostosen und auch zur Knochenneubildung an der Dura führen, wodurch ein chronischer Reiz auf die Hirnrinde ausgeübt wird; ein gleicher Effekt kann resultieren, wenn traumatisch entstandene eitrige Prozesse im Knochen sich abspielen und die benachbarten Hüllen des Gehirns und die Gehirnsubstanz in Mitleidenschaft ziehen. Es können durch Ruptur der Meningealarterien umschriebene Blutergüsse mit irritativen Folgezuständen der Hirnrinde entstehen, bei deren operativer Behandlung im frischen Stadium die günstigste Wirkung erzielt werden kann (Sahli, A u erbach). Eine außerordentlich wichtige ätiologische Rolle spielen die Blutaustritte in die weichen Hirnhäute mit den sich anschließenden chronischen, arachnoitischen Prozessen und deren Folgezuständen, auf die, wie bereits oben erwähnt, von chirurgischer Seite (Til mann, Krause, Bungart) nachdrücklich hingewiesen worden ist. Eine große Rolle spielen z. Z. begreiflicherweise die durch Kriegsverletzungen entstandenen traumatischen Epilepsieformen. Auf die Notwendigkeit der radikalen Entfernung von traumatisch entstandenen Narben und Cysten hat neuerdings auch Eliasberg in Übereinstimmung mit Borchard und Gulecke hingewiesen, selbst wenn man sich in der Nähe der motorischen Region befindet und entsprechende Extremitätenlähmungen befürchten muß. Bei der Entwicklungsfähigkeit der übrigen Hirnregionen ist durch eine solche Lähmung das Freibleiben von Anfällen nicht zu teuer erkauft, da bei der Fortdauer derselben und zumal beim Auftreten in Statusform doch in den allermeisten Fällen ein psychischer Verfall zu erwarten ist.

Neben den traumatischen Epilepsieformen indizieren ein operatives Vorgehen diejenigen mit Herd-bzw. Jacksonerscheinungen, bei denen F. Kra use 3 Gruppen unterscheidet: Erstens solche, die durch Geschwulstbildungen im Gebiet der motorischen Region bedingt sind, zweitens solche, die im Anschluß an die cerebrale Kinderlähmung auftreten, und drittens Fälle ohne pathologische Veränderungen, wo auch epileptogene Zonen und sensible Auraerscheinungen vermißt werden.

Was das Technische bei der operativen Epilepsiebehandlung betrifft, so ist natürlich auf die chirurgischen Spezialwerke, vor allem 
F. Krauses grundlegendes Buch, ferner die Arbeiten von Tilmann, Braun, Großmann, Kümmel u. a. zu verweisen. An dieser Stelle seien nur einige Punkte berührt; zuerst die Frage der ein- oder zweizeitigen Operationen, von denen die letztere von $\mathrm{F}$. Kra u se bei Eingriffen der Hirnsubstanz selbst empfohlen wird. Wenn auch der genannte Autor seine günstigen Erfolge mit dem zweizeitigen Verfahren erzielt hat, so sind doch auch von anderen Chirurgen mit der einzeitigen Operation gute Resultate erreicht worden, bei der entschieden die Infektionsgefahr vermindert wird und auch die sonstigen mit einem operativen Eingreifen verbundenen Alterationen vermieden werden. Um auf die von F. Kra use unterschiedenen Epilepsiegruppen zurückzukommen, so ist es bei den zwei ersten ebenso wie oben bei den traumatischen Residuen von Wichtigkeit, möglichst alles krankhafte Gewebe zu entfernen, da eben die epileptischen Krankheitserscheinungen nur von den Residuen des krankhaften Hirnprozesses ausgelöst werden, während aseptische Operationsnarben sich reizlos verhalten. Das wird natürlich bei großer Ausbreitung meningoencephalitischer Prozesse nicht möglich sein, so daß man sich mit der Ventilbildung begnügen muß. Wohl aber ist zu erwägen, ob nicht beim Vorhandensein einer stärkeren Duraspannung, auch im Hinblick auf den günstigen Ausgang von Fall 21, eine Ventrikeldrainage anzulegen ist. Bei den Jacksonfällen der dritten Kategorie ohne makroskopisch nachweisbare, pathologische Veränderungen und auch bei negativem Ausfall der Hirnpunktion kommt die Rindenexcision nach Horsley bis zu einer Ausdehnung von $2-3 \mathrm{~cm}$ Breite und $5 \mathrm{~mm}$ Tiefe nach vorausgegangener färadischer Bestimmung der epileptogenen Zonen in Frage. Allerdings ist zu bemerken, daß der faradische Reizungsversuch nicht immer gelingt, und daß bei stärkerer Reizung corticale Schädigungen eintreten können. H. Bra u n ${ }^{44}$ ) macht darauf aufmerksam, daß die Hirnreizung erfolglos sein kann bei tief narkotisierten Kranken, bei langer Dauer der Entblößung und dadurch herbeigeführter Abkühlung der Hirnoberfläche, ferner bei stark anämischem Gehirn. Schließlich wurde, worauf auch Großmann hinweist, noch ein Ausbleiben der faradischen Reaktion an den makroskopisch nicht veränderten Hirnteilen beobachtet, wenn sich bei der späteren mikroskopischen Untersuchung schwere Alterationen feststellen ließen. Die Excision des primär krampfenden Zentrums wird von F. Kra use in sehr kleiner Ausdehnung $(15-20 \mathrm{~mm})$ in den Fällen empfohlen, in denen vor der Operation keine Lähmungen und Paresen bestanden haben. Dagegen sollen bei cerebraler Kinderlähmung aus der veränderten Zentralregion größere Stücke bis zu $30 \mathrm{~mm}$ Höhe und $24 \mathrm{~mm}$ Breite entfernt werden. Natürlich ist bei der Rindenexcision mit Ausfallserscheinungen zu rechnen, die in manchen Fällen wohl persistieren, in zahlreichen anderen jedoch früher oder später eine auffallende Rückbildung erfahren können. 
Einerseits dürfte das auf das Vorhandensein der Försterschen Hilfsursprungsfelder zurückzuführen sein, andererseits auf die namentlich bei jugendlichen Individuen bestehende cerebrale Restitutions- und Kompensationsfähigkeit, auf die auch Auerbach und Großmann hinweisen. Zur Erzielung des Erfolges ist jedoch, was auch von Kotzen. berg ${ }^{45}$ ) besonders betont wird, eine peinliche Asepsis nötig, damit völlig reizlose Narben entstehen. Ferner sind natürlich Blutungen im Hinblick auf ihre Folgezustände auf das Mindestma $ß$ zu beschränken. Da Unterbindungen und Umstechungen zuweilen nicht zum Ziele führen und die Rindensubstanz bei diesen Manipulationen erheblich alteriert werden kann, so wäre evtl. zum Auflegen von Muskelsubstanz auf die blutende Stelle zu schreiten, wodurch in einem hiesigen Falle eine prompte Blutstillung ohne schädliche Nachwirkungen erzielt wurde. Zur Vermeidung solcher Komplikationen empfiehlt Bircher ${ }^{46}$ ), die erkrankten Hirnrindenteile mit dem Finger zu massieren, um ein reizloses Absterben der Hirnoberfläche zu erzielen und Lähmungen zu vermeiden. Von Trendelenburg ${ }^{47}$ ) ist die Unterschneidung der betreffenden Rindenbezirke empfohlen und von Kirschner ${ }^{48}$ ) sowie von Haberer ${ }^{49}$ ) praktisch erprobt worden. Beide Methoden könnten auch für größere, erkrankte Rindenbezirke in Frage kommen, wo Excision nicht mehr anwendbar ist. Über ihre Zweckmäßigkeit können jedoch erst weitere Erfahrungen entscheiden. Noch ein kurzes Wort über die Deckung des Schädeldefekts. Vor einer knöchernen Deckung möchten auch wir auf Grund unserer Erfahrungen in Übereinstimmung mit Eliasberg, sowie Goldstein und Reichmann warnen. Ferner sei noch dazu bemerkt, daß wir bei der großen Reihe der beobachteten Fälle noch niemals infolge des Knochendefektes eine Schädigung oder Gefährdung des Kranken beobachtet haben. Zum Schluß sei noch erwähnt, daß mit der Vornahme der Trepanation auch ein Übermaß geschehen kann. Diesbezügliche Krankengeschichten von drei nutzlos operierten Fällen teilt Sicard ${ }^{50}$ ) mit: Der eine war in einem Zeitraum von 11 Jahren nicht weniger als 7 mal, der zweite in 7 Jahren 4 mal, der dritte in 5 Jahren 3 mal trepaniert worden.

Im Anschluß an die operative Freilegung des Gehirns seien noch zwei weitere Eingriffe bei Epilepsie erwähnt: Der Balkenstich [Anton und v. Bramann $\left.{ }^{51}\right)$ ] und der Suboccipitalstich [Anton und Schmieden $\left.\left.{ }^{52}\right)\right]$. Über die Anwendung des Balkenstiches hat Reinecke ${ }^{53}$ ) an der Hand von 30 Fällen berichtet, bei denen Heilung in 5, weitgehende Besserung in 6, eine günstige Beeinflussung in 16 Fällen erzielt wurde. Die Indikation besteht in erster Linie bei den hydrocephalischen Epilepsieformen, die durch das Röntgenbild und den klinischen Befund diagnostiziert werden können. Vor Jahren wurde auch in hiesiger Anstalt bei einer Reihe von entsprechenden Fällen der Balkenstich ausgeführt. Bei 
den mehr oder weniger veralteten und fortgeschrittenen Fällen wurden allerdings nur vorübergehende Besserungen erzielt. Da der beim Balkenstich gebildete Kanal infolge seiner Lage sich verlegen kann und einen Druckausgleich nicht so leicht gestattet, wie das bei einer entsprechenden Kanalbildung in tieferen Gehirnpartien der Fall ist, so wurde von Anton und Schmieden der Suboccipitalstich empfohlen, der auch in hiesiger Anstalt wiederholt angewendet worden ist. Da die verflossene Zeit (6-8 Monate) zu kurz und das bisherige Material noch klein ist, soll später noch einmal über die erzielten Resultate berichtet werden. Zur Zeit sei nur soviel bemerkt, daß in 3 Fällen eine außerordentliche subjektive und objektive Besserung erzielt wurde: Der erste Kranke litt an heftigen Kopfschmerzen vor und nach den zahlreichen und schweren Anfällen und drohte zu verblöden, der zweite an äußerst heftigen Spasmen in den Beinen, die nach den Anfällen sich einstellten, der dritte an epileptischen Anfällen, die einzeln und in Gruppen auftraten und von heftigsten Angstzuständen gefolgt waren.

Hiermit sei die Erörterung der operativen gegen die epileptischen Krankheitserscheinungen gerichteten Maßnahmen abgeschlossen. Wenn bei einem Rückblick auf die 50 trepanierten Fälle sich auch eine große Zahl erfolglos operierter Kranker ergibt, so ist der Mißerfolg doch keineswegs der operativen Behandlungsmethode an sich, sondern vielmehr einer Reihe anderer Faktoren zuzuschreiben, wie aus der Charakterisierung der einzelnen Fälle hervorgeht. Auf einen nach unserem Dafür. halten sehr wichtigen Punkt sei noch besonders hingewiesen, der sich auch auf Grund der oben beschriebenen Fälle ergibt: Im Anschluß an die Operation hat die Allgemeinbehandlung mit hygienisch-diätetischen und medikamentösen Mitteln, sowie mit Hilfe der Beschäftigungstherapie am besten in Anstaltspflege oder sorgfältiger neurologischer Leitung sofort wieder einzusetzen, um eine Heilung oder wenigstens eine Besserung zu gewährleisten. Wenn trotz fortschreitender chirurgischer Technik und genauer Indikation die Operationsresultate dieses weitverbreiteten, schweren Leidens immer beschränkt bleiben werden, so ist jeder einzelne geheilte Fall im Hinblick auf das abgewendete, traurige Schicksal als wertvollster Gewinn zu betrachten. Ferner müssen auch langdauernde Besserungen und Verhütung der epileptischen Demenz nach dem übereinstimmenden Urteil aller maßgebenden chirurgischen und neurologischen Autoren bei Beurteilung der Operationsresultate als Erfolge angesehen werden, wenngleich einst E. v. Bergmann den Standpunkt vertrat, entweder heile die Epilepsie oder nicht. Dagegen müssen wir dem genannten Autor beipflichten, wenn er bei der Therapie der Epilepsie in Übereinstimmung mit $F$ é $r$ é darauf hinweist, daß für eine erfolgreiche Behandlung vor allem die Erforschung der Ursachen der epileptischen Krankheitserscheinungen notwendig sei. Bei Berücksichtigung aller 
ätiologischen Faktoren gelten im Hinblick auf die Verhütung und Heilung der epileptischen Krankheitserscheinungen die gleichen Gesichtspunkte wie bei der Mehrzahl der Geistesstörungen überhaupt, die Kra epelin ${ }^{54}$ ) in weitblickender Weise als Ziele und Wege psychiatrischer Forschung hinstellt, nämlich Bekämpfung aller verderblichen Einflüsse, die zu erblicher Entartung und Keimschädigung führen. Für deren Entstehung kommen bekanntlich in erster Linie Alkohol und Syphilis in Bztracht. Da weiterhin die akuten Infektionen eine sehr wichtige ätiologische Rolle für die Entstehung der epileptischen Krankheitserscheinungen spielen, so ergibt sich auch im Hinblick auf die Verhütung der Epilepsie die dringende Notwendigkeit der Verhütung und Bekämpfung der Infektionskrankheiten.

\section{Literaturverzeichnis.}

1) Bergmann, E. v., Die chirurgisehe Behandlung der Hirnkrankheiten. Berlin 1899. - $\left.{ }^{2}\right)$ Redlich und Schüller, Röntgenbefunde am Schädel von Epileptikern. Fortschr. a. d. Geb. d. Röntgenstr. 14. - ${ }^{3}$ ) Krae pelin, Psychiatrie. IV. Bd. 1915. $\left.-{ }^{4}\right)$ Weinert, im Handbuch der ärztlichen Erfahrungen im Weltkrieg 1914/18. VIII. Bd. Pathologische Anatomie. - ${ }^{5}$ ) Bratz, Die affektepileptischen Anfälle der Neuropathen und Psychopathen. Monatsschr. f. Psychiatr. u. Neurol. 29. 1911. - ${ }^{6}$ ) Ibrahim, Über respiratorische Affektkrämpfe im frühen Kindesalter. Zeitschr. f. d. ges. Neurol. u. Psychiatr., Orig., 5. 1911. - 7 ) Til man n, Die Pathogenese der Epilepsie. Festschrift der Kölner Akademie 1915. 8) Tilmann, Zur Pathogenese der Epilepsie. Virchows Arch. 229, H. 1/2. 1920. $\left.{ }^{9}\right)$ Redlich, Epilepsie und Linkshändigkeit. Arch. f. Psychiatr. u. Nervenkr ınkh. 44. 1908; und Epilepsia III. 1912. - 10) Bungart, Zur Frage des Auftretens und der Behandlung akut entzündlicher Erweichungsherde im Gehirn nach Scharlach. Dtsch. med. Wochenschr. Nr. 45. 1920. - 11) Wildermuth, Zur Ätiologie der Epilepsie. Stuttgart 1897. - 12) Wendel, Bericht über die Verhandlungen der Deutschen Gesellschaft für Chirurgie 10.-13. IV. 1912. $\left.{ }^{13}\right)$ Op penhei m, Lehrbuch der Nervenkrankheiten. Berlin 1908. - ${ }^{14}$ ) Krause, F., Die Behandlung der nicht traumatischen Formen der Epilepsie. Verhandld. dtsch. Ges. f. Chir. 1910. - ${ }^{15}$ ) Tilmann, 45. Versammlung d. dtsch. Ges. f. Chir. 30. III.-2. IV. 1921. - ${ }^{18}$ ) Großmann und A uerbach, 17. Internat. med. Kongreß. London 1913. - 17) Redlich, Die klinische Stellung der sog. genuinen Epilepsie. Berlin, Karger, 1913. - ${ }^{18}$ ) Bauer, J., Die konstitutionelle Disposition zu inneren Krankheiten. Berlin, Springer, 1917. - ${ }^{19}$ ) Marburg, Wien. klin. Wochenschr. 1919, Nr. 32. - ${ }^{20}$ ) Frisch, Die patho-physiologischen Grundlagen der Epilepsie. Zeitschr. f. d. ges. Neurol. u. Psychiatr., Orig., 65, H. 3-5. 1921. - 21) Allers, Ergebnisse stoffwechselpathologischer Untersuchungen bei Psychosen (Epilepsie). Zeitschr. f. d. ges. Neurol. u. Psychiatr., Ref. 4, 48. 1912. - ${ }^{22}$ ) Ha u ptmann, Ein Weg das Wesen der ,genuinen" Epilepsie zu erforschen. Monatsschr. f. Psychiatr. u. Neurol. 48. 1920. - ${ }^{23}$ ) Pollak, Anlage und Epilepsie. Arb. a. d. neurol. Inst. d. Univ. Wien 23; von Lewy ref. in der Zeitschr. f. d. ges. Neurol. u. Psychiatr., Ref., 24. 1921. — ${ }^{24}$ ) Krause, F., Die Chirurgie des Gehirns und Rückenmarks. Wien 1908 u. 1911. — ${ }^{25}$ ) Schwartz, Ph., Die Ansaugungsblutungen im Gehirn Neugeborener. Zeitschr. f. Kinderheilk. 29, H. 1/2. 1921. - ${ }^{26}$ ) Redlich, Zur Pathologie der Epilepsie nach Schädelschußverletzungen. 48. Bd. 1919. - ${ }^{27}$ ) Braun, Neue deutsche Chirurgie. Ver- 
letzungen des Gehirns. III. - ${ }^{28}$ ) Bielschowsky, M., Journ. f. Psychol. u. Neurol. 1916. $-{ }^{29}$ ) Kocher, Chirurgischer Beitrag zur Physiologie des Gehirns und Rückenmarks. Dtsch. Zeitschr. f. Chirurg. 36; sowie Chirurgenkongre $B$ 1899. - ${ }^{30}$ ) Bier, A., Über den Einfluß künstlich erzeugter Hyperämie des Gehirns und künstlich erhöhten Hirndrucks auf Epilepsie, Chorea usw. Grenzgeb. d. Med. u. Chirurg. y, H. 2 u. 3. 1901. - ${ }^{31}$ ) Tilman n, Verhandl. d. dtsch. Ges. f. Chir. 10.-13. IV. 1912. - ${ }^{32}$ ) Redlich und Pötzl, Untersuchungen über das Verhalten des Liquor cerebrospinalis bei der Epilepsie. Zeitschr. f. d. ges. Neur. u. Psychiatr., Orig., 3. 1910. - ${ }^{33}$ ) Friedrich, Über die operative Beeinflußbarkeit des Epileptikerhirns. Arch. f. klin. Chirurg. yr. - ${ }^{34}$ ) Reichardt, Über Hirnschwellung. Zeitschr. f. d. ges. Neurol. u. Psychiatr., Ref. u. Erg., 3. 1911. 35) Gennerich, Die Syphilis des Zentralnervensystems, ihre Ursache und ihre Behandlung. Berlin, Springer, 1921. - ${ }^{36}$ ) $\mathrm{K}$ ü m mel, Zentralbl. f. Chirurg. 1913, Nr. 51. - $\left.{ }^{37}\right)$ Sahli, Über hirnchirurgische Operationen vom Standpunkt der inneren Medizin. Samml. klin. Vorträge, Nr. 11. Innere Medizin 1890-1894. $\left.{ }^{38}\right)$ A uerbach, Klinisches und Anatomisches zur operativen Epilepsiebehandlung. Mitt. a. d. Grenzgeb. d. Med. u. Chirurg. 19, H. 2. 1909. - ${ }^{39}$ ) Weil, Die operative Behandlung der Epilepsie. Bruns' Beitr. z. klin. Chirurg. ro. - ${ }^{40}$ ) Elias berg, Zur traumatischen Epilepsie und ihrer Behandlung. Dtsch. med. Wochensehrift 1921, Nr. 25. - ${ }^{41}$ ) Vogt, H., Die Epilepsie im Kindesalter. Berlin, Karger. — $\left.{ }^{42}\right)$ Schüller, Röntgendiagnostik der Erkrankungen des Kopfes. Wien 1912. 43) Bingel, Encephalographie. Fortschr. a. d. Geb. d. Röntgenstr. 28. ${ }^{44}$ ) Brau n, H., Beiträge zur Frage über die elektrische Erregbarkeit des Großhirns. Eckhards Beitr. z. Anat. u. Physiol. y. 1874. - ${ }^{45}$ ) Kotzen berg, Zur Frage der operativen Behandlung der idiopathischen Epilepsie. Bruns' Beitr. z. klin. Chirurg. 55. 1907. $-{ }^{46}$ ) Bircher, Ein Beitrag zur operativen Behandlung der Epilepsie. Münch. med. Wochenschr. 1910, Nr. 4. - ${ }^{47}$ ) Trendelenburg, Die Methodik der operativen Ausschaltung der Hirnrinde am Affen mit Bezug auf die Behandlung der menschlichen Epilepsie. Zeitschr. f. d. ges. exp. Med. 3. 1914. - ${ }^{48}$ ) Kirschner, Behandlung der Epilepsie mit flächenhafter Unterschneidung des auslösenden Rindengebietes. Zentralbl. f. Chirurg. 1917. $\left.{ }^{49}\right)$ Haberer, v., Zentralbl. f. Chirurg. 1917, Nr. 19. _- ${ }^{50}$ ) Sicard, Inutilité ou danger des trépanations successives au cours de l'épilepsie traumatique. Ref. im Neurolog. Zentrabl. 1911, Nr. 11. - ${ }^{51}$ ) Anton und v. Bramann, Behandlung der angeborenen und erworbenen Gehirnkrankheiten mit Hilfe des Balkenstichs. Berlin, Karger, 1913. - ${ }^{52}$ ) Anton und Schmieden, Der Suboccipitalstich. Zentralbl. f. Chirurg. 1917, Nr. 10. - ${ }^{53}$ ) Rei necke, Behandlung der Epilepsie mit dem Balkenstich. Arch. f. Psychiatr. u. Nervenkrankh. 62. 1920. - ${ }^{54}$ ) Krae pelin, Ziele und Wege psychiatrischer Forschung. Zeitschr. f. d. ges. Neurol. u. Psychiatr., Orig., 42, H. 3-5. 